Pacific Northwest

National Laboratory

Operated by Battelle for the

U.S. Department of Energy

\title{
RSG Deployment Case Testing Results
}

\author{
SL Owsley Jr \\ TA Seim \\ MG Dodson \\ DL Alexander \\ BK Hatchell \\ WT Hawthorne
}

September 2005

Prepared for the U.S. Department of Energy under Contract DE-AC05-76RL01830 


\title{
DISCLAIMER
}

This report was prepared as an account of work sponsored by an agency of the United States Government. Neither the United States Government nor any agency thereof, nor Battelle Memorial Institute, nor any of their employees, makes any warranty, express or implied, or assumes any legal liability or responsibility for the accuracy, completeness, or usefulness of any information, apparatus, product, or process disclosed, or represents that its use would not infringe privately owned rights. Reference herein to any specific commercial product, process, or service by trade name, trademark, manufacturer, or otherwise does not necessarily constitute or imply its endorsement, recommendation, or favoring by the United States Government or any agency thereof, or Battelle Memorial Institute. The views and opinions of authors expressed herein do not necessarily state or reflect those of the United States Government or any agency thereof.

\author{
PACIFIC NORTHWEST NATIONAL LABORATORY \\ operated by \\ BATTELLE \\ for the \\ UNITED STATES DEPARTMENT OF ENERGY \\ under Contract DE-AC05-76RL01830
}

Printed in the United States of America
Available to DOE and DOE contractors from the Office of Scientific and Technical Information,
P.O. Box 62, Oak Ridge, TN 37831-0062;
ph: (865) 576-8401
fax: $(865)$ 576-5728
email: reports@adonis.osti.gov

\begin{abstract}
Available to the public from the National Technical Information Service, U.S. Department of Commerce, 5285 Port Royal Rd., Springfield, VA 22161 ph: (800) 553-6847 fax: $(703) 605-6900$ email: orders@ntis.fedworld.gov online ordering: http://www.ntis.gov/ordering.htm
\end{abstract}

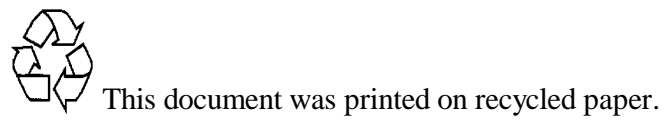




\title{
RSG Deployment Case Testing Results
}

\author{
Authors: \\ Stan Owsley \\ Mike Dodson \\ Brian Hatchell \\ Tom Seim \\ Dave Alexander \\ Woody Hawthorne-Northrup Grumman Information Technology
}

September 2005 
RSG Deployment Case Design and Testing Parameters .....................................................................................................1

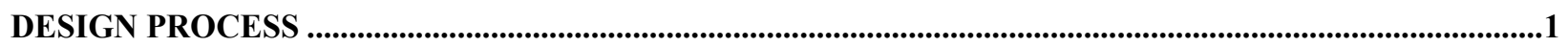

SYSTEM REQUIREMENTS ...........................................................................................................................

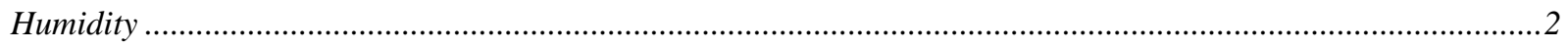

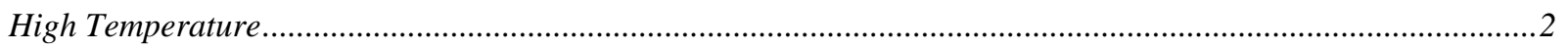

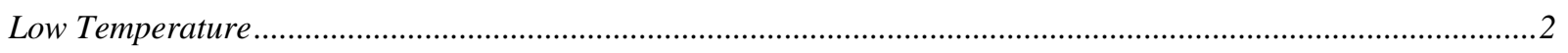

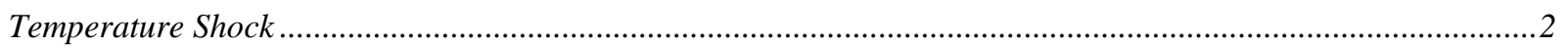

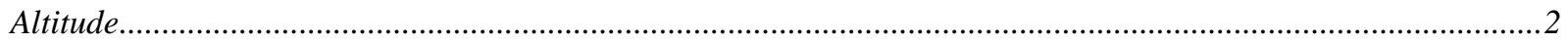

Rain

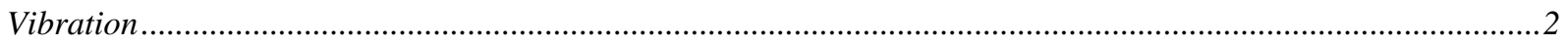

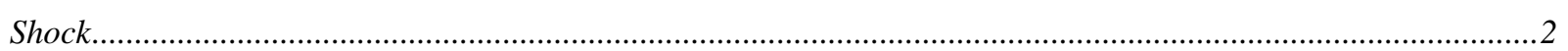

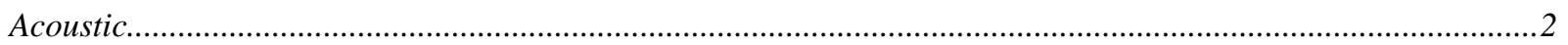

Magnetic Field Radiated Emissions …………….......................................................................................

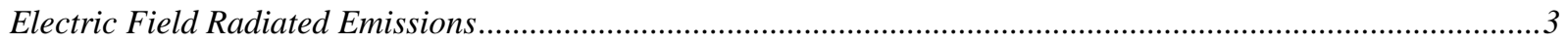

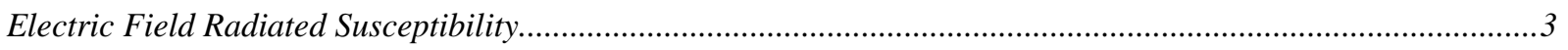

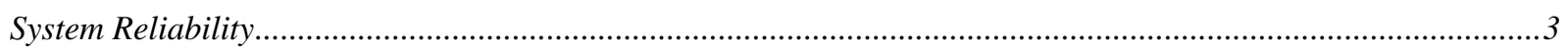

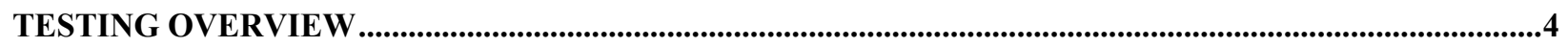

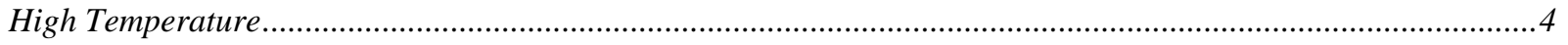

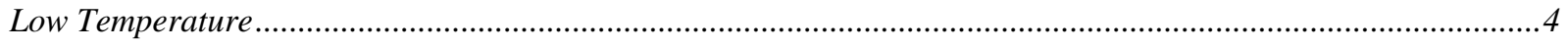

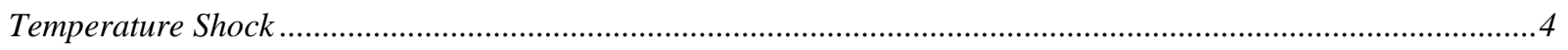

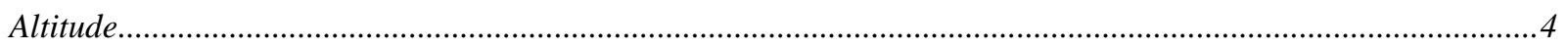

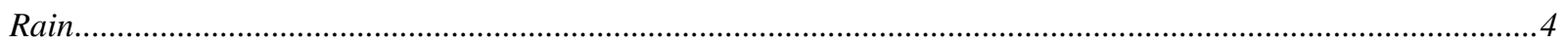

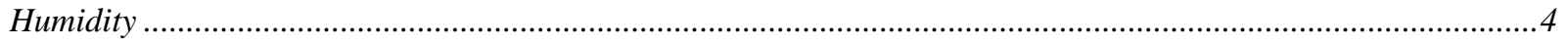

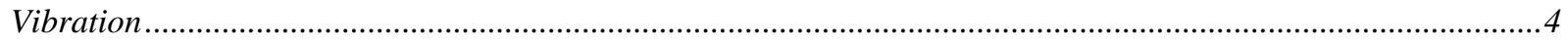

Shock

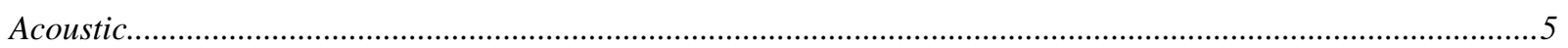

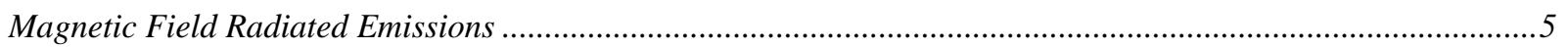

Electric Field Radiated Emissions..........................................................................................................

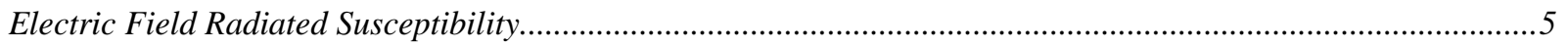

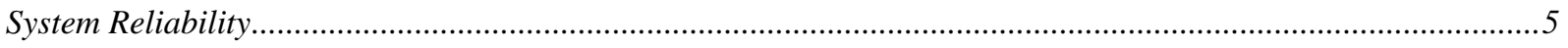

TESTING RESULTS

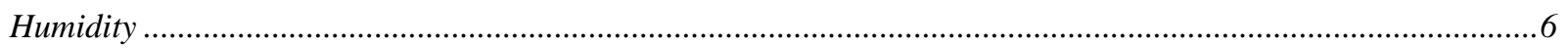

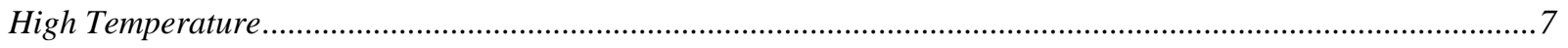

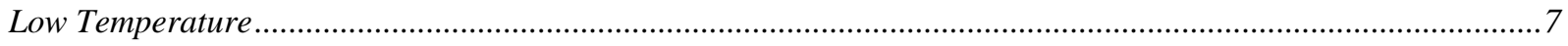

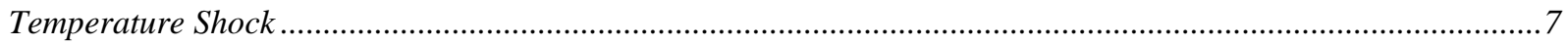




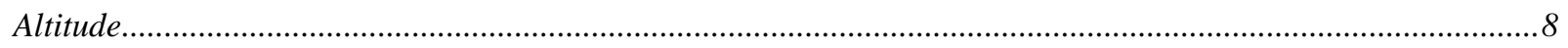

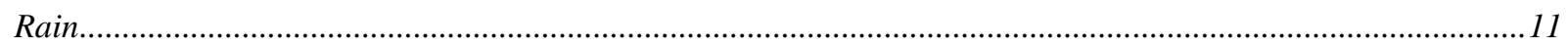

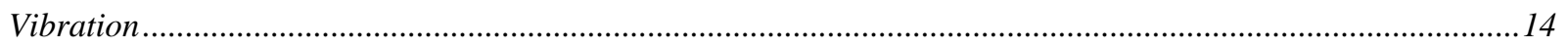

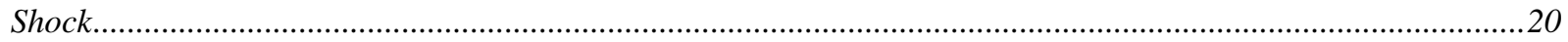

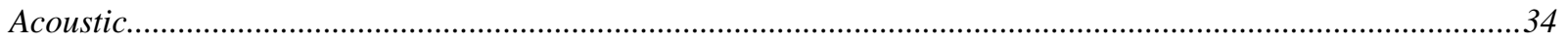

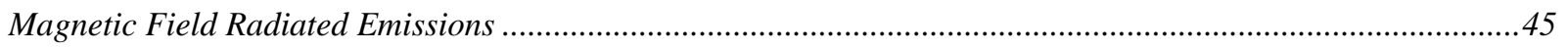

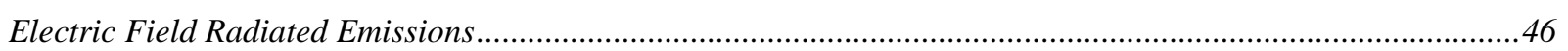

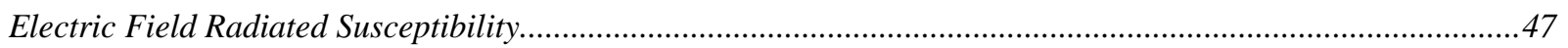

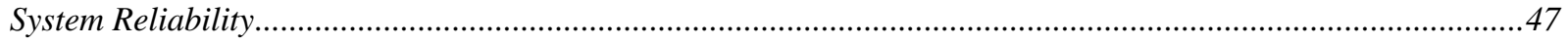

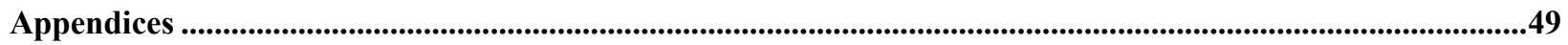




\section{RSG Deployment Case Design and Testing Parameters}

\section{DESIGN PROCESS}

The RSG deployment case design is centered on taking the RSG system and producing a transport case that houses the RSG in a safe and controlled manner for transport. The transport case was driven by two conflicting constraints, first that the case be as light as possible, and second that it meet a stringent list of Military Specified requirements. The design team worked to extract every bit of weight from the design while striving to meet the rigorous Mil-Spec constraints. In the end compromises were made primarily on the specification side to control the overall weight of the transport case.

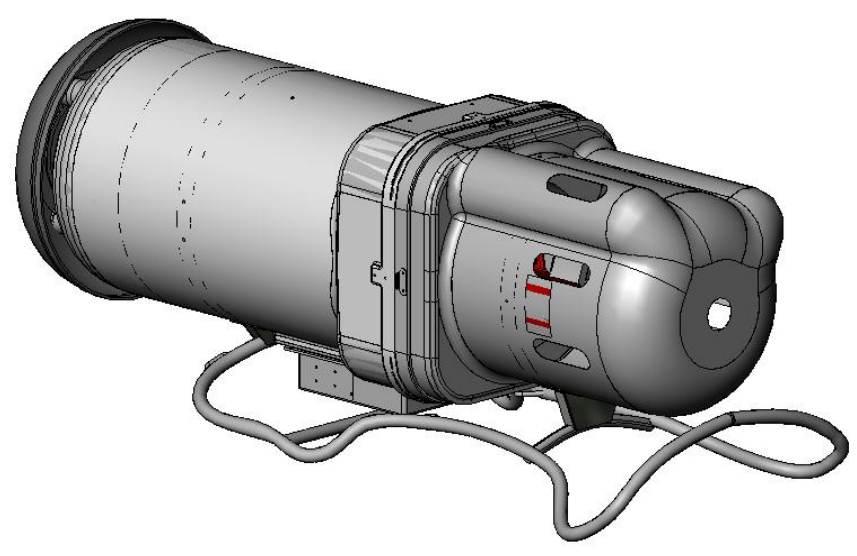

Figure 155 Watt Transport Full Case

The backbone of the transport system is a commercial backpack frame. These were procured from a well known company and modified as required for the project. The RSG itself was packaged inside a pair of rigid plenum components that housed the top and bottom with a composite flow guide between them to duct cooling air. The entrance plenum holds a thermostatically controlled fan that operates in response to the cooling requirements of the RSG. Surrounding the rigid housing components are closed-cell foam components that suspend the RSG and the previously mentioned components in the case shell. The foam was selected for both its energy absorption and temperature performance characteristics. Housing all of the interior components are the case outer shell and cover. These components are fabricated from graphite composite material. Mounted externally to the composite case are the rain cover and the electrical box. The latter contains the control circuitry for the cooling fan which operates autonomously unless it is overridden manually by an operator. 


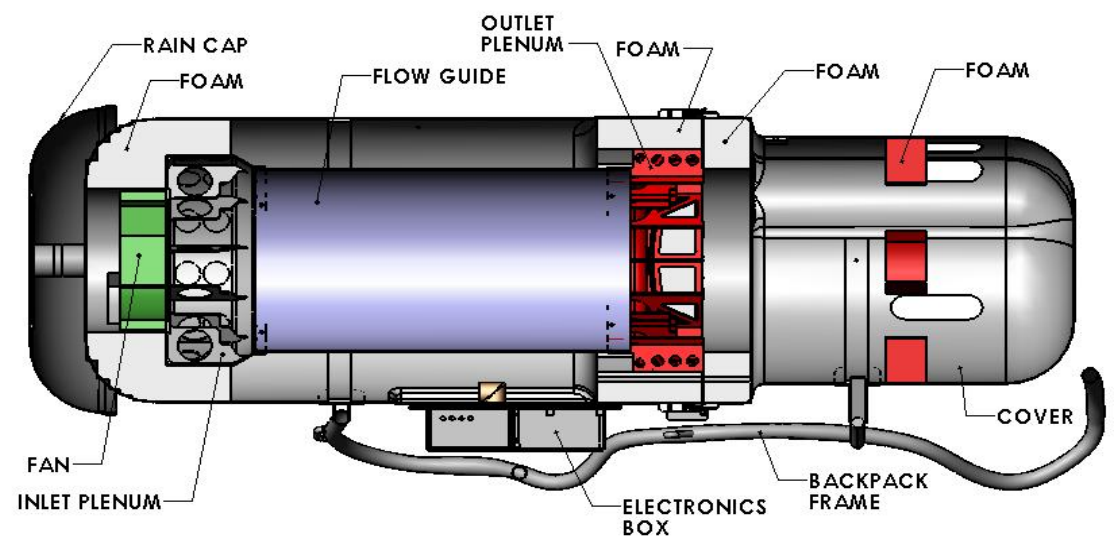

SECTION VIEW OF COMPONENTS

Appendix A, B, and C contains material specifications for materials used in the construction of the transport case and components.

At the project inception, the transport case was required to conform and pass the following MilSpec.:

\section{SYSTEM REQUIREMENTS}

Humidity, MIL-STD-810F, Method 507.4 (10\% to 100\%, including direct condensation)

High Temperature, MIL-STD-810F, Method 501.4 Procedure I, 50degree C

Low Temperature, MIL-STD-810F, Method 502.4 Procedure I, -32degree C

Temperature Shock, MIL-STD-810F, Method 503.4, Procedure I, temperature shock requirement at the extremes (-32 degrees $\mathrm{C}$ to 50 degrees $\mathrm{C})$

Altitude, MIL-STD-810F, Method 500.4 Procedure I, 15,000’

Rain, MIL-STD-810F, Method 506.4 Procedure I

Vibration, MIL-STD-810F, Method 514.5 Cat 24 both general use and helicopter material for duration of 60 minutes in each three orthogonal axes for a total test time of 3 hours.

Shock, MIL-STD-810F, Method 516.5 Procedure IV, tailored for 18” drop on to compact soil.

Acoustic, Shall not exceed the 30 meter acoustic non-detectable limit as defined in Table 2-II Quietest Area Ambient Noise Level in Table 2-III of MIL-Stand-1474D when measured at a distance of 2 meter. 
Magnetic Field Radiated Emissions, MIL-STD-461E RE101, Radiated Emissions, $10 \mathrm{KHz}$ to $18 \mathrm{GHz}$.

Electric Field Radiated Emissions, MIL-STD-461E RE102, Radiated Emissions, $10 \mathrm{KHz}$ to $18 \mathrm{GHz}$

Electric Field Radiated Susceptibility, MIL-STD-461E RE103, Radiated Susceptibility, Electric Field, $10 \mathrm{KHz}$ to $18 \mathrm{GHz}$

System Reliability, MIL-HDBK-217F, 0.999 reliability per year 


\section{TESTING OVERVIEW}

Over the course of the design and testing the following modifications to these requirements were made at the direction of the sponsor.

High Temperature, MIL-STD-810F, Method 501.4 Procedure I, 50degree C

A modified test program was performed on the electronics package at PNNL. The test sequence was shortened in time duration, but full temperature range was exercised in the test. The electronics system operated at all check points. The sponsor accepted the results with temperature specifications for all materials used in design.

Low Temperature, MIL-STD-810F, Method 502.4 Procedure I, -32degree C

A modified low temperature test was performed on the electronics package at PNNL. The qualified chamber was only capable of a low temperature of $-18 \mathrm{C}$. The electronics were checked for operation during the test sequence and the system functioned as required. Sponsor accepted test with temperature specifications for all materials used in the design.

Temperature Shock, MIL-STD-810F, Method 503.4, Procedure I, temperature shock requirement at the extremes (-32 degrees $\mathrm{C}$ to 50 degrees $\mathrm{C})$

Temperature shock test were conducted at the beginning of the Low Temperature test when the case was placed in the $-18^{\circ} \mathrm{C}$ chamber from $22^{\circ} \mathrm{C}$ room temperature. At the end of the Low Temperature testing the case environment changed from $-18^{\circ} \mathrm{C}$ chamber to the room temperature of $22^{\circ} \mathrm{C}$. All systems functioned as expected before and after testing.

Altitude, MIL-STD-810F, Method 500.4 Procedure I, 15,000’

Altitude testing was not performed per procedure. A cooling test was performed at PNNL and the results extrapolated to altitude conditions. Sponsor accepted results.

Rain, MIL-STD-810F, Method 506.4 Procedure I

System passed rain testing. Test was performed at a laboratory with NIST traceable instrumentation, but laboratory did not have full Mil-Spec. accreditation. Sponsor approved test site and results.

Humidity, MIL-STD-810F, Method 507.4 (10\% to 100\%, including direct condensation)

The humidity test was not performed by request of sponsor. A discussion of data that defend the decision to wave this test is in a later section.

Vibration, MIL-STD-810F, Method 514.5 Cat 24 both general use and helicopter material for duration of 60 minutes in each three orthogonal axes for a total test time of 3 hours. 
System passed vibration testing. Test was performed at a laboratory with NIST traceable instrumentation, but laboratory did not have full Mil-Spec. accreditation. Sponsor approved test site and results.

Shock, MIL-STD-810F, Method 516.5 Procedure IV, tailored for 18" drop on to compact soil.

System failed shock test original criteria, sponsor accepted results. Tests were performed at PNNL.

Acoustic, Shall not exceed the 30 meter acoustic non-detectable limit as defined in Table 2-II Quietest Area Ambient Noise Level in Table 2-III of MIL-Stand-1474D when measured at a distance of 2 meter.

System passed test performed at PNNL and was accepted by sponsor.

Magnetic Field Radiated Emissions, MIL-STD-461E RE101, Radiated Emissions, $10 \mathrm{KHz}$ to $18 \mathrm{GHz}$.

System passed test performed at qualified laboratory.

Electric Field Radiated Emissions, MIL-STD-461E RE102, Radiated Emissions, $10 \mathrm{KHz}$ to $18 \mathrm{GHz}$

System failed one portion of the test performed at qualified laboratory, sponsor accepted test result, and waived compliance.

Electric Field Radiated Susceptibility, MIL-STD-461E RE103, Radiated Susceptibility, Electric Field, $10 \mathrm{KHz}$ to $18 \mathrm{GHz}$

System failed one portion of the test, sponsor accepted test result, and waived compliance.

System Reliability, MIL-HDBK-217F, 0.999 reliability per year

System fails operation for a full year, but the system will meet the 0.999 reliability for a full month of operation at extreme temperatures. Sponsor accepted deviation with the expectation that the system will not actually operate any longer than a week during deployment. 


\section{TESTING RESULTS}

Humidity, MIL-STD-810F, Method 507.4 (10\% to 100\%, including direct condensation)

The humidity test is designed to determine the susceptibility of components to high humidity conditions under varying temperature. This test is inappropriate for systems that are hermetically sealed or that have commercial subsystems that carry certifications to the same test conditions. In this case, the commercial fan has such qualifications from the manufacturer. The custom electronic package is sealed in a metal box and has all seams and connectors waterproofed. The system was operated in an environmental chamber for the High Temperature test which ran the system under power through changing temperature conditions. With the system sealed, the internal components will only react to the temperature changes. Thus the high temperature profile tests can take the place of the humidity tests. The program also performed the rain test which had direct impingement of water on the control electronics box. Both tests were passed without incident.

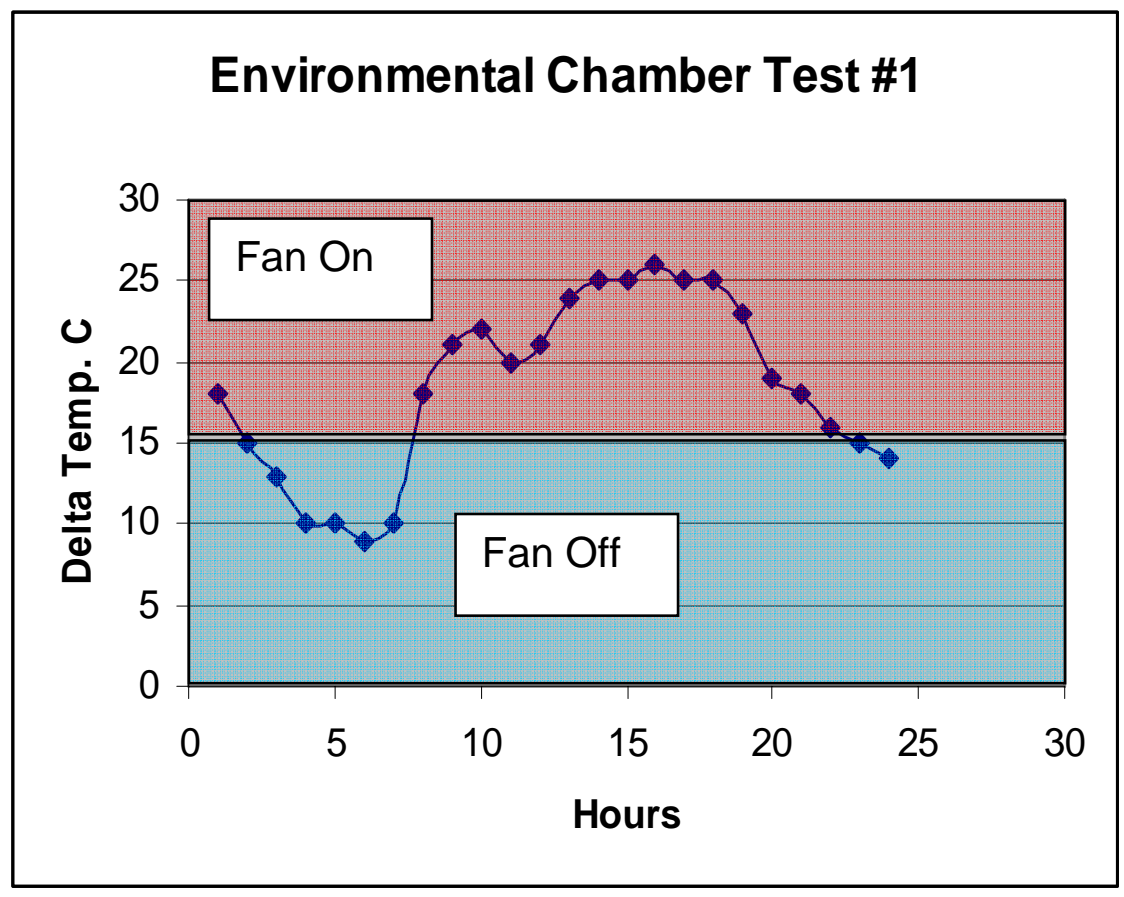

Figure 3 Environmental Chamber Test 
High Temperature, MIL-STD-810F, Method 501.4 Procedure I, 50degree C

Testing was preformed at PNNL in an environmental test chamber. This chamber has NIST traceable instrumentation. One of the completed electronic control systems was placed in the chamber and all of the connections to the fan and the four control thermistors were made. The two control thermistors that are mounted on the RSG were left in the chamber, the two air temperature sensing thermistors were passed out through an instrument port in the chamber wall. This port was used for the power lead from the battery pack and the power lead to the cooling fan, both of which were located outside the chamber. The chamber temperature profile was programmed into the controller for the chamber and all temperatures were logged automatically on an external computer. When the temperature differential between the chamber and the external thermistors was $15 \mathrm{C}^{\mathrm{o}}$ or greater the fan is activated. At several points, the system was monitored to check that the fan was operating and the fan speed was logged. The data logs are in appendix D and E. All three runs were monitored by a video system; a camera was placed so that it could monitor the fan and see a temperature readout for the room. The video system turned on for one minute each hour and wrote the video output with time and date stamp to a computer hard disk. This data is archived on DVDs. Figure 3 reflects the temperature profile that was used for all three runs.

Low Temperature, MIL-STD-810F, Method 502.4 Procedure I, -32degree C

Testing was preformed at PNNL in an environmental test chamber that could reach $-18^{\circ} \mathrm{C}$. This chamber has NIST traceable instrumentation. One of the completed electronic control systems was placed in the chamber and all of the connections to the fan and the four control thermistors were made. All thermistors were left in the chamber; the two RSG temperature sensing thermistors were passed out through an instrument port in the chamber wall manually to activate the fan to confirm that the electronics were operating. The test was conducted twice a day.

The port in the chamber was used for the power lead from the battery pack and the power lead to the cooling fan, both of which were located outside the chamber. The chamber temperature profile was programmed into the controller for the chamber and all temperatures were logged automatically on an external computer. At several points, the system was monitored to check that the fan was operating and the fan speed was logged.

\section{Temperature Shock}

MIL-STD-810F, Method 503.4, Procedure I, temperature shock requirement at the extremes (-32 degrees $\mathrm{C}$ to 50 degrees $\mathrm{C}$ )

Temperature shock testing was conducted at the beginning of the Low Temperature test when the case was placed in the $-18^{\circ} \mathrm{C}$ chamber from $22^{\circ} \mathrm{C}$ room temperature. At the end of the Low Temperature testing the case environment changed from $-18^{\circ} \mathrm{C}$ chamber to the room temperature of $22^{\circ} \mathrm{C}$. All systems functioned as expected before and after testing. 
Altitude, MIL-STD-810F, Method 500.4 Procedure I, 15,000’

Altitude Cooling Flow Analysis from Sea Level to 15,000 feet

Bounding Conditions: The performance of the cooling system is governed by the requirements set forth in the '55-Watt Radioisotope Stirling Generator (RSG) System Requirements Document (SRD)'. This document then references MIL-STD-810F for specific requirements. Determination was made that the most extreme condition would be cooling the RSG at sea level with an ambient temperature of $50^{\circ} \mathrm{C}$.

Bounding Tests: Based on the bounding conditions discussed above, a test was conducted in a PNNL atmospheric chamber in August 2004. In preparation for this activity, a dummy RSG was configured with a resistance heater whose output was controlled to $0.3 \mathrm{~kW}$. The surface of the RSG was instrumented with thermocouples and the leads were passed through an instrumentation port to calibrated readouts. Data was recorded at intervals for $\sim 1$ hour and 45 minutes. During the test, the cooling fan for the RSG was operated at 12 VDC. The results for these tests can be seen in the following graph.

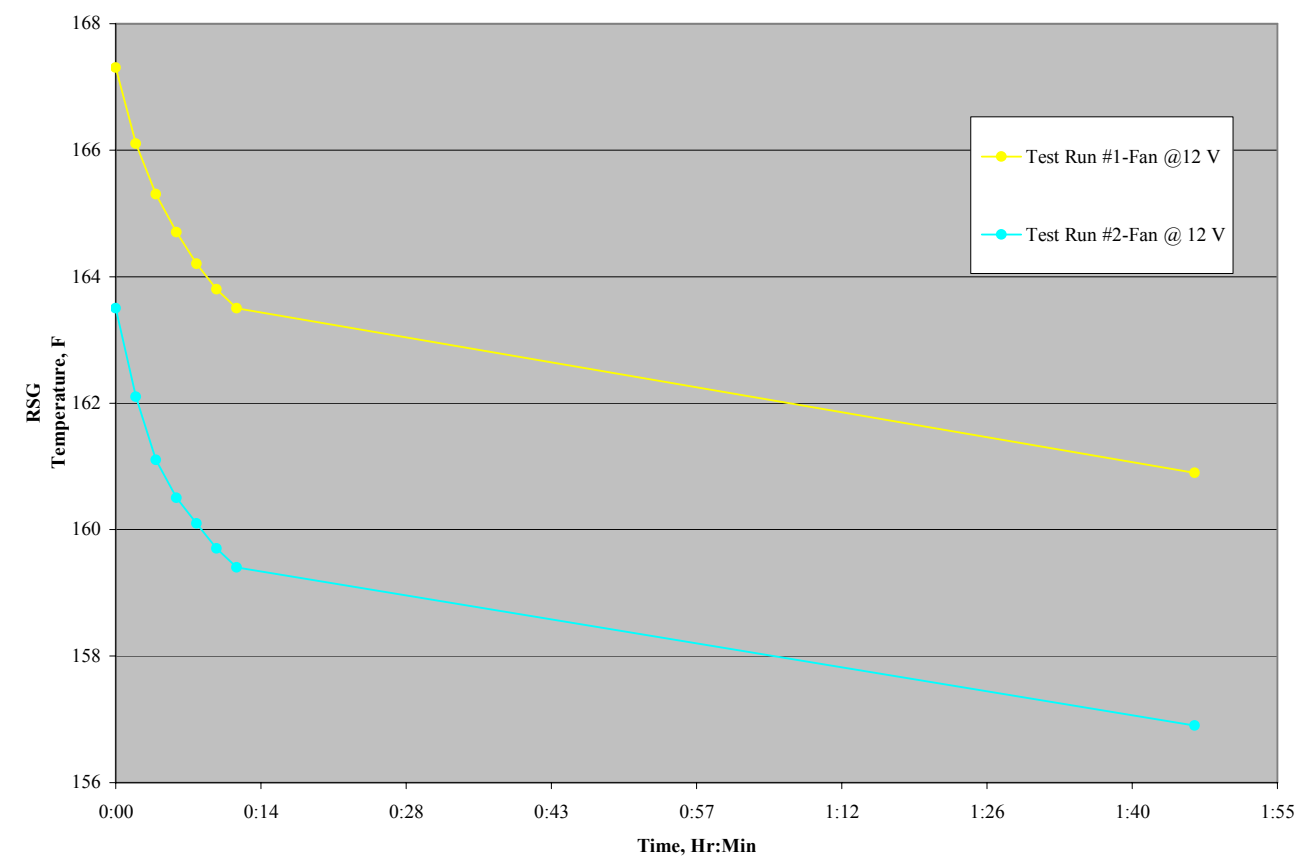

Figure 4 RSG Cooling Curves

In both of the runs shown, the RSG was placed in the environmental booth and the heater was turned on. The ambient temperature in the booth was maintained at $50^{\circ} \mathrm{C}$ throughout the test. When the RSG temperature reached the maximum allowable temperature of $75^{\circ} \mathrm{C}\left(\left(167^{\circ} \mathrm{F}\right)\right.$, the fan was turned on with a controlled voltage of 12 VDC. As can be seen in the graphs, the temperature of the RSG immediately began to drop, and continued to do so over the entire test period. 
The fan voltage had been pre-selected as the maximum voltage that could be used to maintain the acoustic signature allowed for the system. The test clearly established the adequacy of the fan in this bounding condition.

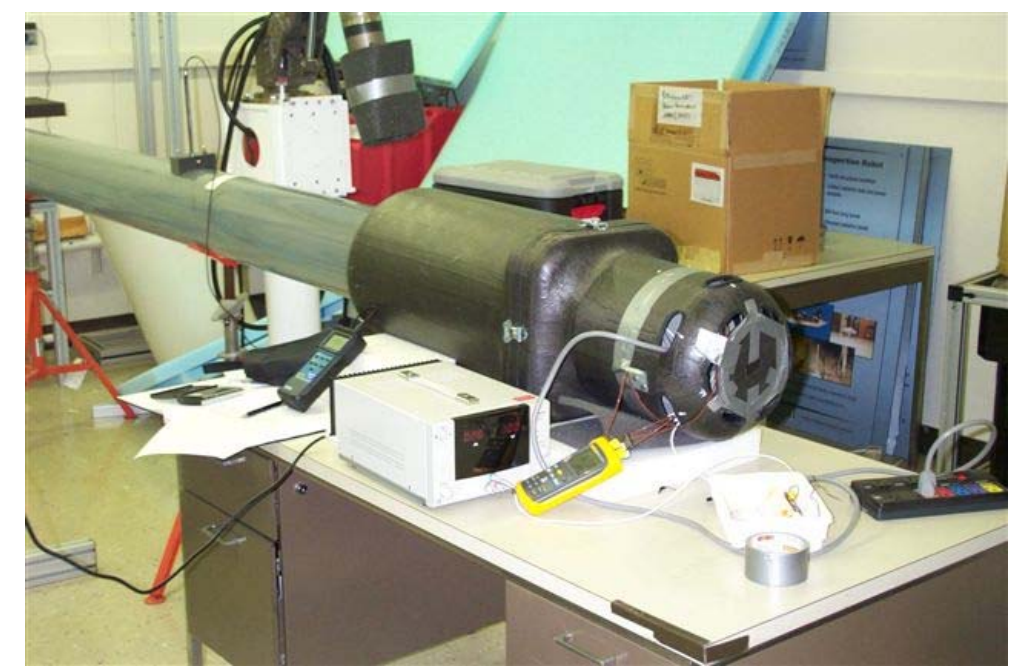

Figure 5 Flow Testing Apparatus

Flow Testing: A laboratory test was performed in August of 2004 to determine the flow through the system using a dummy RSG and the prototype inner components. The inner components were placed in the composite case in a prototypic manner with all of the requisite foam mounting parts, and placed on a laboratory table. A clear plastic flow tube was mounted to the inlet case. A flow indicating anemometer was placed on the flow tube, 10 pipe diameters down from the end of the tube insuring there were 5 diameters between the anemometer and the mouth of the RSG outer case. REF: Crane Flow of Fluids Technical Paper No. 410. This gave the flow enough time to equilibrate before the anemometer. Fan speed was controlled by a precision DC power supply, set at 12 volts.

The test was conducted using a calibrated flow meter placed in line with the input of the system. The chart below is a compilation of the data taken.

\begin{tabular}{|l|l|l|l|}
\hline Date & $\begin{array}{l}\text { Fan } \\
\text { Voltage }\end{array}$ & $\begin{array}{l}\text { Flow } \\
\text { (ft/min) }\end{array}$ & $\begin{array}{l}\text { Flow } \\
\text { Rate } \\
\text { (CFM) }\end{array}$ \\
\hline $8 / 19 / 2004$ & 12 & 177 & 74 \\
\hline $8 / 19 / 2004$ & 12 & 179 & 75 \\
\hline $8 / 19 / 2004$ & 12 & 177 & 74 \\
\hline $8 / 19 / 2004$ & 12 & 177 & 74 \\
\hline $8 / 19 / 2004$ & 12 & 204 & 85 \\
\hline $8 / 19 / 2004$ & 12 & 204 & 85 \\
\hline $8 / 19 / 2004$ & 12 & 204 & 85 \\
\hline $8 / 20 / 2004$ & 12 & 216 & 90 \\
\hline $8 / 20 / 2004$ & 12 & 216 & 90 \\
\hline & & Average & 81 \\
\hline
\end{tabular}


The flow average of $81 \mathrm{CFM}$ and the minimum flow recorded, $74 \mathrm{CFM}$ provided a basis for bounding the operating envelope of the cooling system.

Altitude Calculations: A further cooling requirement for the RSG cooling system is performance at various altitudes up to 15,000 feet. Since altitude testing is very expensive and can be done in only a few locations in the country, a computational analysis was done to determine whether an actual test would be required. A set of calculations were made based on data supplied by the fan vendor. These formulas were developed and applied to cooling situations where electronics must perform under varying altitude conditions.

$\mathrm{CFM}=$ Cubic Feet per Minute $\quad \mathrm{Q}=$ Heat transferred $(\mathrm{kW})$

$\mathrm{Cp}=$ Specific Heat of Air $(\mathrm{kJ} / \mathrm{kg} \cdot \mathrm{K}) \rho=$ Air Density $(\mathrm{kg} / \mathrm{m} 3)$

$\Delta \mathrm{T}=$ Change in Temp ${ }^{\circ} \mathrm{C}$

Required $\mathrm{CFM}=\mathrm{Q} /\left(\mathrm{Cp}^{*} \rho^{*} \Delta \mathrm{T}\right) 1$

Altitude temp. change $6.5^{\circ} \mathrm{C} / \mathrm{km}$ of altitude

Energy generated by RSG 300 watts, or $.3 \mathrm{~kW}$

Air temp. at sea level $50^{\circ} \mathrm{C}$

Maximum surface RSG temp. $75^{\circ} \mathrm{C} .7711 .06$

$\begin{array}{llll} & \text { Sea Level } & \mathbf{5 0 0 0} & \mathbf{1 5 0 0 0} \\ \mathbf{Q} & .3 \mathrm{~kW} & .3 \mathrm{~kW} & .3 \mathrm{~kW} \\ \mathbf{C p} & 1.021(\mathrm{~kJ} / \mathrm{kg} \cdot \mathrm{K}) & 1.021(\mathrm{~kJ} / \mathrm{kg} \cdot \mathrm{K}) & 1.021(\mathrm{~kJ} / \mathrm{kg} \cdot \mathrm{K}) \\ \boldsymbol{\rho} & 1.19 \mathrm{~kg} / \mathrm{m} 3 & 1.06 \mathrm{~kg} / \mathrm{m} 3 & .771 \mathrm{~kg} / \mathrm{m} 3 \\ \boldsymbol{\Delta} \mathbf{T} & 25^{\circ} \mathrm{C} & 35^{\circ} \mathrm{C} & 54.72{ }^{\circ} \mathrm{C} \\ \mathbf{C F M} & \mathbf{2 0 . 9 1} & \mathbf{1 6 . 7 7} & \mathbf{1 4 . 7 5}\end{array}$

The calculations show that only $21 \mathrm{CFM}$ are required to control the heat load of a system, and this has been corroborated by the original tests in a heated chamber. As the altitude is increased, the change in temperature dominates the calculation, and the flow required actually goes down. Thus it is expected that the cooling configuration that is currently in place is more than adequate for altitude conditions required by the project.

\footnotetext{
${ }^{1}$ References: http://www.comairrotron.com/engineering_notes_17.asp
} 
Rain, MIL-STD-810F, Method 506.4 Procedure

The rain test will conform to MIL-STD-810F, Method 506.4 Procedure I (Rain and Blowing Rain). The purpose of this method is to help determine the following with respect to rain, water spray, or dripping water:

- The effectiveness of protective covers, cases, and seals in preventing the penetration of water into the materiel.

- The capability of the materiel to satisfy its performance requirements during and after exposure to water.

- Any physical deterioration of the materiel caused by the rain.

- The effectiveness of any water removal system.

- The effectiveness of protection offered to a packaged material.
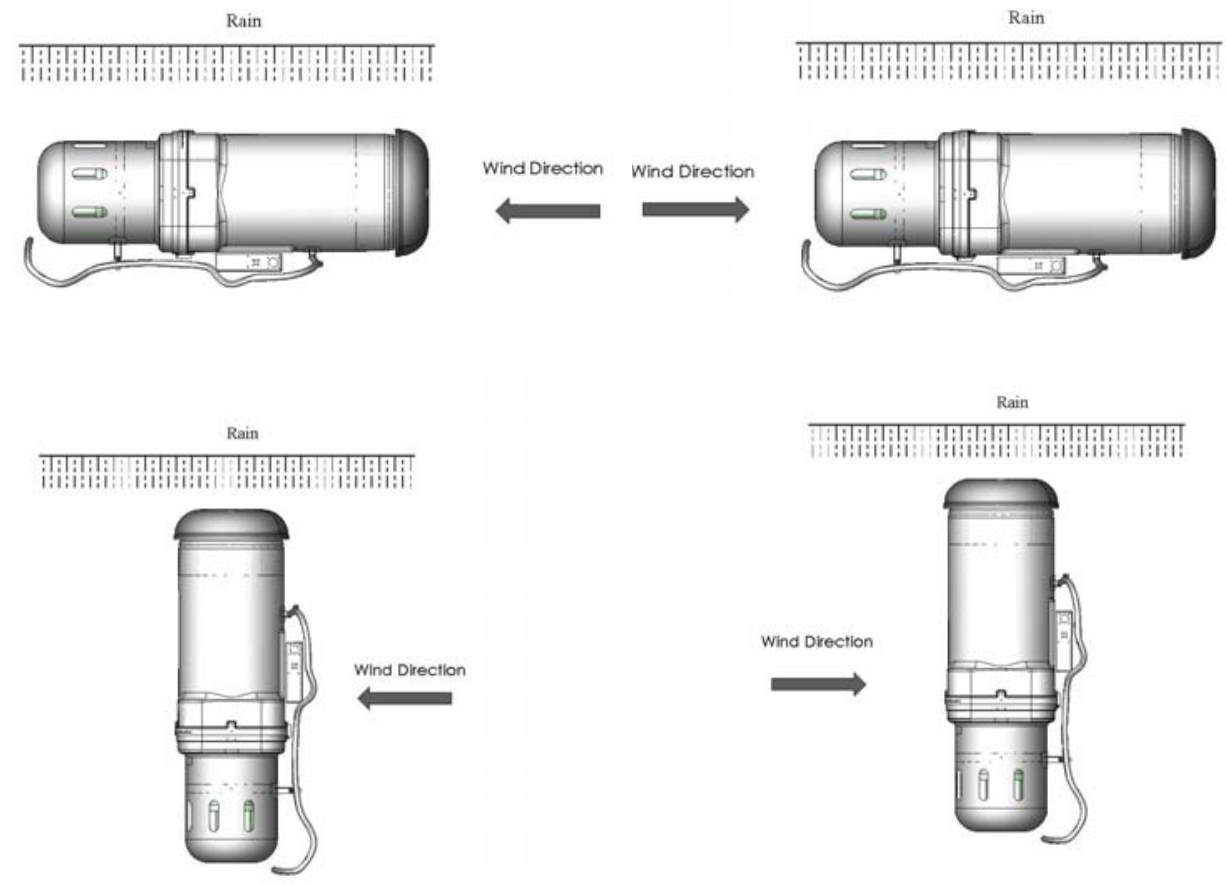

Figure 6 Case Orientations for Rain Testing 


\section{TEST SETUP}

Test specimen setup. The case specimen will be placed on a stand or small table so that it is off the floor of the chamber. Sufficient clearance is needed around the case so that air can circulate in the chamber and through the test case. The case will be tested in four positions: upright wind on back, upright wind on front, sideways wind on top and sideways wind on bottom. Each position is illustrated in Figure 6.

\section{Pass/Fail Criteria:}

- The cooling system is operational and capable of cooling the case to within the required temperature limits.

- The weight of the case after completion of all the tests is no more than $5 \%$ greater than the original weight.

- There is no visible degradation of the case including the foam.

- There is no swelling of the foam that would make insertion and removal of the case contents difficult.

\section{Testing:}

The final Rain test was conducted at Systima Technologies on August 22, 2005. Richard Davis conducted the testing for Systima and Stan Owsley was the representative from PNNL.

The Rain tests were conducted per MIL-STD-810F Method 506.4 Procedure 1 with the following exceptions due to set up limitations. The specifications states that the wind velocity should be $18 \mathrm{mps}$ and the water drop velocity should be $9 \mathrm{mps}$. The actual testing wind velocity was $15.8 \mathrm{mps}$ and the water drop rate was $7 \mathrm{mps}$. The sponsor was notified of the variance and agreed the variance was acceptable.

At the beginning of each test run the surface temperature of the case and the weight of the case were documented. Data is found in the final report that Systima delivered to PNNL, Appendix E.

\section{Summary:}

At the conclusion of all of the Rain testing the cooling system operated as expected. The weight of the case never increased over 5\% and there were no visible degradation or swelling of the case components. 


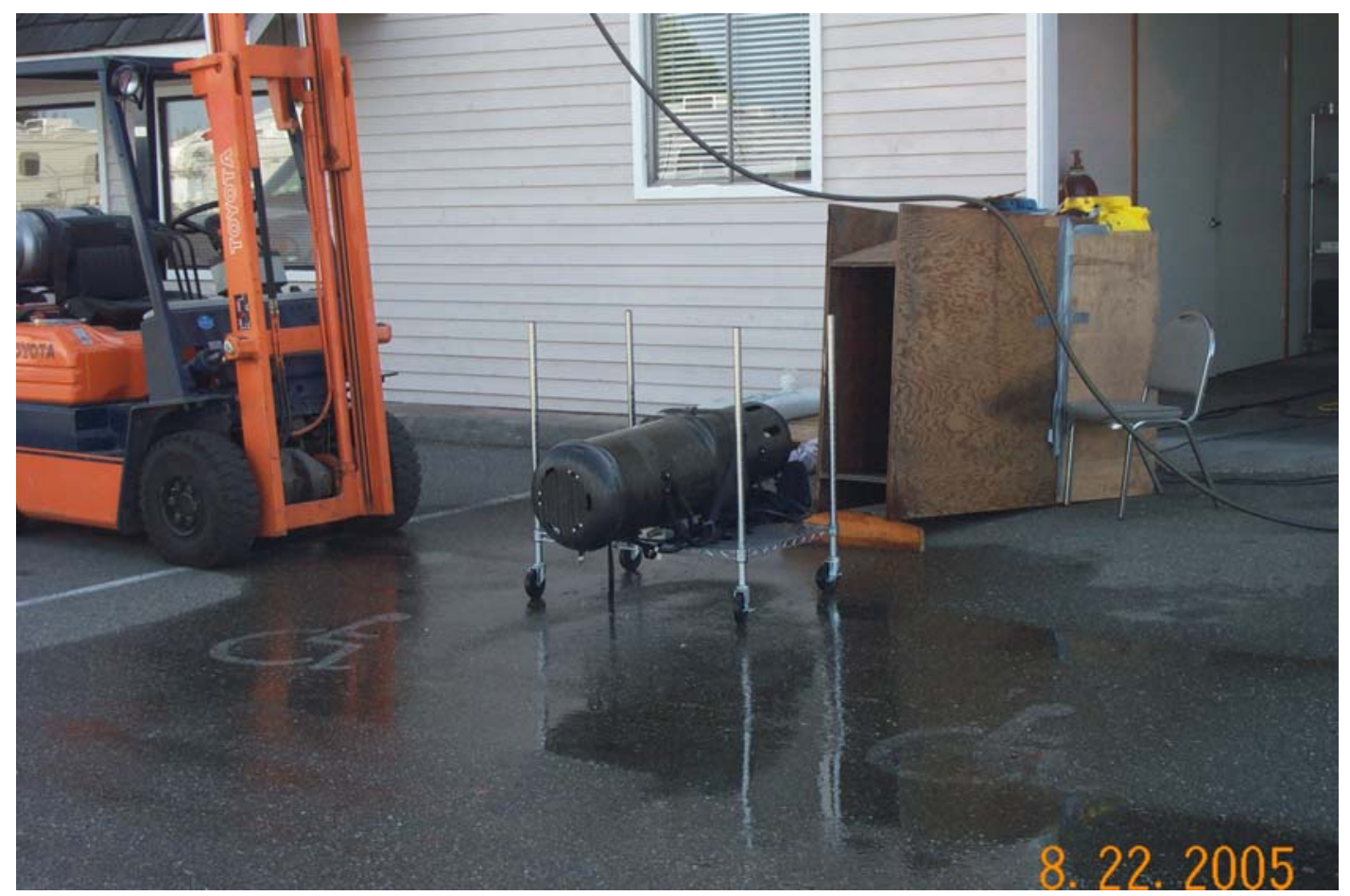

Figure 7 Rain Test Setup. The forklift held the water chamber with all of the pipettes for modulating water droplet size. The plywood structure guides the airflow from the six blowers. 


\section{Vibration}

MIL-STD-810F, Method 514.5 Cat 24 both general use and helicopter material for duration of 60 minutes in each three orthogonal axes for a total test time of 3 hours.

\section{TEST RESULTS}

On June 7-8, 2005 PNNL staff (Stan Owsley and Dave Alexander) along with a contractor witness (Chris Park) met at Systima Technologies in Bothell, WA to conduct vibration testing on the RSG Deployment Case. The vibration testing was conducted per MIL-STD-810F, Method 514.5, Category 24. The purpose of the vibration testing was to provide reasonable assurance that the case and cooling system could withstand the vibrations associated with everyday handling and transportation. The pass/fail criteria set forth was that: (1) maximum acceleration measured on the RSG accelerometers is less than or equal to $20 \mathrm{~g}$ on every channel, (2) there is no visible damage or degradation of the case that would result in the case not being able to fulfill its mission, and (3) the case cooling system still operates as required at the completion of the vibration testing.

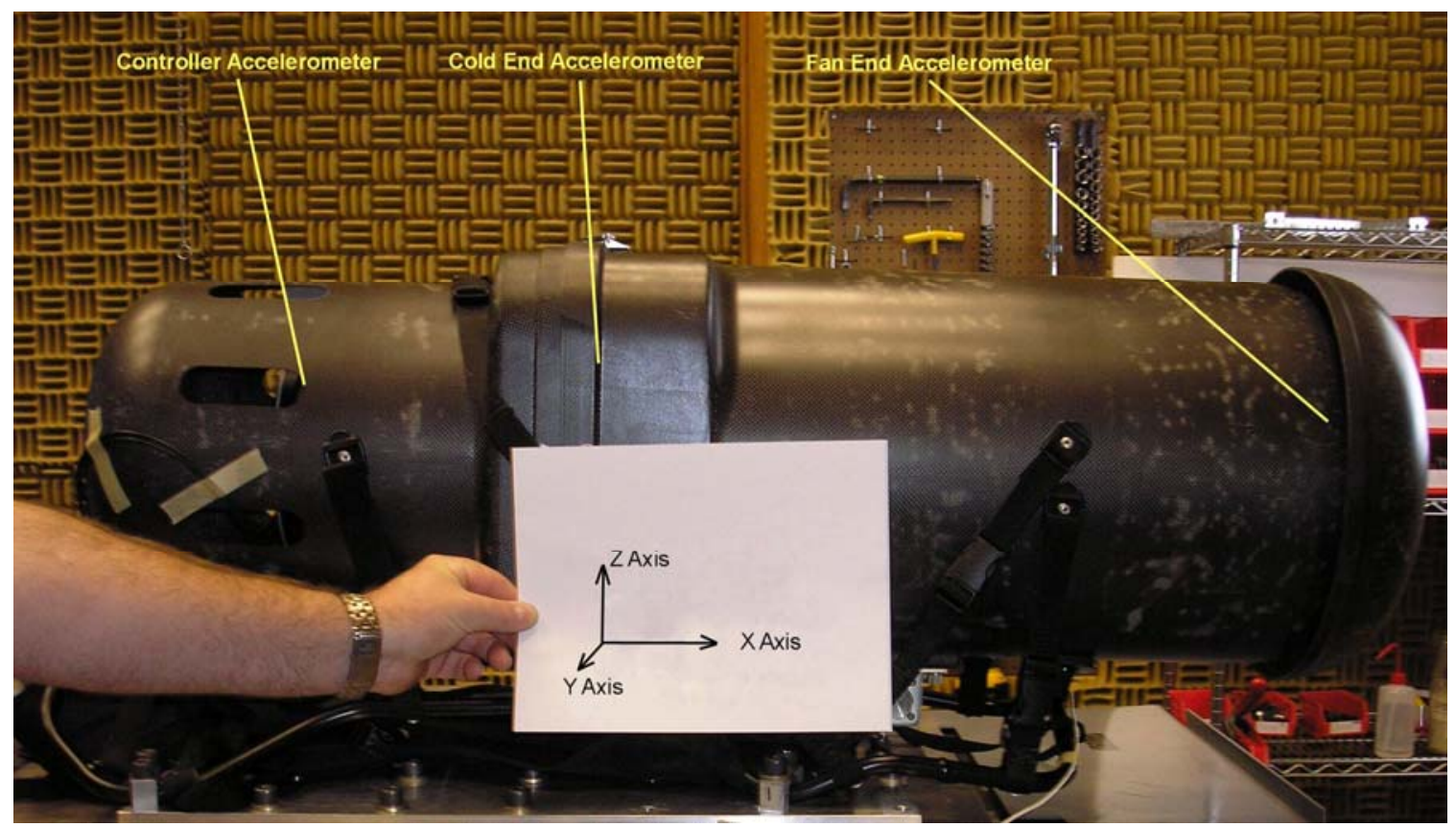

Figure 8 Vibration Accelerometer Orientation at Systima Technologies

The maximum acceleration measured on the RSG accelerometers was $9.1 \mathrm{~g}$ at $51.1 \mathrm{~Hz}$ on the $\mathrm{Z}$ axis on the fan end accelerometer (Figure 9). There was visible damage to the backpack frame and to outlet plenum of the case at the end of the testing, but the damage would not hinder the completion of the mission or the safety of the RSG. After each sine and random vibration test the cooling system operated as designed. Overall, the results of the testing show that the RSG Deployment Case meets or exceeds all required criteria. 


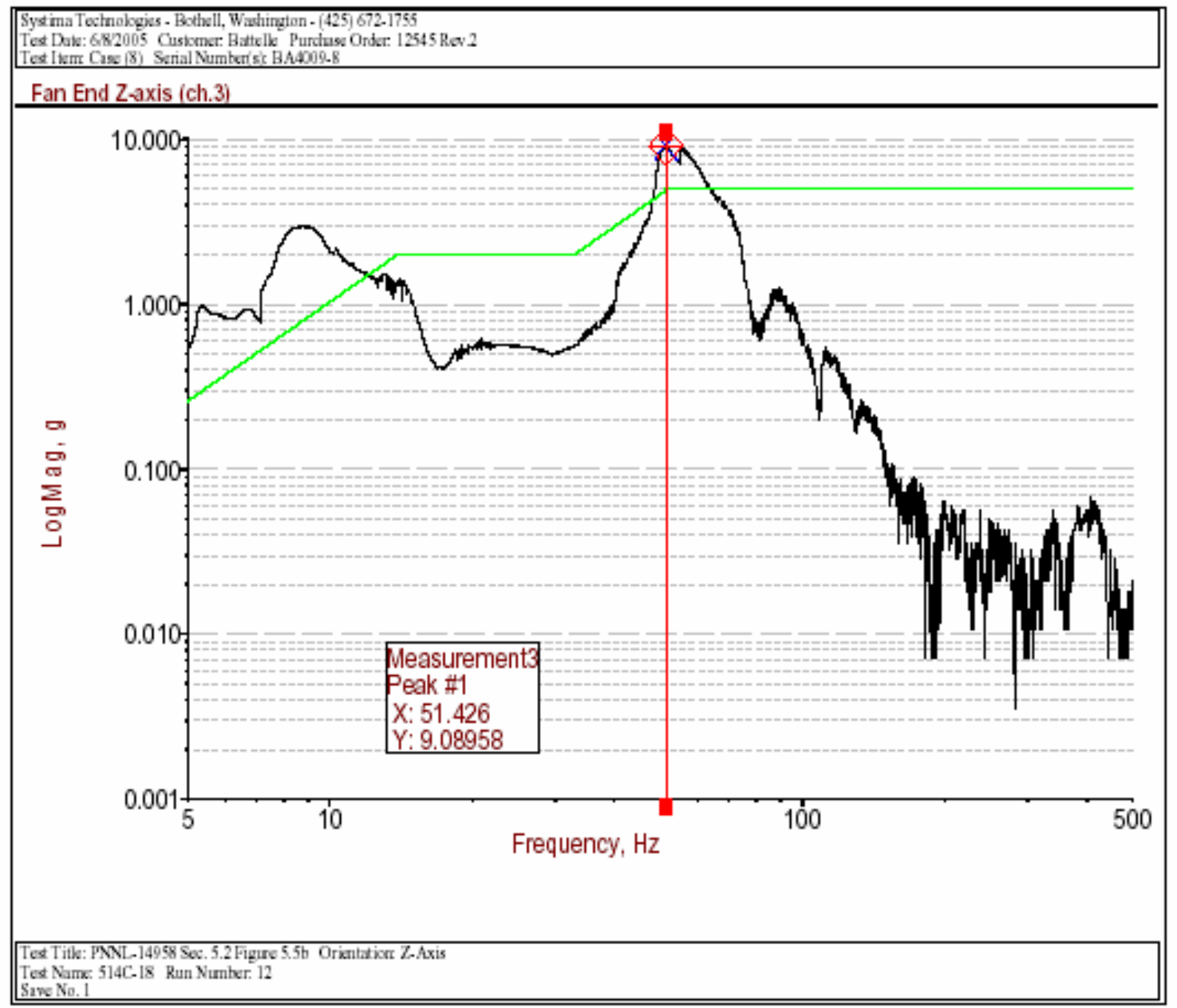

Figure 9

\section{Testing Results Notes:}

All vibration testing was conducted using the following components:

Case \# BA4009-8, Electrical Box \# 1, Cooling Housing \# BA4009-8

The only components that were changed during the vibration testing were the backpack frames. All other components completed the entire vibration test (6 hours). 
Test \#1 X Axis Sine Vibration

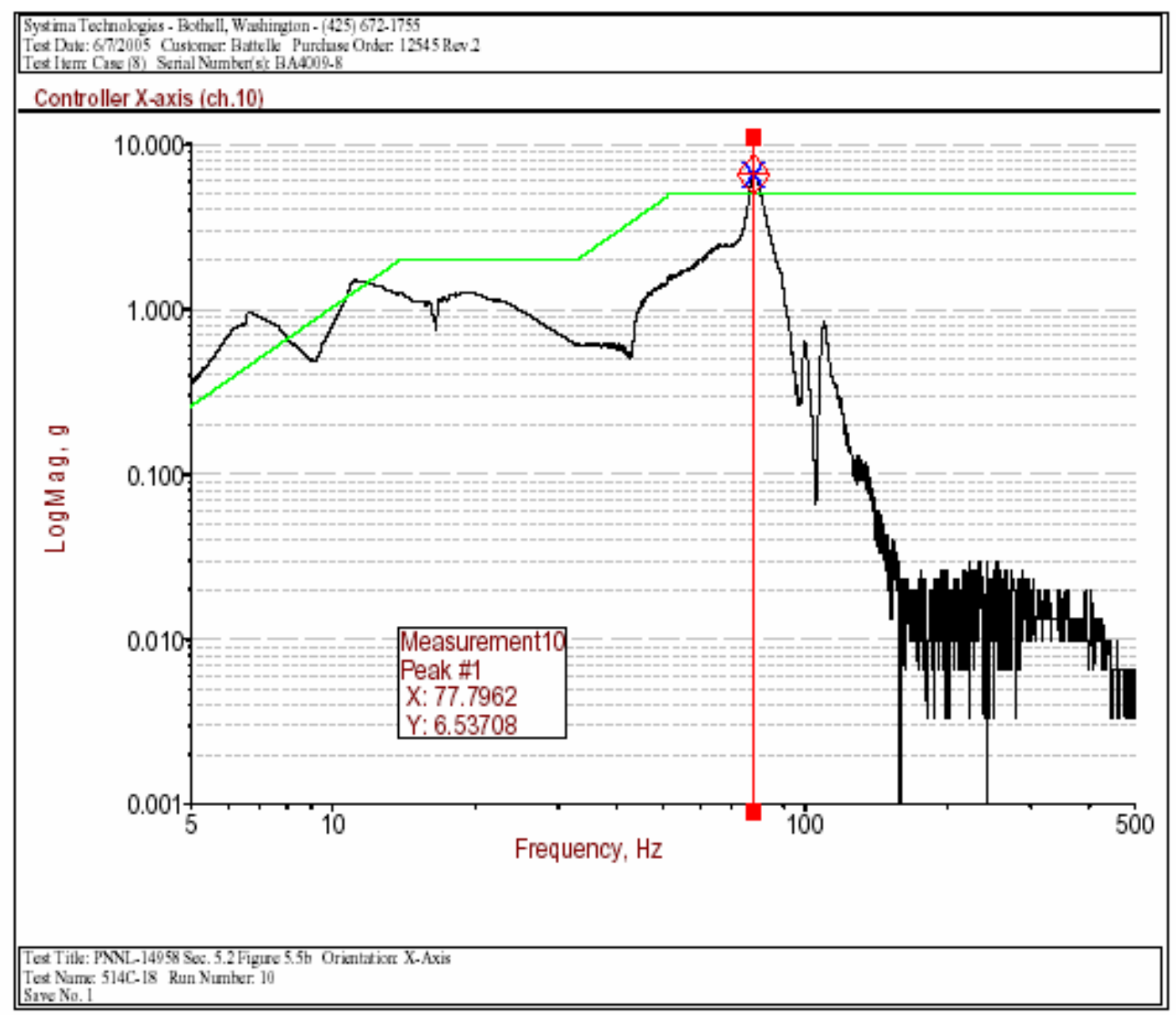

Figure 10

The maximum g levels, as seen in Figure 10, are $6.5 \mathrm{~g}$ 's at $77.8 \mathrm{~Hz}$ on the $\mathrm{X}$ axis of the controller accelerometer.

No visible damage to case after test. Electronics functioned after test. Fan speed was $1541 \mathrm{rpm}$ after test.

Test \#2 X Axis Random Vibration

Electronics function and fan speed was $1575 \mathrm{rpm}$ after testing concluded.

Small filings from the inlet plenum were seen on the vibration table after the test concluded. No structural damage was detected. 
Test \#3 Y Axis Sine Vibration

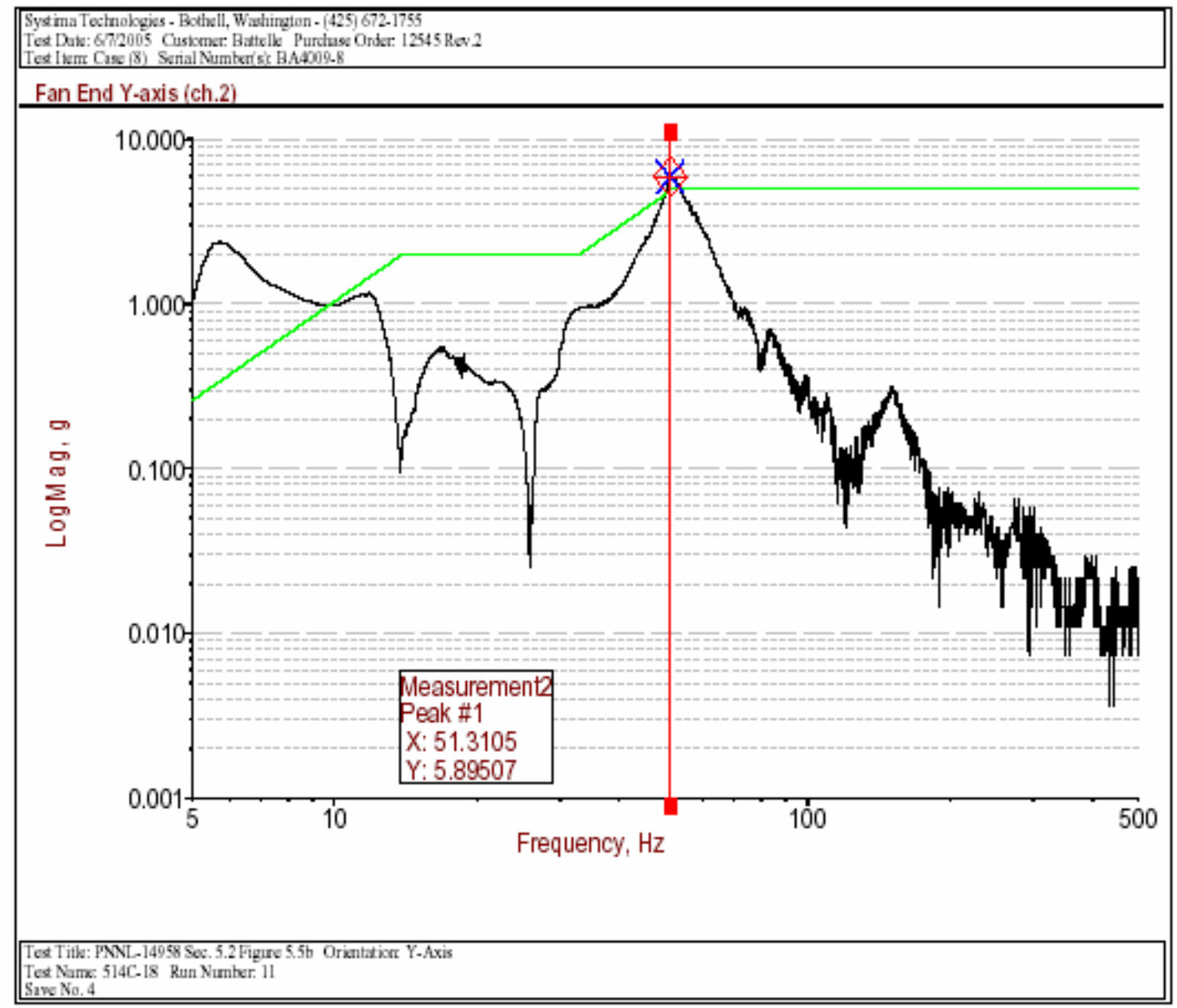

Figure 11

The maximum g levels, as seen in Figure 11, are 5.9 g's at $51.3 \mathrm{~Hz}$ on the $\mathrm{Y}$ axis of the fan end accelerometer.

Electronics functioned and fan speed was $1584 \mathrm{rpm}$ after test.

Small filings from Inlet and Outlet Plenums were visible. No structural damage was apparent on the plenums.

Test \#4 Y Axis Random Vibration

Top part of unsupported backpack frame bends down $\sim 1 / 2$ " during testing and the Outlet plenum has several small fractures in the structure.

Tall backpack upright broke after $\sim 20$ minutes of testing. The test was completed with the upright broken.

Test \#5 Z Axis Sine Vibration

A new backpack frame replaced the broken frame used in the Y axis testing. During the first 15 minute sweep the tall upright on the backpack frame began to bend over again, but did not fail. A resonance was hit at $\sim 8 \mathrm{~Hz}$ and the RSG controller began to visibly bounce around inside the case much more than any other test because the outlet plenum support structure began to break apart. With the outlet plenum broke and the tie down straps loosening because the backpack frame upright bent over, the highest g loading was recorded at 9.1 g's (Figure 12). 


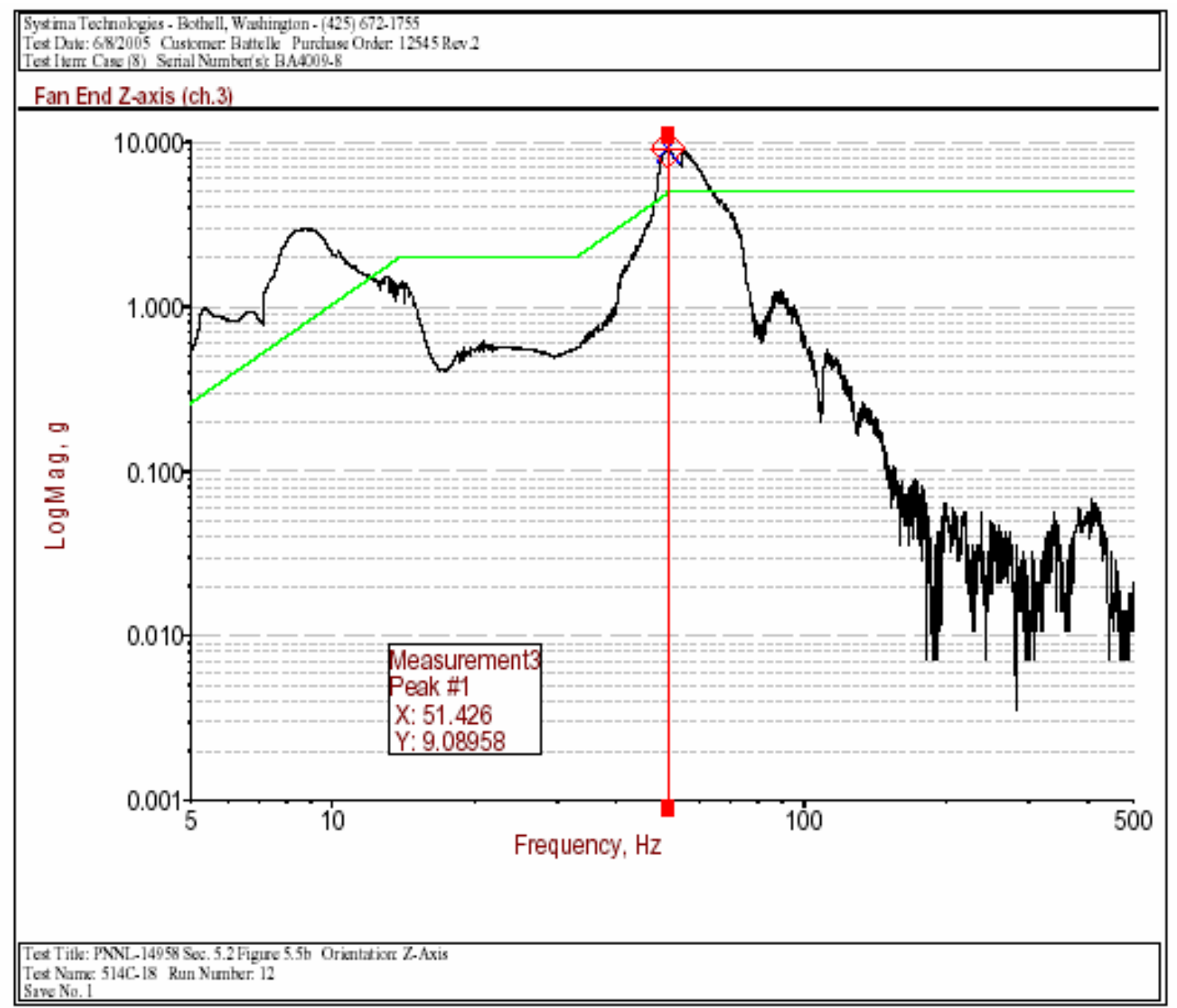

Figure 12

The test was stopped after 15 minutes to change out the backpack frame and with consultation with Chris Park we determined that we had enough information on the $Z$ axis sine sweep and needed to run the $\mathrm{Z}$ axis random test before we damage the internals.

Electronics functioned after test and the fan speed was $1550 \mathrm{rpm}$.

After completing the $\mathrm{Z}$ axis random test the case ran through the rest of the sine sweeps (45 minutes, three 15 minute sweeps) with the backpack frame that had been used for the $\mathrm{X}$ axis testing. The backpack frame uprights did not bend throughout this test. With the uprights remaining in tact the g levels decreased because the hold down straps held the case tight against the frame. Even though the controller was visibly traveling much farther than seen on any other testing, the g levels still remained below the requirements at 7.4 g's as seen in Figure 13. 


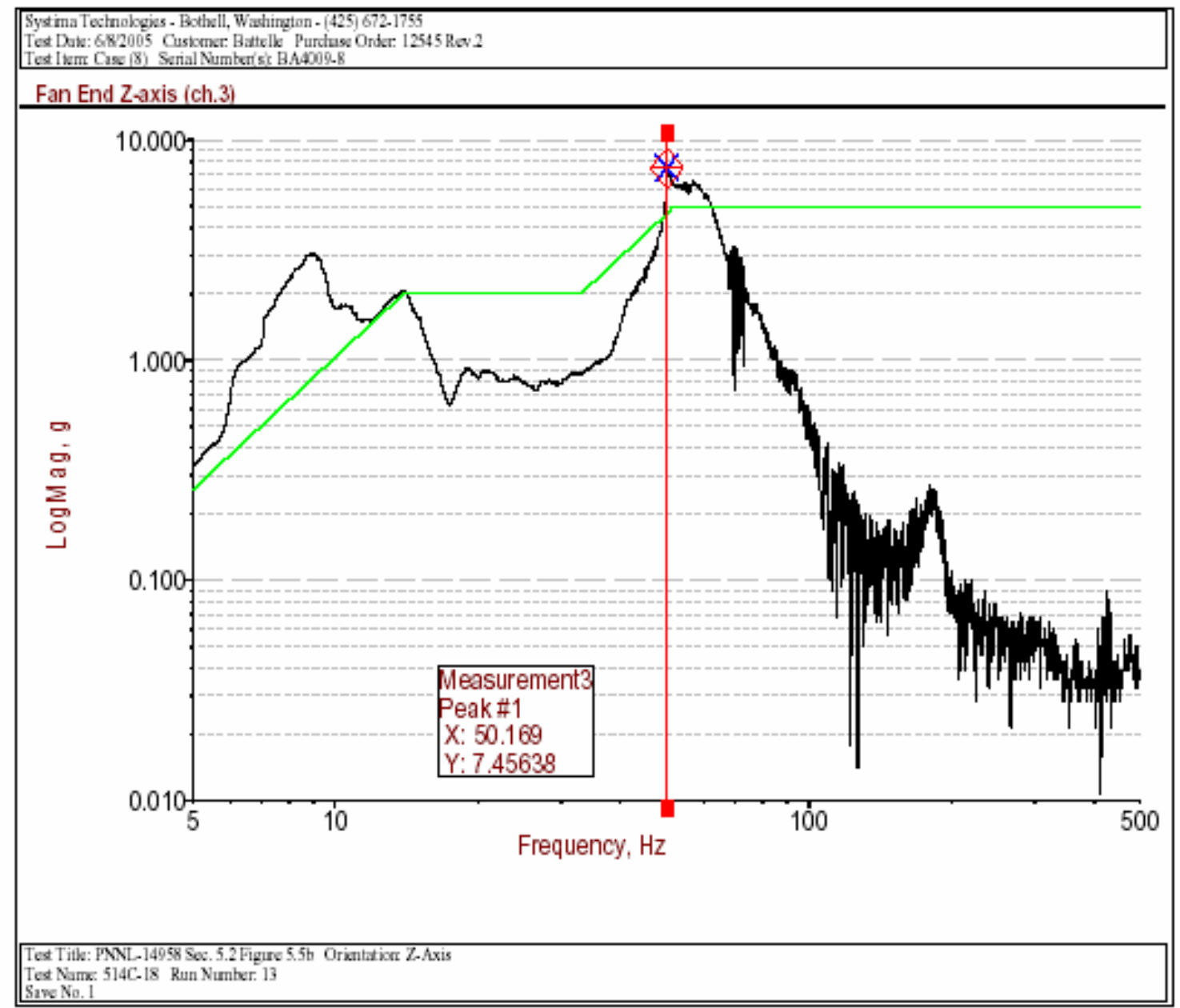

Figure 13

The backpack frame that completed all of the $\mathrm{x}$ axis testing and all but 15 minutes of the $\mathrm{Z}$ axis testing did finally break through the frame tube in the last 15 minutes of the sine sweep test. At the completion of the last three sweeps the electronics functioned and the fan speed was 1571 rpm.

Test \#6 Z Axis Random Vibration

Before this test was started the outlet plenum showed substantial damage and the tall upright on the backpack frame was already bent from previous testing.

At the completion of the test the control electronics and pendant were operating properly. The fan speed at the end of the test was $1561 \mathrm{rpm}$. 


\section{Shock}

MIL-STD-810F, Method 516.5 Procedure IV, tailored for 18" drop on to compact soil Scope and Objectives

Shock testing of the deployment case was accomplished per MIL-STD-810F, Method 516.5, Procedure IV. The purpose of shock testing was to provide a degree of confidence that the material used to construct the case and cooling system can physically and functionally withstand the relatively infrequent, non-repetitive shocks encountered in handling, service, and transportation environments. The procedure was tailored from MIL-STD-810F Method 516.5 Procedure IV-Transit drop by incorporating client consultation and the results of developmental testing. This procedure is used to determine whether the test case is able to withstand the shocks normally induced during man-packed or man-portable transit. Such shocks are accidental but may impair the functioning or the material. The test case was dropped from a height of 18 inches onto compacted soil with eight orientations derived from a structural review of potential case vulnerabilities. These eight drops were divided among two test items, based on a ratio of the number of cases permitted by MIL-STD-810F Method 516.5 Procedure IV (up to five test items for a total of 26 drops).

The case may sustain some physical damage and still remain functional, but it is critical that the cooling system operate properly throughout the testing, that the case protects its contents from the environment and shock, and finally that the cooling system meets the noise requirements during deployment. Other than that, it is assumed a certain amount of physical damage to the case could be tolerated during testing. With regard to the heater, applied shock could cause the following failures.

Failure of outer shell causing collapse or fracture of cooling air passages and loss of cooling efficiency, increased friction between the housing halves resulting in noisy disassembly, or collapse of the rain cover.

Electronic circuit card malfunction.

Electronic connector damage.

Internal electrical conductor breach or break.

External electrical umbilical breach or break.

Permanent mechanical deformation rendering the deployment case unusable.

\section{Test Set-up}

Item to be tested

The test item was a frame-mounted case with approximate dimensions of $48 \times 18 \times 18$ inches (Figure 14). The case contains an electronic cooling system which will maintain the temperature of a heater during deployment, however during testing the heater was replaced by a physical mockup with the same mass and size. Three triaxial accelerometers were mounted to the mass mockup inside the case. The case with all of its internal components weighed approximately 75 lb. An external battery was used to verify the operation of the cooling system after each drop. 


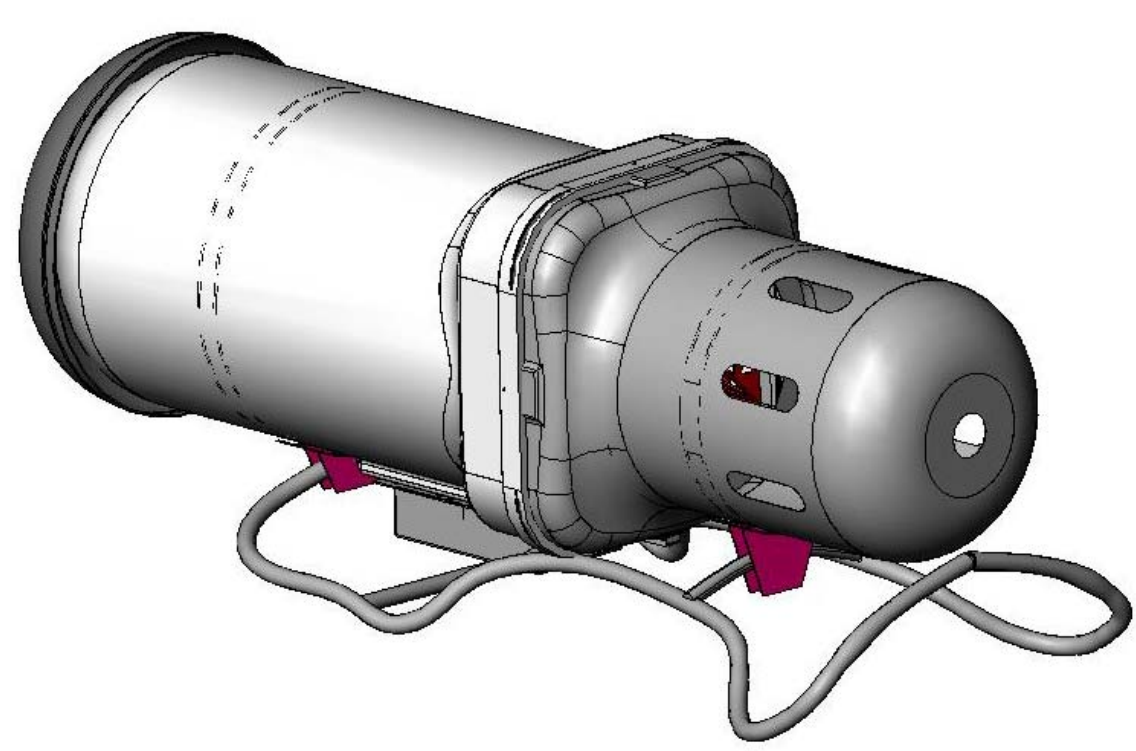

Figure 14 Composite Backpack Case

\section{Test Facility}

Shock testing was conducted near the PNNL 2400 Stevens Facility on compacted soil as shown in Figure 15. Straps were attached to the test case to allow fine adjustments to the angular orientation.

\section{Instrumentation}

The transit shock level experienced by the test case is dictated by the drop height and orientation and thus requires no instrumentation. However, due to the fragility of the case heater, internal shock levels were measured during shock testing. Instrumentation to measure heater shock levels consisted of accelerometers, signal conditioner, data analysis software, and a laptop.

Three triaxial accelerometers (e.g. Dytran Instruments, Inc. Model 3023A1) with specifications that meet the requirements of MIL-STD-810F, Method 516.5, were mounted to the case heater mockup inside the transport case. The location of accelerometers and orientation of the individual channels are shown in Figure 16. The accelerometer serial number for channels 1, 2, and 3 (heater top) was 219, for channels 5,6, and 7 (heater base) was 218, and for channels 4 and 8 was 219 (heater controller). Note that the longitudinal shock at the controller could not be measured because the dynamic signal analyzer was limited to 8 channels. 


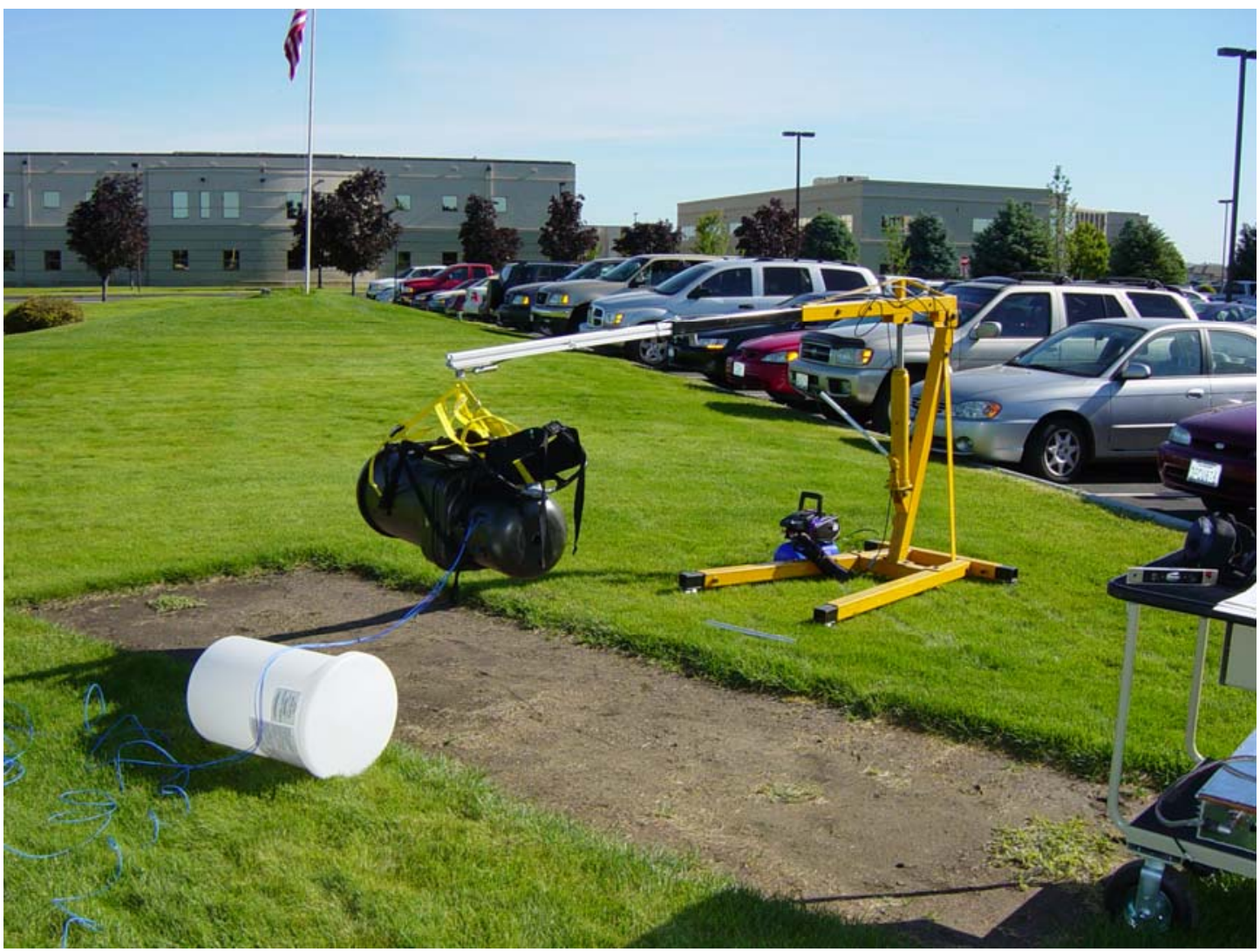

Figure 15 Drop Frame with Quick Release Latch

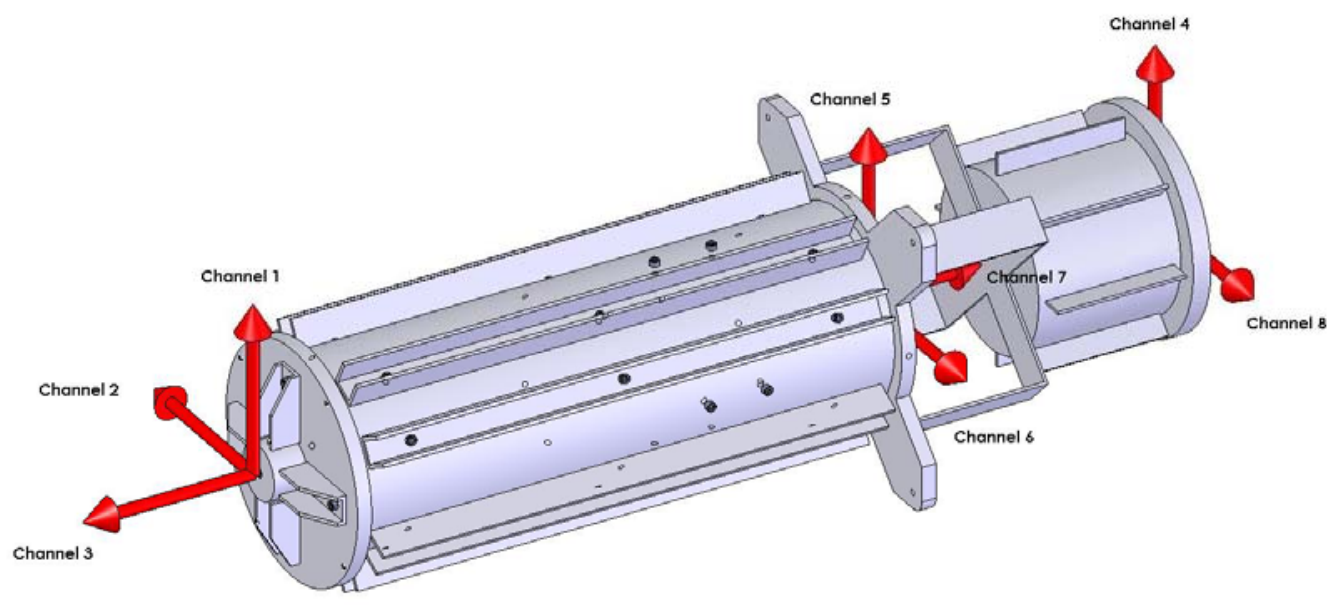

Figure 16 Accelerometer Locations and Channel Orientations 
The signals from the accelerometers were converted to voltages by a Focus II Dynamic Signal Analyzer (Model FCS 200, S/N 4235860 Rev. A) manufactured by LDS Dactron. AC coupling was used to remove the DC component of the input signal. The sensors were powered using the ICP protocol. The AC coupling high-pass filter cutoff frequency set at $0.7 \mathrm{~Hz}$. The Fast Fourier Transform analysis routine was set to the following parameters:

Lines: 1600

Span: $2000 \mathrm{~Hz}$

Window: Hanning

\section{Calibration and Tolerances}

The accelerometers and signal conditioner used in conducting the tests were calibrated to laboratory standards, traceable to the National Standards via primary standards. The calibration date for these components is as follows:

Dytran Instruments Inc. triaxial accelerometer Model 3023A1 SN 218 6/25/2004

Dytran Instruments Inc. triaxial accelerometer Model 3023A1 SN 219 4/22/2004

Dytran Instruments Inc. triaxial accelerometer Model 3023A1 SN 298 6/17/2004

Focus II Dynamic Signal Analyzer SN 4235860 1/6/2004

The calibration dates were slightly outside the desired calibration interval of 1 year per ISO 10012-1; however, the operation and sensitivity of the accelerometers was verified by a calibration exciter for accelerometers (Ono Sokki VX-1100) prior to testing.

The actual drop height was within $2.5 \%$ of the specified drop height per MIL-STD-810F, paragraph 4.5.5.2. Thus, the drop height was $18 \pm 0.45$ inches. The corner drops required the deployment case to be held at various angles with respect to the ground. To determine these angles, a CAD program was used to align the center of gravity (cg) with the point of impact. Once the orientation was established, the angles between the case surface and the ground were calculated. Using an inclinometer, these angles were employed to orient the deployment case prior to conducting the drop. The tolerance for the case inclination shall be \pm 1 degree.

\section{Test Procedure}

\section{Pre-Test Checkout}

The following pretest functional or operational data was taken prior to commencement of shock testing.

a) Verify operation of cooling system, including a check that cooling fan comes on/turn off at preset temperature.

b) Verify operation of the umbilical.

c) Measure weight of case attached to backpack.

2) Test Execution.

a) Install the heater in its test case as prepared for field use.

b) The drop height will be 18 inches, and a total of eight drop orientations will be tested (see Table 2.1).

i) Drop 1 - side drop on case

ii) Drop 2 - on backpack

iii) Drop 3 - side drop on backpack

iv) Drop 4 - side drop on corner of case

v) Drop 5 - on end of backpack (case oriented $20^{\circ}$ wrt vertical) 
vi) Drop 6 - on rain cap

vii) Drop 7- on top corner of case (case oriented $15^{\circ}$ wrt vertical)

viii) Drop 8 - on bottom corner of case (case oriented $13^{\circ}$ wrt vertical)

c) Perform the required drops using drop frame with quick release latch. Secure the case to the latch using adjustable wire harness and orient the case so that, upon impact, a line from the struck corner or edge to the center of gravity of the case and its contents is perpendicular to the impact surface. Adjust the height of the drop frame to achieve the desired drop height of 18 inches.

d) Ensure that the area under the drop frame is clear of objects or personnel. There needs to be sufficient space under the drop point to allow the case to topple and bounce without contacting the drop frame. Drop the case.

e) Visually inspect the deployment case.

f) Photograph location of impact point and any obvious damage

g) Subject the heater thermocouples to $40{ }^{\circ} \mathrm{C}$ water, apply battery power to the control system, and verify operation of the cooling system, fan, and umbilical.

\section{Pass/Fail Criteria}

1) Maximum Shock Criteria: Based on developmental testing conducted prior to final testing, it was expected that maximum shock levels measured by accelerometers attached to the heater would not exceed the following limits 2 . The instantaneous longitudinal shock levels from each of the triaxial accelerometers should not exceed 35 g's with duration of less than $50 \mathrm{~ms}$. Instantaneous outputs from the transverse channels ( $\mathrm{X}$ and $\mathrm{Y}$ ) from each triaxial accelerometer were combined by taking the square root of the sum of the squares. The resultant instantaneous transverse shock levels should not exceed 90 g's with a duration of less than $50 \mathrm{~ms}$. The duration level is a bounding number based on the longest duration of a triangularly shaped shock impulse measured during developmental testing.

2) The following functionality was verified upon completion of each drop.

a) Verify operation of cooling system, including a check that cooling fan comes on/turn off at preset temperature.

b) Verify operation of the umbilical.

3) The deployment case is essentially intact and can complete its mission. Exceptions to this would be failure of outer shell causing collapse or fracture of cooling air passages and loss of cooling efficiency, and increased friction between the housing halves resulting in noisy disassembly, or collapse of the rain cover.

\footnotetext{
${ }^{2}$ A separate shock limit was provided for the longitudinal and transverse directions based on the inherent fragility of
} the heater. 


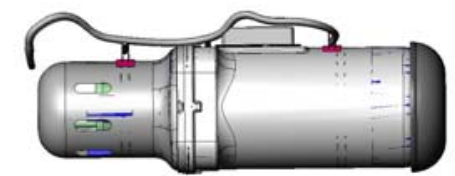

Drop 1 - Side Drop on Case

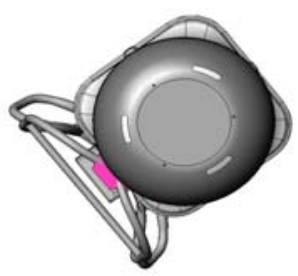

Drop 3 - Side Drop on Backpack

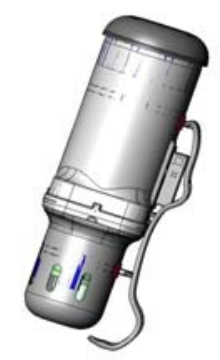

Drop 5 - On End of Backpack

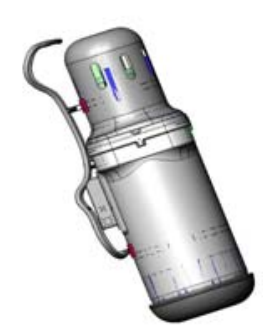

Drop 7 - On Top Corner of Case

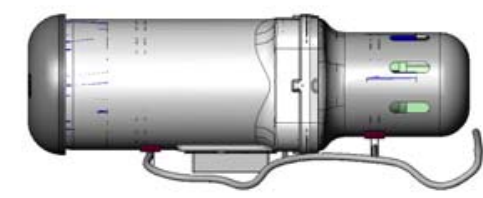

Drop 2 - On Backpack

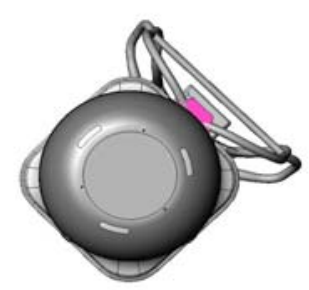

Drop 4 - Side Drop on Corner of Case

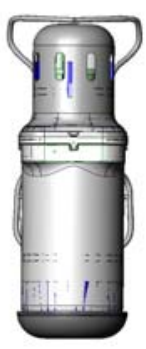

Drop 6 - On Rain cap

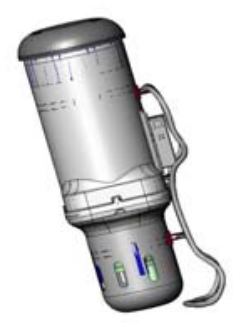

Drop 8 - On Bottom Corner of Case

Figure 17 Drop Test Orientations 


\title{
Test Results
}

\section{Test Progression}

Final shock testing was initiated on June 23, 2005. After Drop 1 (see Figure 17) it was found that the control system did not function. The controller was replaced by a spare, and testing was resumed. After Drop 2 it was found that the control system was again nonfunctional. Testing was suspended and the control system was redesigned. Personnel performing or witnessing the testing on June 23, 2005 included:

\author{
Brian Hatchell - shock measurement system operator \\ Stan Owsley - shock test engineer \\ Dave Alexander - project manager \\ Dennis Kreid - program manager \\ Tim Augauer - Sponsor
}

Final shock testing was resumed and successfully completed on August 17, 2005. All 8 drops were completed in the desired sequence without any control system failures. It should be noted that the same case and frame used for the two drops on June 23, 2005 were reused for the subsequent resumption of testing. Personnel performing or witnessing the testing on August 17, 2005 included:

\author{
Brian Hatchell - shock measurement system operator \\ Stan Owsley - shock test engineer \\ Dave Alexander - project manager \\ Dennis Kreid - program manager \\ DOE Representative \\ Mike Evers - Sponsor
}

After Drop 3, it was noticed that the frame bracket was deformed (Figure 18). The case was opened and a moderate degree of cracking was noticed in the exit plenum (Figure 19 and 20). The frame and exit plenum was replaced and the remaining drops were completed with this configuration. The case bottom cracked during drop 8 (see Figure 21 ), and upon disassembly similar damage to the inlet and exit plenums was noted (Figures 22-24). The damage was not deemed sufficient to jeopardize a mission since the damage did not affect the functionality of the case, did not cause collapse or fracture of cooling air passages or loss of cooling efficiency, and did not result in noisy disassembly. 


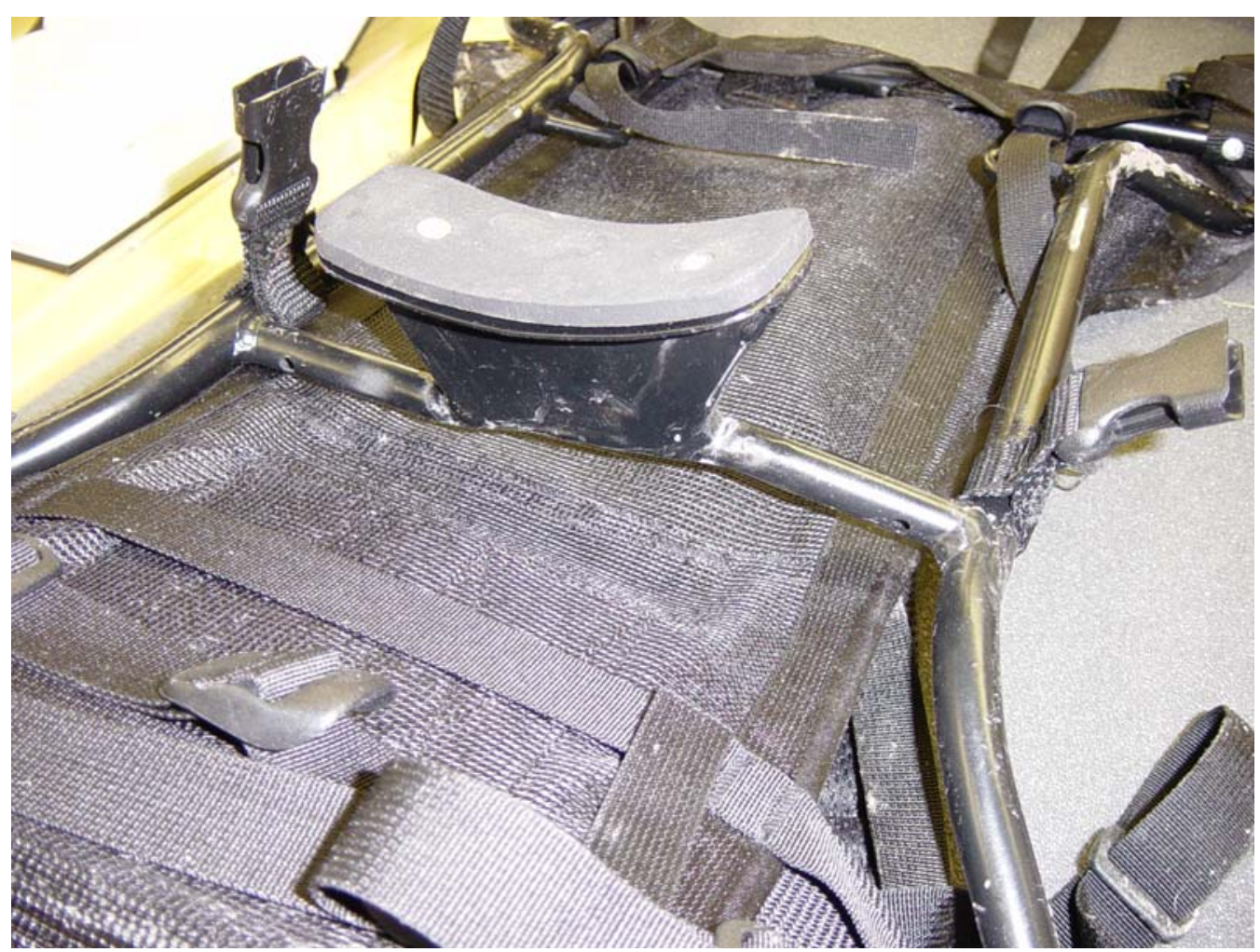

Figure 18 Frame Bracket Deformation after Drop 3

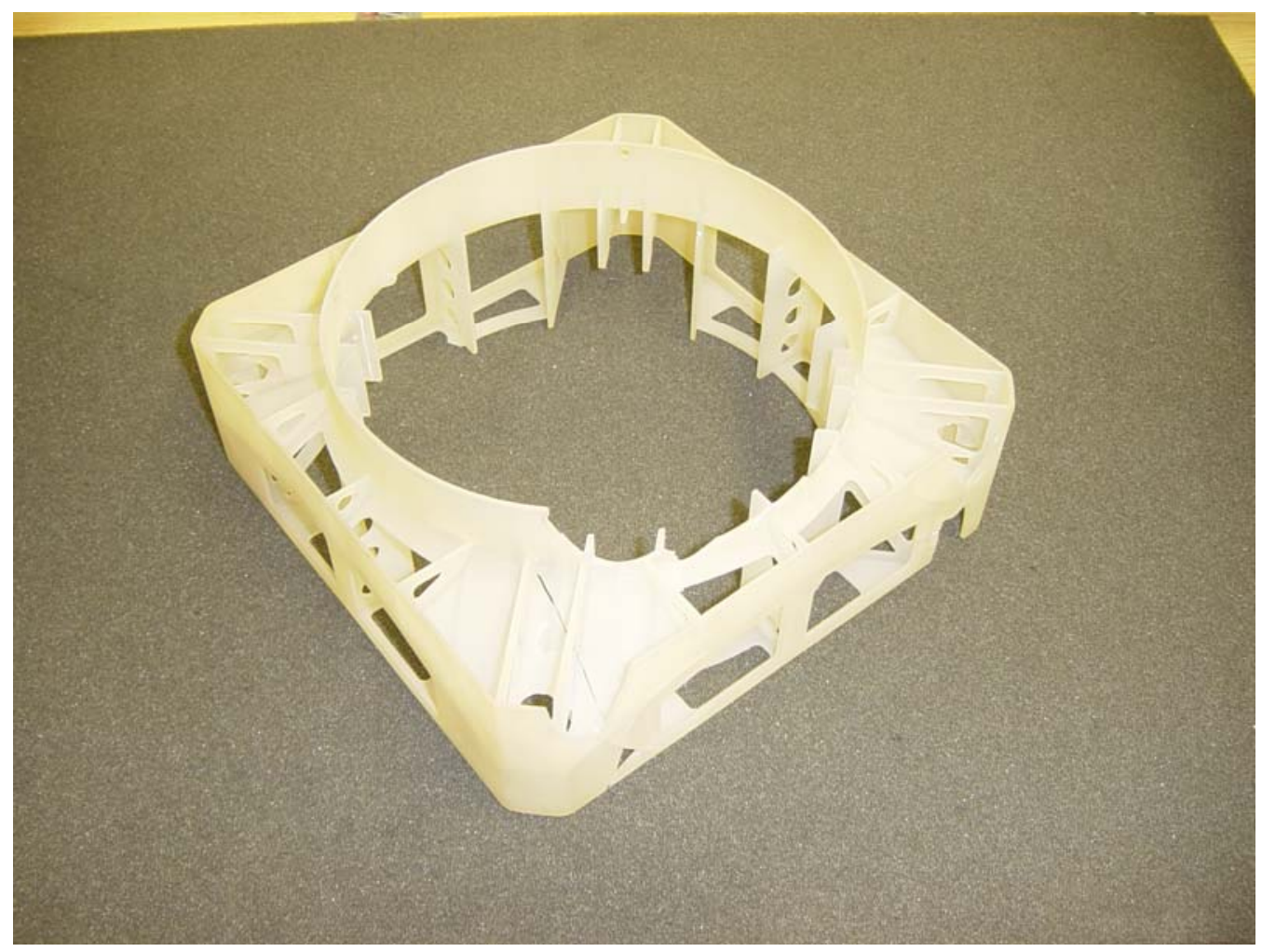

Figure 19 Cracks in Exit Plenum noted after Drop 3 (view 1) 


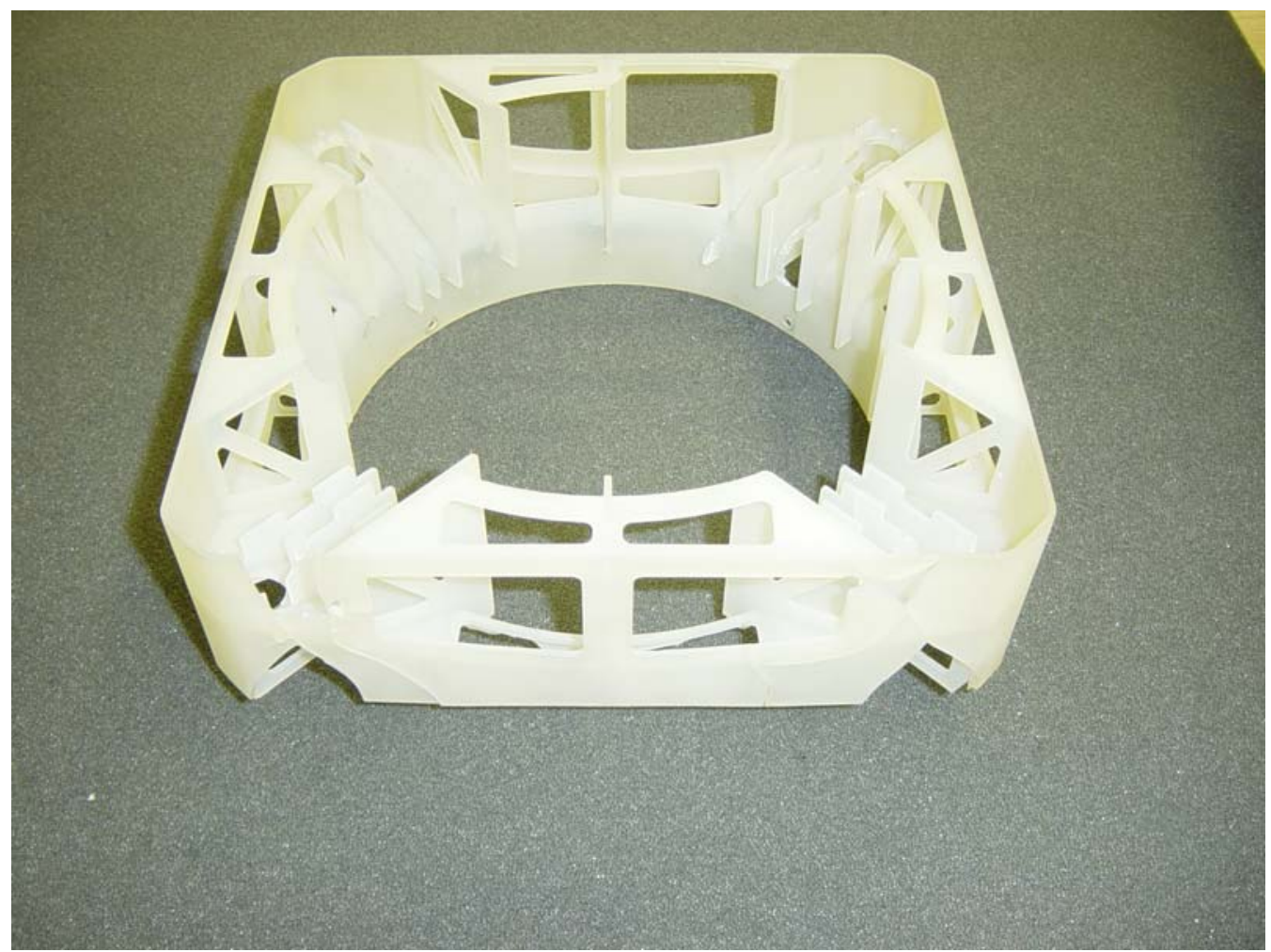

Figure 20 Cracks in Exit Plenum Noted after Drop 3 (view 2)

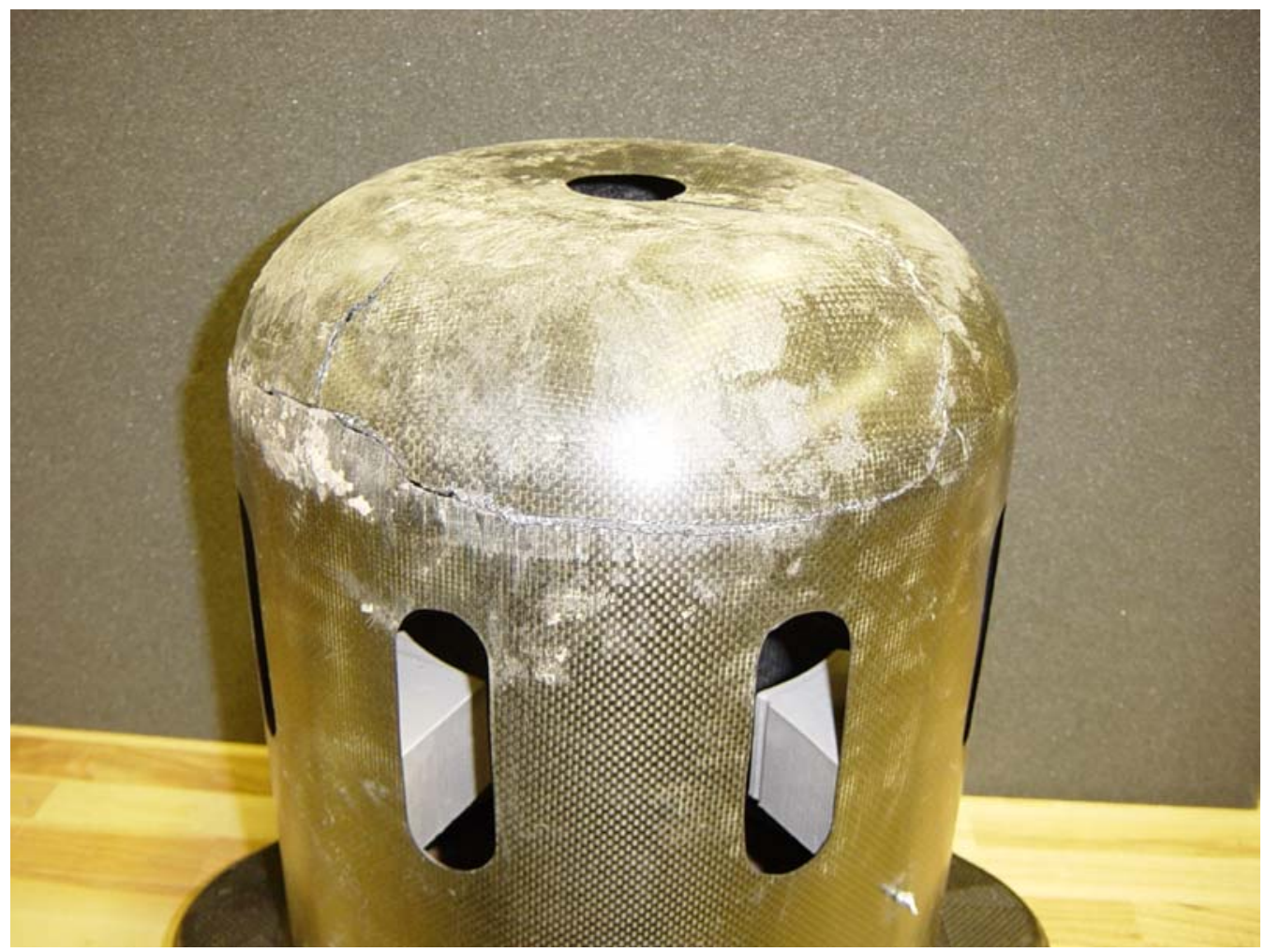

Figure 21 Cracks in Case after Drop 8 


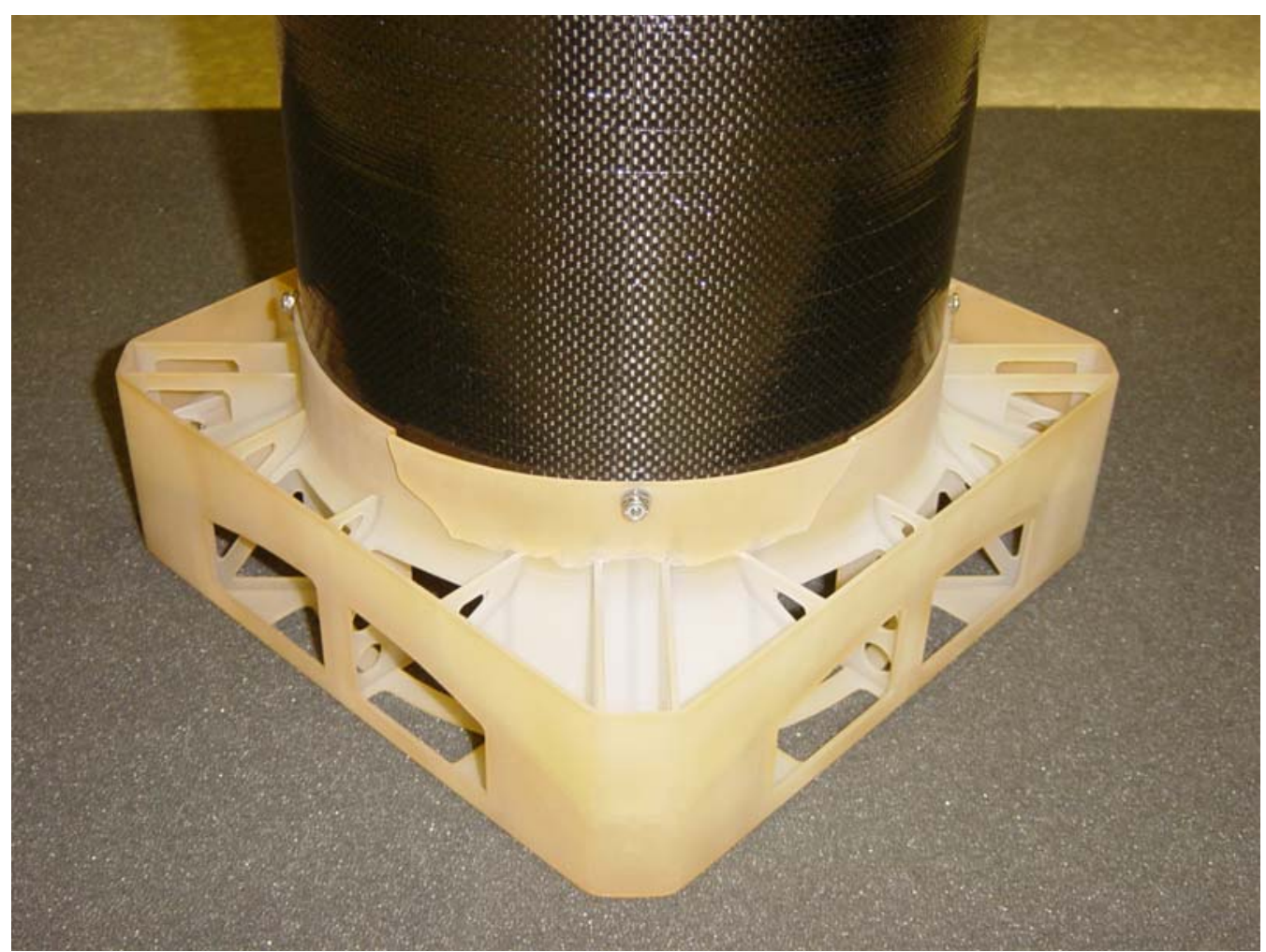

Figure 22 Cracks in Exit Plenum Noted after Drop 8 (view 1)

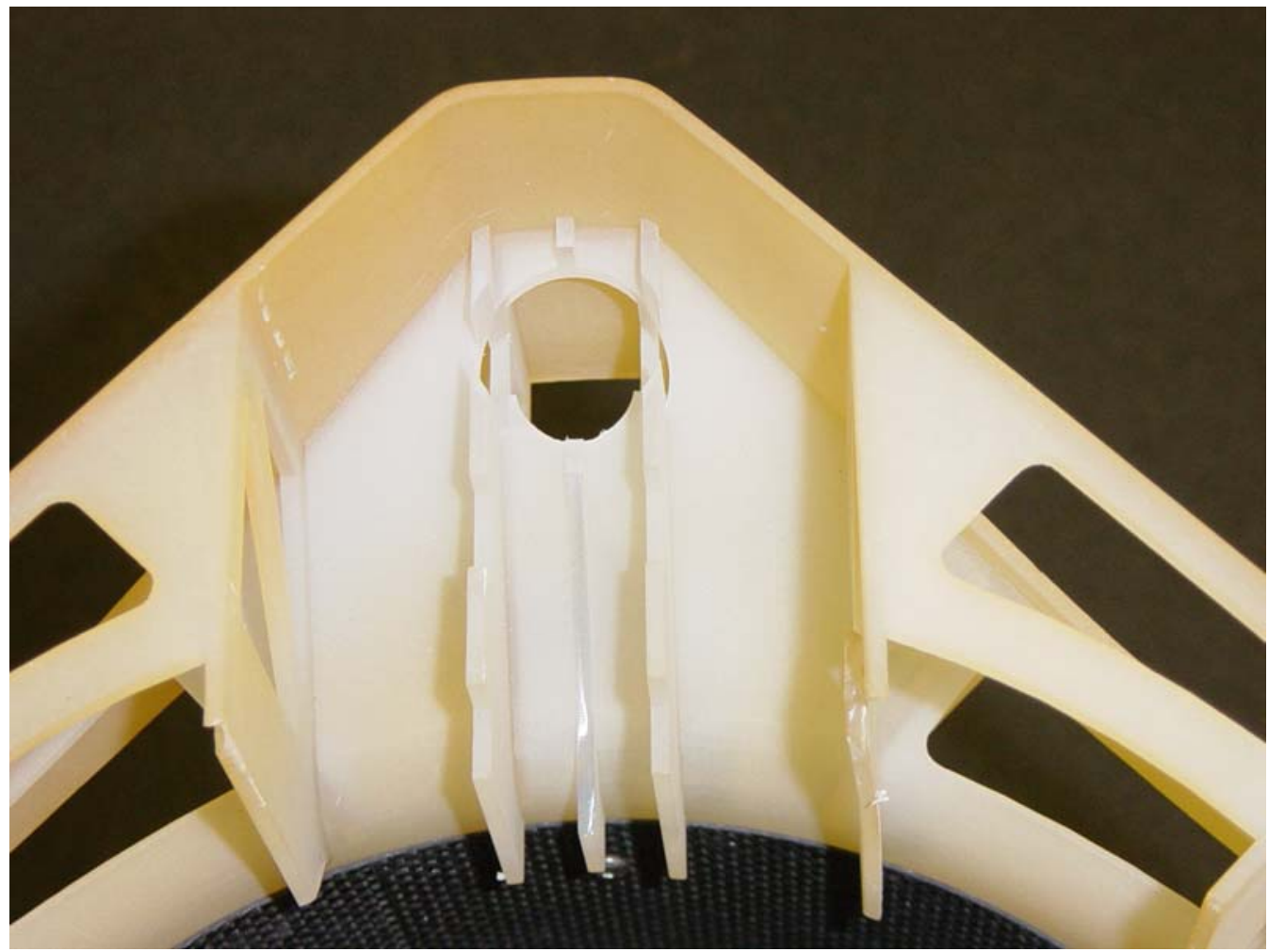

Figure 23 Cracks in Exit Plenum Noted after Drop 8 (view 2) 


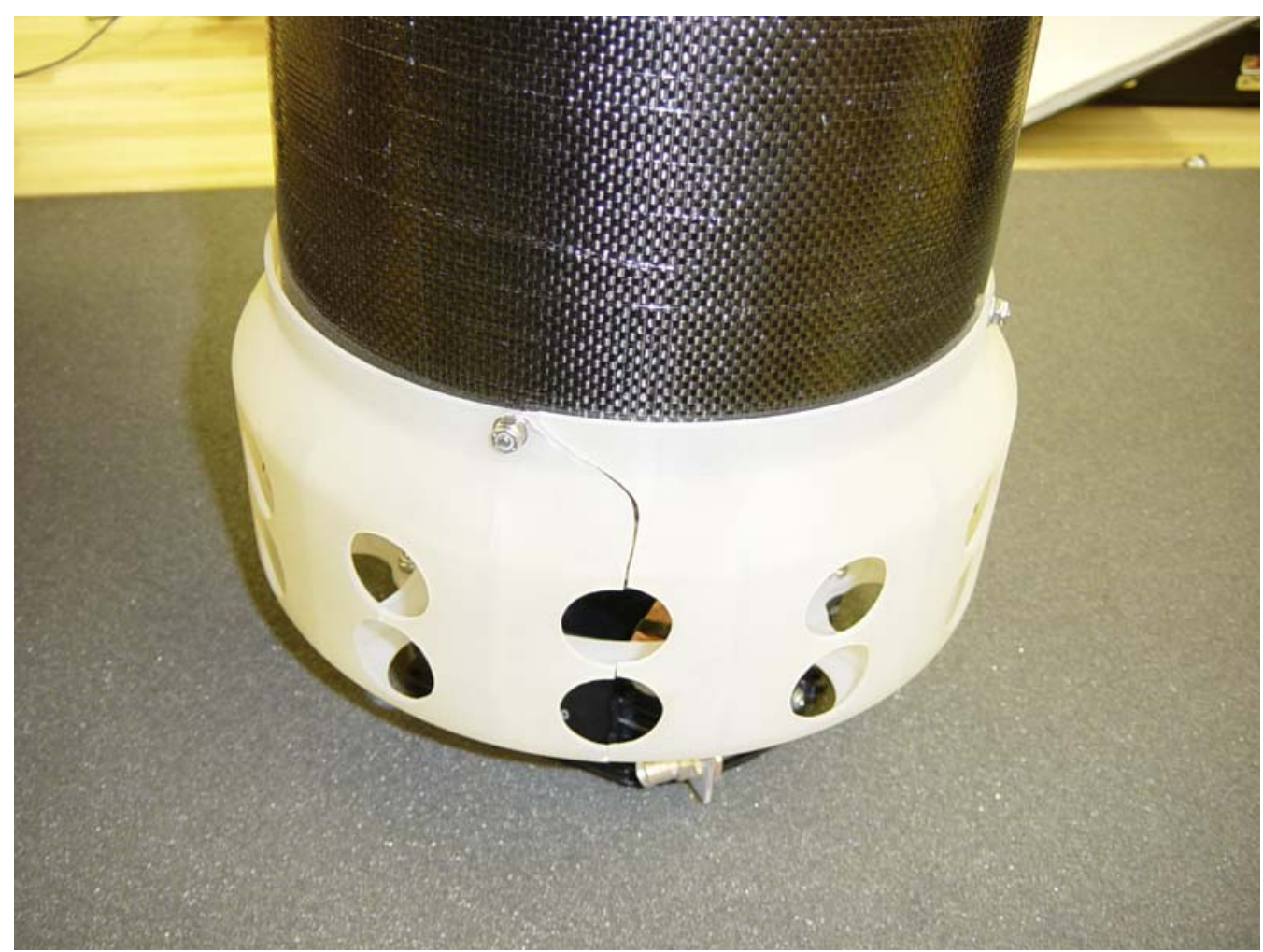

Figure 24 Cracks in Inlet Plenum Noted after Drop 8

\section{Summary of Heater Shock Levels}

Photographs of the test orientation and shock levels measured during the tests are provided in Appendix G. Peak shock levels from all the tests are summarized in Table 1. In Table.2, peak shock levels are compared to the maximum shock criteria. As described in Pass/Fail Criteria, a separate shock limit was specified for the longitudinal ( $<35$ g's) and transverse $(<90 \mathrm{~g}$ 's) directions based on the inherent fragility of the heater. Several shock levels exceeded the criteria. In Drop 1 (date 8/17/2005), the maximum longitudinal shock was instantaneously $53 \mathrm{~g}$ 's, which is higher that the criteria of $35 \mathrm{~g}$ 's. Note that this shock level was measured perpendicular to the direction of the drop, and so a high shock level in this direction was not expected. However, the shock level during Drop 1 (date 6/23/2005) was within the criteria, so the $53 \mathrm{~g}$ 's is probably atypical for this orientation. Maximum longitudinal shock levels were also exceeded for Drop 6 and 7 (60 and $82 \mathrm{~g}$ 's respectively). Finally, in Drop 8, the maximum longitudinal shock was 41 $\mathrm{g}$ 's, which is higher that the criteria of $35 \mathrm{~g}$ 's.

\section{Comparison with Developmental Testing Heater Shock Levels}

Prior to the deployment case Critical Design Review, a preliminary sequence of drop tests was completed using a prototype case. The relevant differences between preliminary testing and final testing were: 1) there was no accelerometer on the controller, 2) the fan and electronics box were not included, and 3) the corner drop onto the rain cap (Drop 7) was excluded due to high shock levels measured during Drop 6. The shock levels from these preliminary tests are provided in Table 3. The shock data 
from final testing (Table 2) and preliminary testing (Table 3 ) are fairly consistent in terms of peak shock levels and the axis that received the highest shock, but some differences are apparent due to the inherent variability of drop testing. In Drop 1 and Drop 8, the maximum longitudinal shock was 18.5 g's and 18.4 g's respectively, which are well below the criteria of $35 \mathrm{~g}$ 's. During final drop testing, these values exceeded the shock criteria. High longitudinal shock levels were measured for the drop onto the rain cap (> $200 \mathrm{~g}$ 's). Design changes were implemented in the final design to improve the shock protection afforded by the rain cap and were effective in reducing the shock level but not to the level of the criteria. The case damage noted in preliminary testing was very similar to the damage described above (frame deformation, plenum cracking, and case bottom cracking).

Table 1. Peak Shock Levels Measured during Shock Testing

\begin{tabular}{||l|l|l|l|l|l|l|l|l||}
\hline $\begin{array}{l}\text { DROP } \\
\text { ORIENT } \\
\text { \& DATE }\end{array}$ & $\begin{array}{l}\text { PEAK } \\
\text { G'S } 1 *\end{array}$ & $\begin{array}{l}\text { PEAK } \\
* \text { CH 2* } \\
\text { G'S }\end{array}$ & $\begin{array}{l}\text { PEAK } \\
* \text { CH 3* } \\
\text { G'S }\end{array}$ & $\begin{array}{l}\text { PEAK } \\
* \text { CH 4* } \\
\text { G'S }\end{array}$ & $\begin{array}{l}\text { PEAK } \\
* \text { CH 5* } \\
\text { G'S }\end{array}$ & $\begin{array}{l}\text { PEAK } \\
* \text { CH 6* } \\
\text { G'S }\end{array}$ & $\begin{array}{l}\text { PEAK } \\
* \text { CH 7* } \\
\text { G'S }\end{array}$ & $\begin{array}{l}\text { PEAK } \\
* \text { CH 8* } \\
\text { G'S }\end{array}$ \\
\hline $1(6 / 23)$ & 56.9 & 12.5 & 8.7 & 56.9 & 42.2 & 18.2 & 22.1 & 14.0 \\
\hline $1(8 / 17)$ & 37.3 & 9.4 & 11.3 & 58.1 & 54.6 & 22.1 & 53.0 & 5.0 \\
\hline $2(6 / 23)$ & 24.2 & 9.6 & 4.3 & 33.5 & 22.1 & 11.5 & 9.6 & 9.7 \\
\hline $2(8 / 17)$ & 25.7 & 10.0 & 5.3 & 33.5 & 22.1 & 5.4 & 9.2 & 6.6 \\
\hline $3(8 / 17)$ & 12.5 & 14.9 & 3.5 & 7.9 & 7.9 & 9.4 & 4.0 & 7.8 \\
\hline $4(8 / 17)$ & 12.8 & 11.1 & 12.7 & 33.0 & 28.3 & 25.2 & 12.2 & 23.6 \\
\hline $5(8 / 17)$ & 13.6 & 4.1 & 14.2 & 6.7 & 10.4 & 5.9 & 16.8 & 3.9 \\
\hline $6(8 / 17)$ & 19.0 & 15.9 & 60.1 & 2.9 & 12.1 & 19.0 & 49.9 & 4.4 \\
\hline $7(8 / 17)$ & 47.0 & 29.4 & 81.9 & 20.4 & 9.9 & 8.4 & 36.5 & 4.5 \\
\hline $8(8 / 17)$ & 17.9 & 14.5 & 9.1 & 16.0 & 8.9 & 9.9 & 41.9 & 32.1 \\
\hline
\end{tabular}

Table 2. Shock Levels during Shock Testing

\begin{tabular}{||l|l|l|l|l|l||}
\hline \multirow{2}{*}{$\begin{array}{l}\text { DROP } \\
\text { ORIENTATION } \\
\text { AND } \\
\text { DATE }\end{array}$} & \begin{tabular}{l} 
HEATER TOP \\
\cline { 2 - 6 } \\
Traximum \\
Shock, g's
\end{tabular} & $\begin{array}{l}\text { Maximum } \\
\text { Longitudinal } \\
\text { Shock, g's }\end{array}$ & $\begin{array}{l}\text { Maximum } \\
\text { Transverse } \\
\text { Shock, g's }\end{array}$ & $\begin{array}{l}\text { Maximum } \\
\text { Longitudinal } \\
\text { Shock, g's }\end{array}$ & $\begin{array}{l}\text { Maximum } \\
\text { Transverse } \\
\text { Shock, g's }\end{array}$ \\
\hline $1(6 / 23)$ & $<90$ g's & $<35$ g's & $<90$ g's & $<35$ g's & $<90$ g's \\
\hline $1(8 / 17)$ & 58.3 & 8.7 & 46.0 & 22.1 & 58.6 \\
\hline $2(6 / 23)$ & 38.5 & 11.3 & 58.9 & 53.0 & 58.3 \\
\hline $2(8 / 17)$ & 26.0 & 4.3 & 24.9 & 9.6 & 34.9 \\
\hline $3(8 / 17)$ & 27.6 & 5.3 & 22.8 & 9.2 & 34.1 \\
\hline $4(8 / 17)$ & 19.4 & 3.5 & 12.3 & 4.0 & 11.1 \\
\hline $5(8 / 17)$ & 16.9 & 12.7 & 37.9 & 12.2 & 40.6 \\
\hline $6(8 / 17)$ & 14.2 & 14.2 & 12.0 & 16.8 & 7.8 \\
\hline $7(8 / 17)$ & 24.8 & 60.1 & 22.5 & 49.9 & 5.3 \\
\hline $8(8 / 17)$ & 55.4 & 81.9 & 13.0 & 36.5 & 20.9 \\
\hline
\end{tabular}


Table 3. Shock Levels during Preliminary Shock Testing

\begin{tabular}{||l|l|l|l|l||}
\hline \multirow{3}{*}{$\begin{array}{l}\text { DROP } \\
\text { ORIENTATION } \\
\begin{array}{l}\text { AND } \\
\text { DATE }\end{array}\end{array}$} & $\begin{array}{l}\text { HEATER TOP } \\
\text { Maximum } \\
\text { Transverse }\end{array}$ & $\begin{array}{l}\text { Maximum } \\
\text { Longitudinal } \\
\text { Shock, g's }\end{array}$ & $\begin{array}{l}\text { Maximum } \\
\text { Transverse } \\
\text { Shock, g's }\end{array}$ & $\begin{array}{l}\text { Maximum } \\
\text { Longitudinal } \\
\text { Shock, g's }\end{array}$ \\
\hline criteria1 & $<90$ g's & $<35$ g's & $<90$ g's & $<35$ g's \\
\hline 1 & 61.2 & 7.6 & 60.6 & 18.5 \\
\hline 2 & 26.1 & 5.9 & 16.4 & 4.8 \\
\hline 3 & 25.0 & 4.7 & 22.0 & 6.8 \\
\hline 4 & 56.4 & 14.2 & 60.6 & 16.8 \\
\hline 5 & 48.3 & 22.5 & 47.7 & 24.5 \\
\hline 6 & 89.2 & 238.2 & 79.9 & 208.8 \\
\hline 7 & na & na & na & na \\
\hline 8 & 48.5 & 8.4 & 21.6 & 18.4 \\
\hline \hline
\end{tabular}

\section{Summary}

Shock testing of the deployment case was accomplished per MIL-STD-810F, Method 516.5 , Procedure IV. The purpose of shock testing was to provide a degree of confidence that the material used to construct the case and cooling system can physically and functionally withstand the relatively infrequent, non-repetitive shocks encountered in handling, service, and transportation environments. The procedure was tailored from MIL-STD-810F Method 516.5 Procedure IV-Transit drop by incorporating client consultation and the results of developmental testing. The test case was dropped from a height of 18 inches onto compacted soil. The test case was dropped from eight orientations derived from a structural review of potential case vulnerabilities. These eight drops were divided among two test items, based on a ratio of the number of cases permitted by MIL-STD-810F Method 516.5 Procedure IV (up to five test items for a total of 26 drops).

Final shock testing was initiated on June 23, 2005. After the first drop (orientation 1) it was found that the control system did not function. The controller was replaced by a spare, and testing was resumed. After the second drop (orientation 2) it was found that the control system was again nonfunctional. Testing was suspended and the control system components were redesigned. It should be noted that the same case and frame used for this first phase were reused for the subsequent resumption of testing.

Final shock testing was restarted and successfully completed on August 17, 2005. All 8 drops were completed in the desired sequence without any cooling system control system failures. Damage was noted in the frame, case, and plenums but was not deemed sufficient to jeopardize a mission since the damage did not affect functionality of the case, did not cause collapse or fracture of cooling air passages or loss of cooling efficiency, and did not result in noisy disassembly.

Peak shock levels were compared to the maximum shock criteria for longitudinal $(<35$ g's) and transverse $(<90 \mathrm{~g}$ 's) directions. Several longitudinal shock levels exceeded the 
criteria of 35 g's. In Drop 1 (8/17/2005), the maximum longitudinal shock was instantaneously $53 \mathrm{~g}$ 's and in Drop 8 the maximum longitudinal shock was $41 \mathrm{~g}$ 's. However, the shock levels measured in the longitudinal direction during preliminary testing were well below the criteria. These differences are apparently due to the inherent variability of drop testing.

Maximum longitudinal shock levels were also exceeded for Drop 6 and 7 (60 and 82 g's respectively). Design changes were implemented in the final design to improve the shock protection afforded by the rain cap and were effective in reducing the shock level but not to the level of the criteria. However, dropping on the rain cap is a fairly unlikely event. Internal shock levels were lowest for drops onto the backpack, which is perhaps the most probable drop scenario. 


\section{Acoustic}

Shall not exceed the 30 meter acoustic non-detectable limit as defined in Table 2-II Quietest Area Ambient Noise Level in Table 2-III of MIL-Stand-1474D when measured at a distance of 2 meter.

\section{Characterization Summary}

The 55 W RSG Deployment Case prototype was characterized for its acoustic profile at the Pacific Northwest National Laboratory (PNNL) Test Facility in Richland, WA from September 13-15, 2004. The case was configured in its most realistic mode. The purpose of this acoustic characterization was to accurately capture acoustic emanations at ground level from an individual carrying the RSG in a backpack. This characterization supplemented the acoustic testing already performed in the PNNL Test Facility and reported in the RSG Case Design Review.

Testing in realistic conditions outdoors showed that the acoustic emissions levels extrapolated to a distance of 30 meters in all test cases met the Table 2-II Quietest Area Ambient Noise Level requirement from MIL-STD-1474D.

Test Participants included:

Woodrow Hawthorne TASC

Bill Jeffries TASC

Mike Evers TASC

Robert Francini, PNNL

References

RSG Acoustic Test Plan, 3 September 2004

RSG Case Design Review, 26 August 2004

MIL-STD-1474D, Table 2-II, Quietest Area Ambient Noise Level

Acoustic Test Data Sheets, RSG test, 20 September 2004

Characterization Test Configuration

\section{Characterization Description}

Characterization configurations were selected based on those configurations most likely to be encountered in the field. Measurement equipment Included:

- Bruel and Kjaer model 2144 Dual Channel Real Time Frequency Analyzer

- Half inch microphone (model 4231)

- Acoustical calibrator for model 4231 microphone

- Sony DAT recorder

- Microphone stand

- Boom extension

Measurements were taken at a distance of $0.5 \mathrm{~m}$ so the low level emanations could be recorded over the ambient. Microphones were set at a height of $1.2 \mathrm{~m}$ above the ground during outdoor measurements. After an ambient was taken, the RSG was characterized in the following outdoor configurations included: 
- Packaged $55 \mathrm{~W}$ RSG placed in a prone position on sawhorses

- Packaged RSG worn as backpack on individual, unit closest to microphone

- Packaged RSG worn as backpack, individual between microphone and RSG

In addition, measurements were taken inside the PNNL whisper chamber with the analyzer in both an A-weighted and linear setting. The configuration mimicked the test configuration PNNL used when characterizing the 55 watt RSG Deployment Case (see acoustics section in RSG Case Design Review). Microphones were placed 2 feet ( 0.645 $\mathrm{m})$ away from the test unit in the whisper chamber. In all test cases the ambient was found to be $10 \mathrm{~dB}$ or more less than the measured signal.

Acoustic analyzer run numbers correspond to data captured by the analyzer and displayed in the accompanying reduced data sheets. In addition, test sounds were captured by a DAT recorder and can be used along with the Acoustic Database to simulate how detectable the RSG fan sounds are in realistic conditions.

Listed below for each test case are pictures of that test case, a list of test cases by corresponding fan power and a graph of the case that was determined to emit the highest emanations of the group. The fan nominally operates at 11VDC.

\subsubsection{Test Unit in prone position}

Place: Test area, PNNL field location

Date: 13 September 2004

Description: 13 Sep- RSG in backpack in prone position on sawhorses, mic $0.5 \mathrm{~m}$ away from fan end. For completeness, measurements with fan voltage set at 13 and $24 \mathrm{~V}$ were taken although these configurations are not expected to be used in the field.

As can be seen from the graph below, the emissions fail to meet the specification at 200 $\mathrm{Hz}$ by $0.8 \mathrm{~dB}$. The emanations of the unit with fan voltage less than $13 \mathrm{~V}$ met the requirement everywhere.

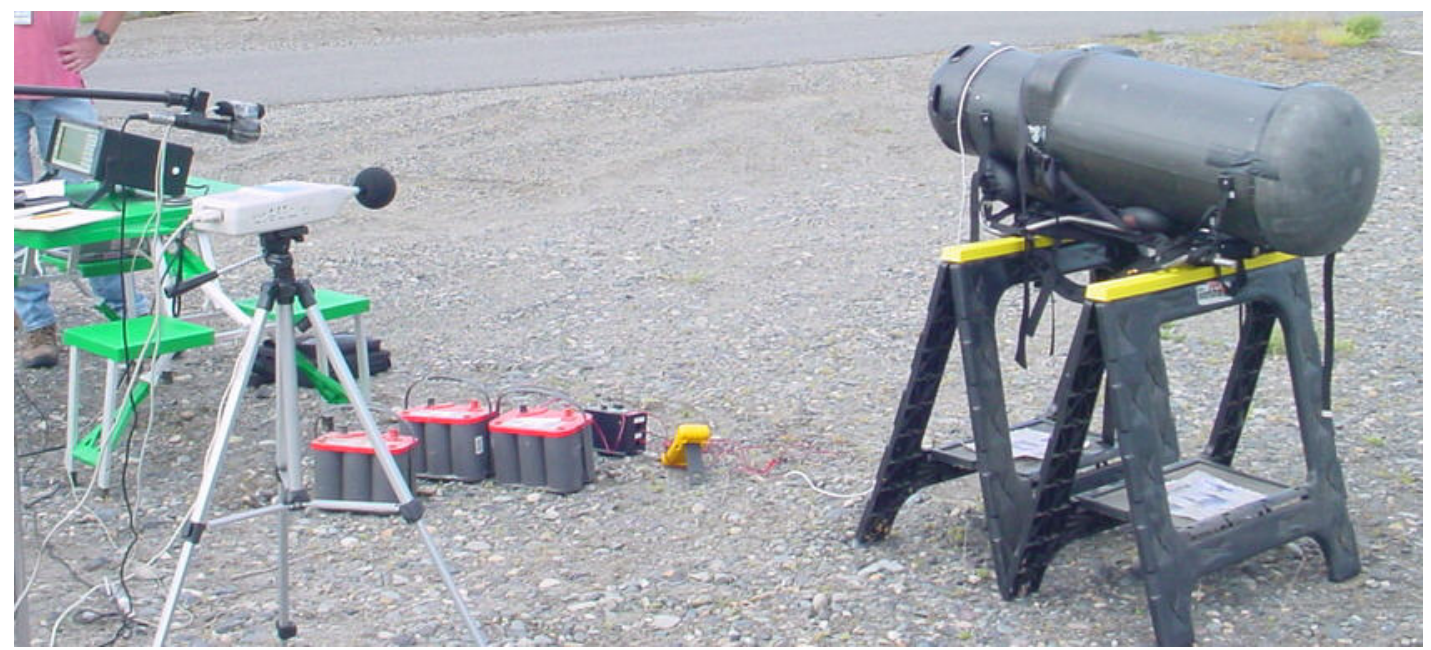

Figure 25 Unit in the Prone Position 


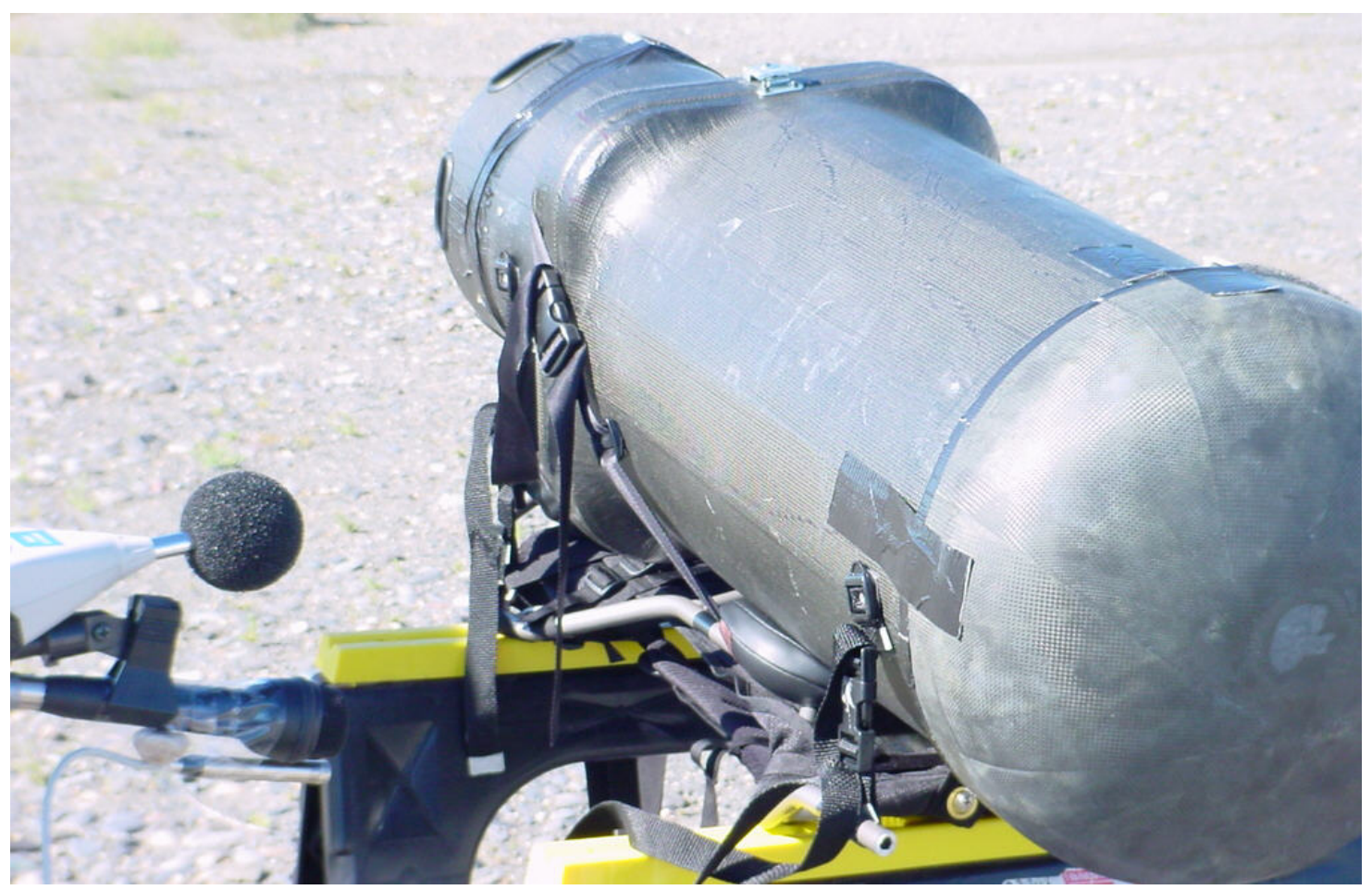

Figure 26 Microphone Position 0.5 m from RSG in the Prone Position

Table 4 RSG Test Cases- Prone Position

\begin{tabular}{|l|l|}
\hline Run \# & Description \\
\hline $5-6$ & A weighted ambient (no wind) \\
\hline 12,13 & $9 \mathrm{~V}$ inlet power to fan \\
\hline 14,15 & $10 \mathrm{~V}$ inlet power to fan \\
\hline 16,17 & $11 \mathrm{~V}$ inlet power to fan \\
\hline 18,19 & $12 \mathrm{~V}$ inlet power to fan \\
\hline 20,21 & $13 \mathrm{~V}$ inlet power to fan \\
\hline 22 & $24 \mathrm{~V}$ inlet power to fan \\
\hline
\end{tabular}




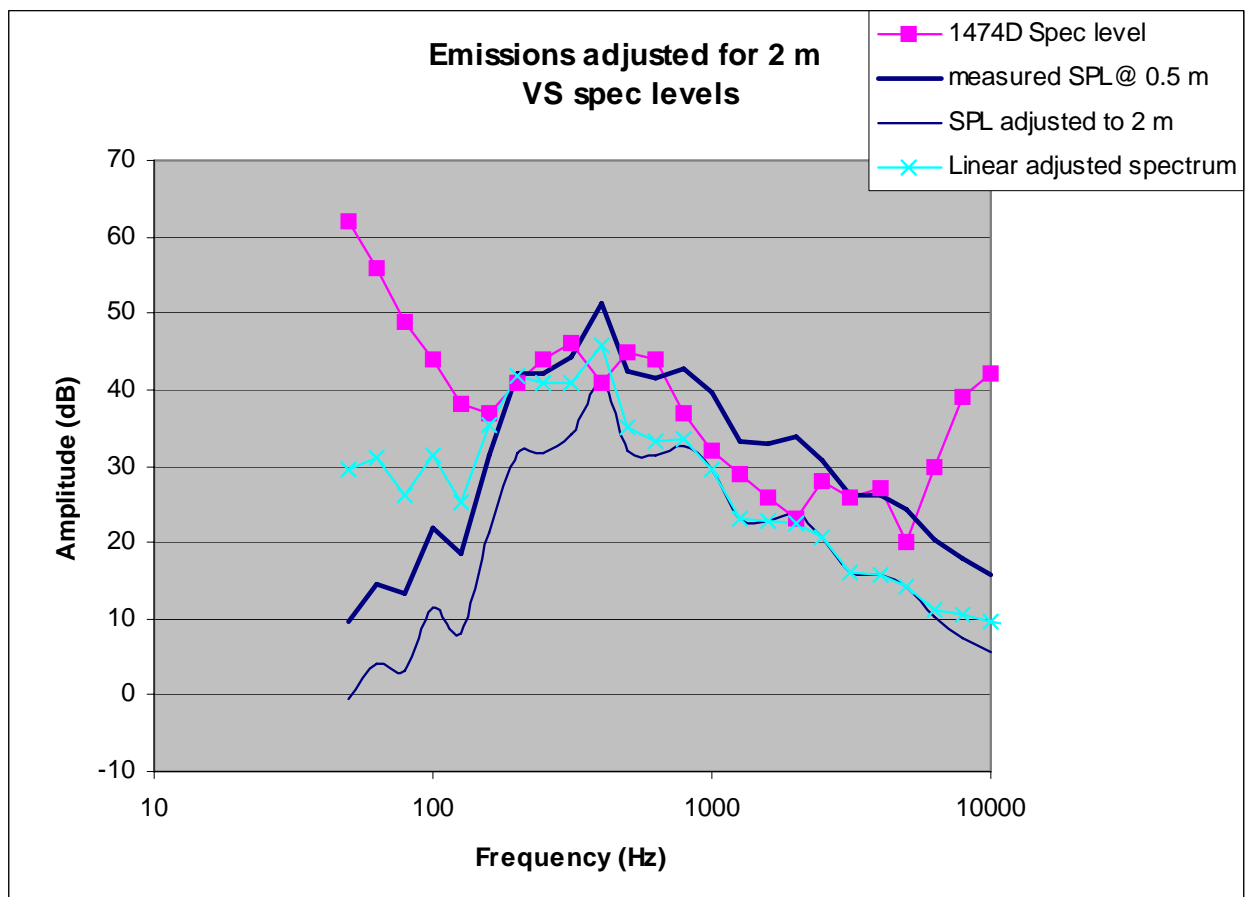

Figure 27 Worst Case Acoustic Emissions VS Specification (Fan powered by 13 VDC)

\section{Test Unit in backpack on Individual}

Description: 13 Sep- RSG in backpack on man's back, fan facing down, RSG facing mic, mic $0.5 \mathrm{~m}$ away from fan end

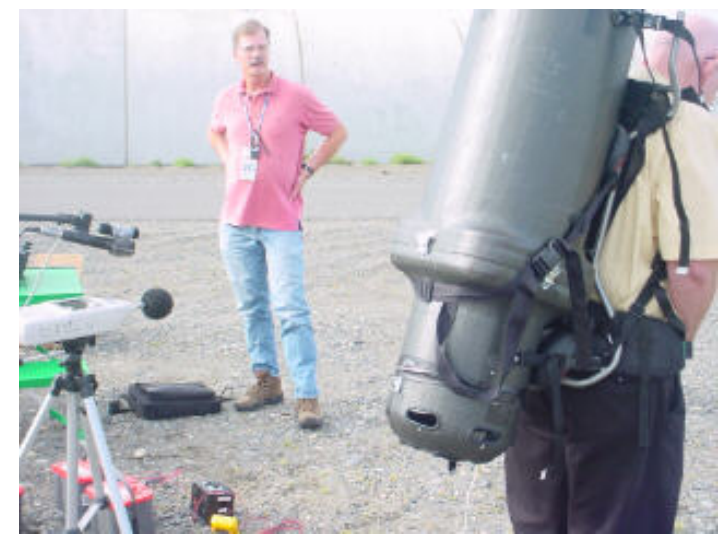

Figure 28 Unit in Backpack on Individual $0.5 \mathrm{~m}$ from Microphone

Table 5 RSG Test Cases- In Backpack Near Microphone

\begin{tabular}{|l|l|}
\hline Run \# & Description \\
\hline 24 & $8 \mathrm{~V}$ inlet power to fan \\
\hline 25,26 & $10 \mathrm{~V}$ inlet power to fan \\
\hline 27,28 & $11 \mathrm{~V}$ inlet power to fan \\
\hline $29-31$ & $12 \mathrm{~V}$ inlet power to fan \\
\hline $32-33$ & $13 \mathrm{~V}$ inlet power to fan \\
\hline
\end{tabular}




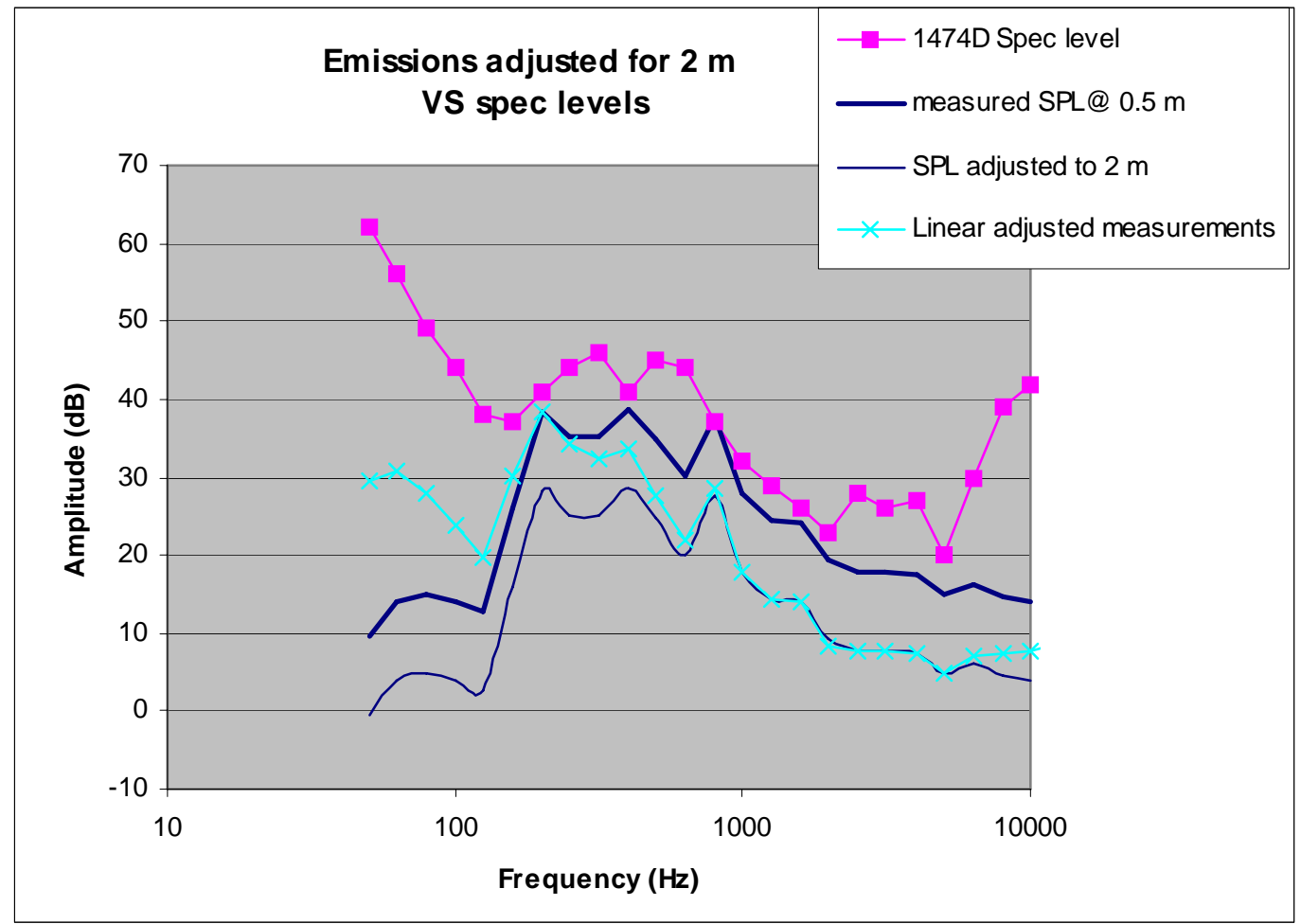

Figure 29 Worst Case Acoustic Emissions VS Specification (Fan powered by 13 VDC) 
Test Unit in backpack on Individual, Individual between microphone and unit

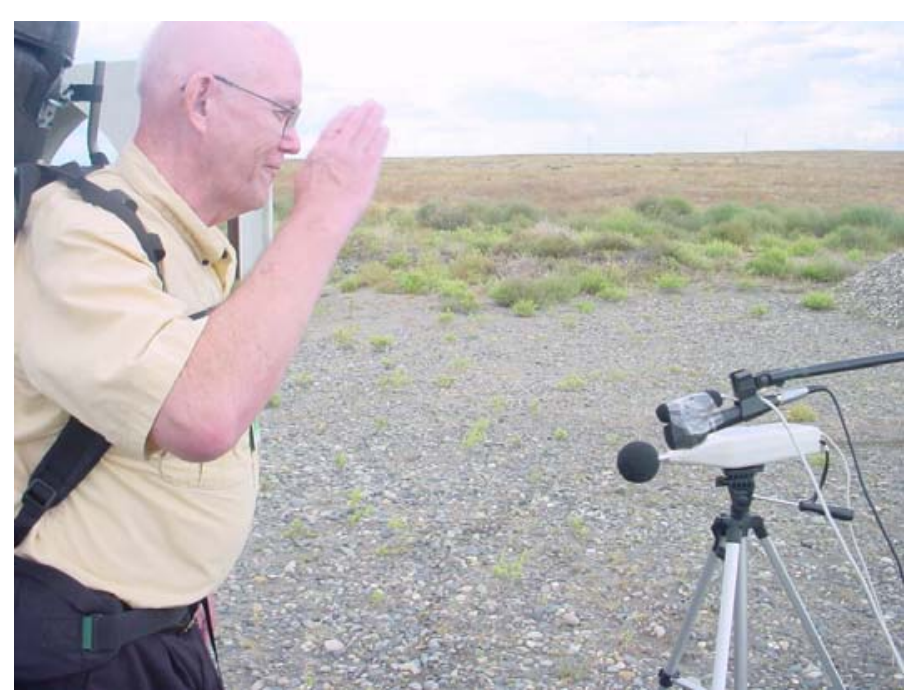

Figure 30 Unit on Back of Individual facing away from Microphone

Description: 13 Sep- RSG in backpack on man's back, fan facing down, man between mic and RSG, mic $0.5 \mathrm{~m}$ away from fan end

Table 6 RSG Test Cases- Unit on Back of Individual facing away from Microphone

\begin{tabular}{|l|l|}
\hline Run \# & Description \\
\hline $34-35$ & $13 \mathrm{~V}$ inlet power to fan \\
\hline $36-37$ & $12 \mathrm{~V}$ inlet power to fan \\
\hline $38-39$ & $11 \mathrm{~V}$ inlet power to fan \\
\hline
\end{tabular}




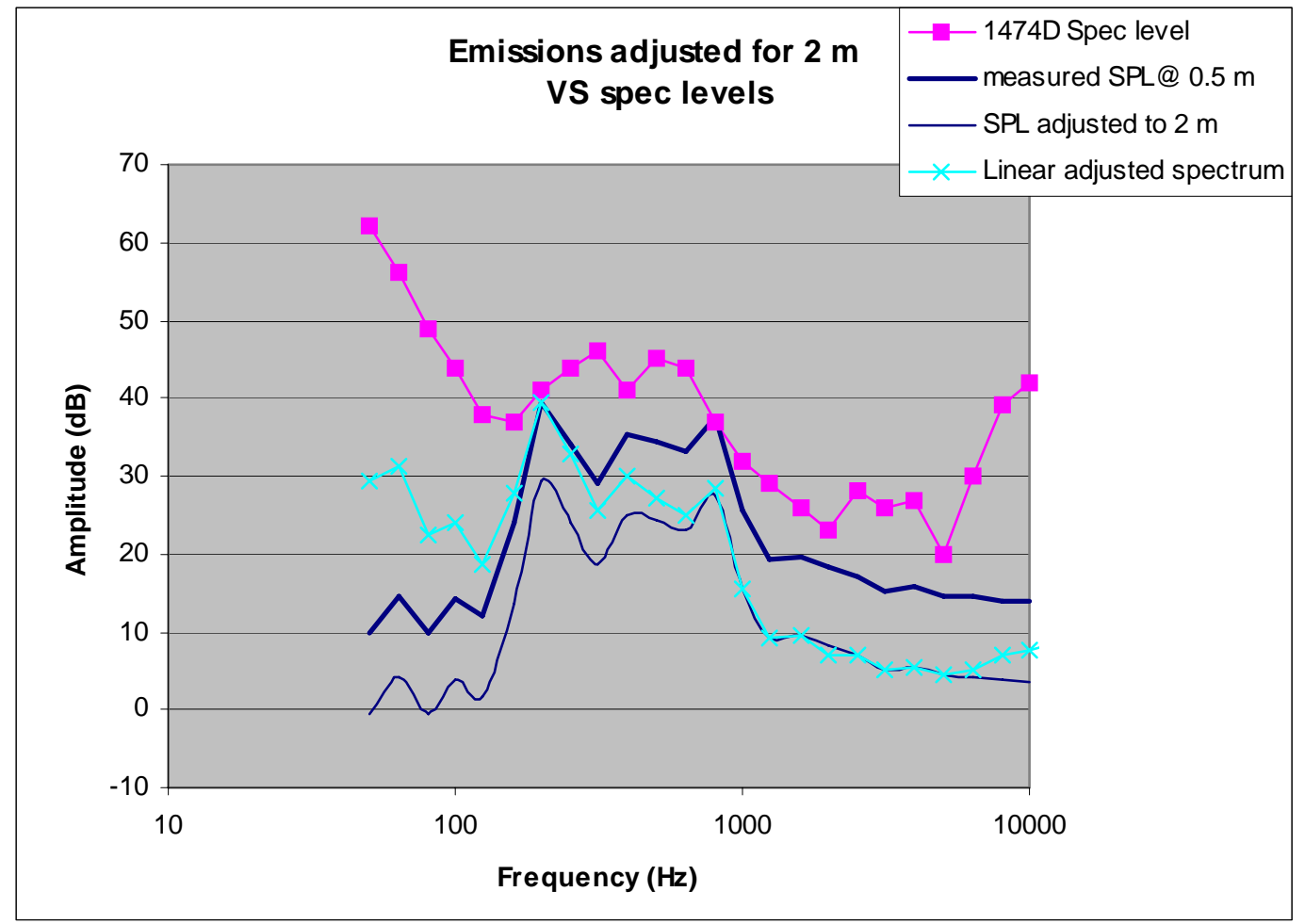

Figure 31 Worst Case Acoustic Emissions VS Specification (Fan powered by 11 VDC)

\section{Test Unit in whisper chamber}

Measurements at each individual fan voltage test case were made unweighted (i.e. there was no linear adjustment necessary).

RSG fan at bottom of chamber

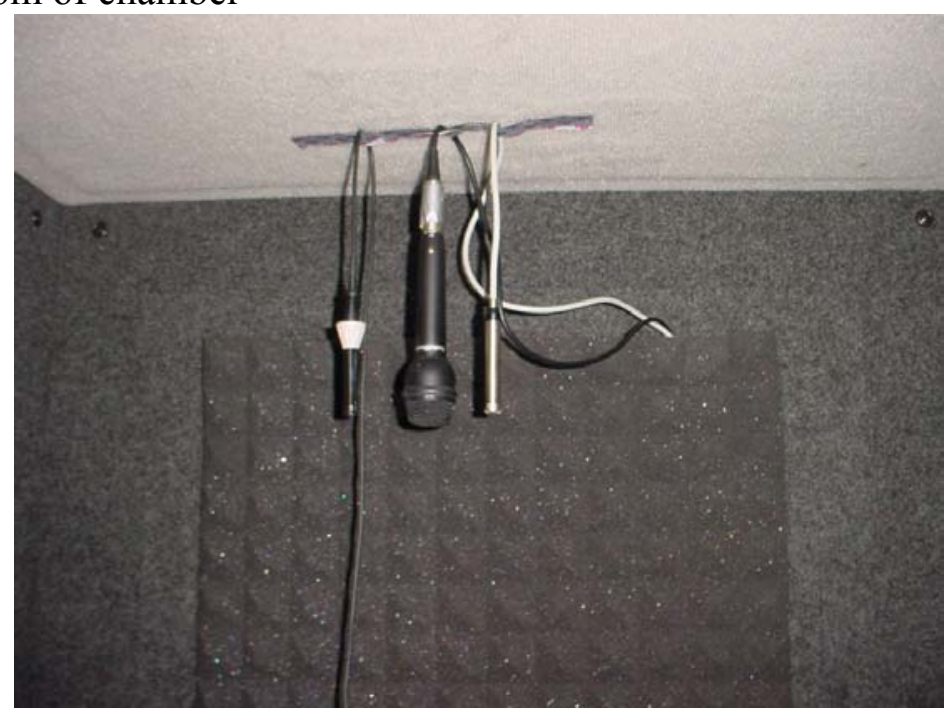

Figure 32 Microphone Position in Whisper Chamber 


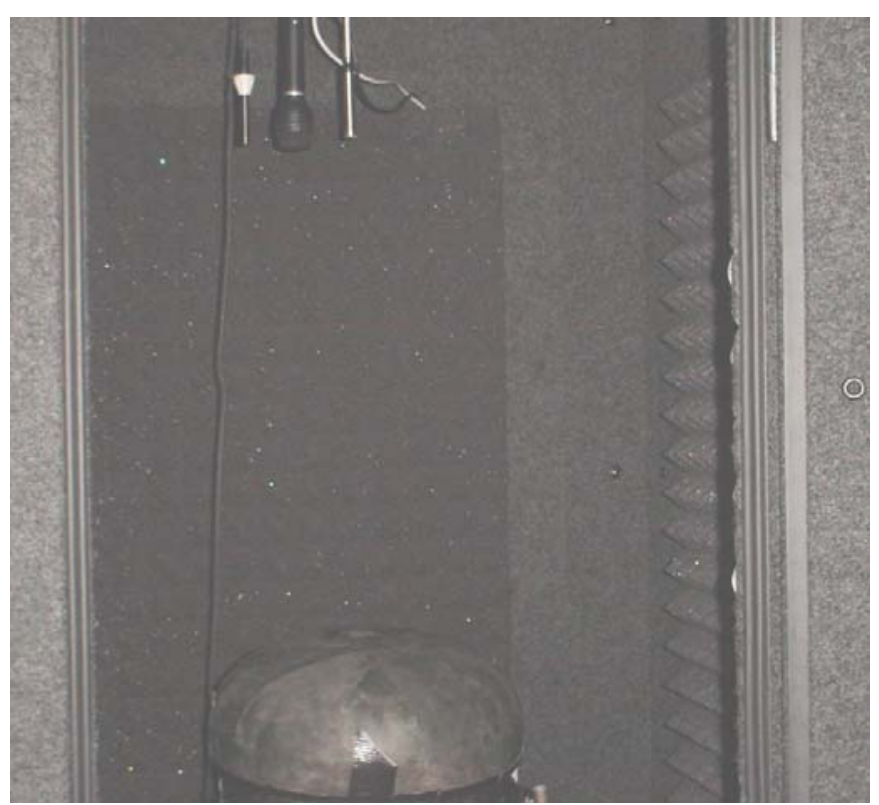

Figure 33 Unit in Whisper Chamber- Heavy End Up

Description: 14 Sep- RSG in whisper chamber, RSG facing down, mic $0.645 \mathrm{~m}$ away from heavy end

Table 7 RSG Test Cases- Unit Fan at Bottom of Chamber

\begin{tabular}{|l|l|}
\hline Run \# & Description \\
\hline $41-43$ & A weighted ambient \\
\hline 44 & Linear ambient \\
\hline $46-47$ & $8 \mathrm{~V}$ inlet power to fan, linear measurement \\
\hline $48-49$ & $9 \mathrm{~V}$ inlet power to fan, linear measurement \\
\hline $50-51$ & $10 \mathrm{~V}$ inlet power to fan, linear measurement \\
\hline $52-53$ & $11 \mathrm{~V}$ inlet power to fan, linear measurement \\
\hline $54-55$ & $12 \mathrm{~V}$ inlet power to fan, linear measurement \\
\hline $56-57$ & $13 \mathrm{~V}$ inlet power to fan, linear measurement \\
\hline $58-59$ & $13 \mathrm{~V}$ inlet power to fan, A weighted measurement \\
\hline $60-61$ & $11 \mathrm{~V}$ inlet power to fan, A weighted measurement \\
\hline
\end{tabular}




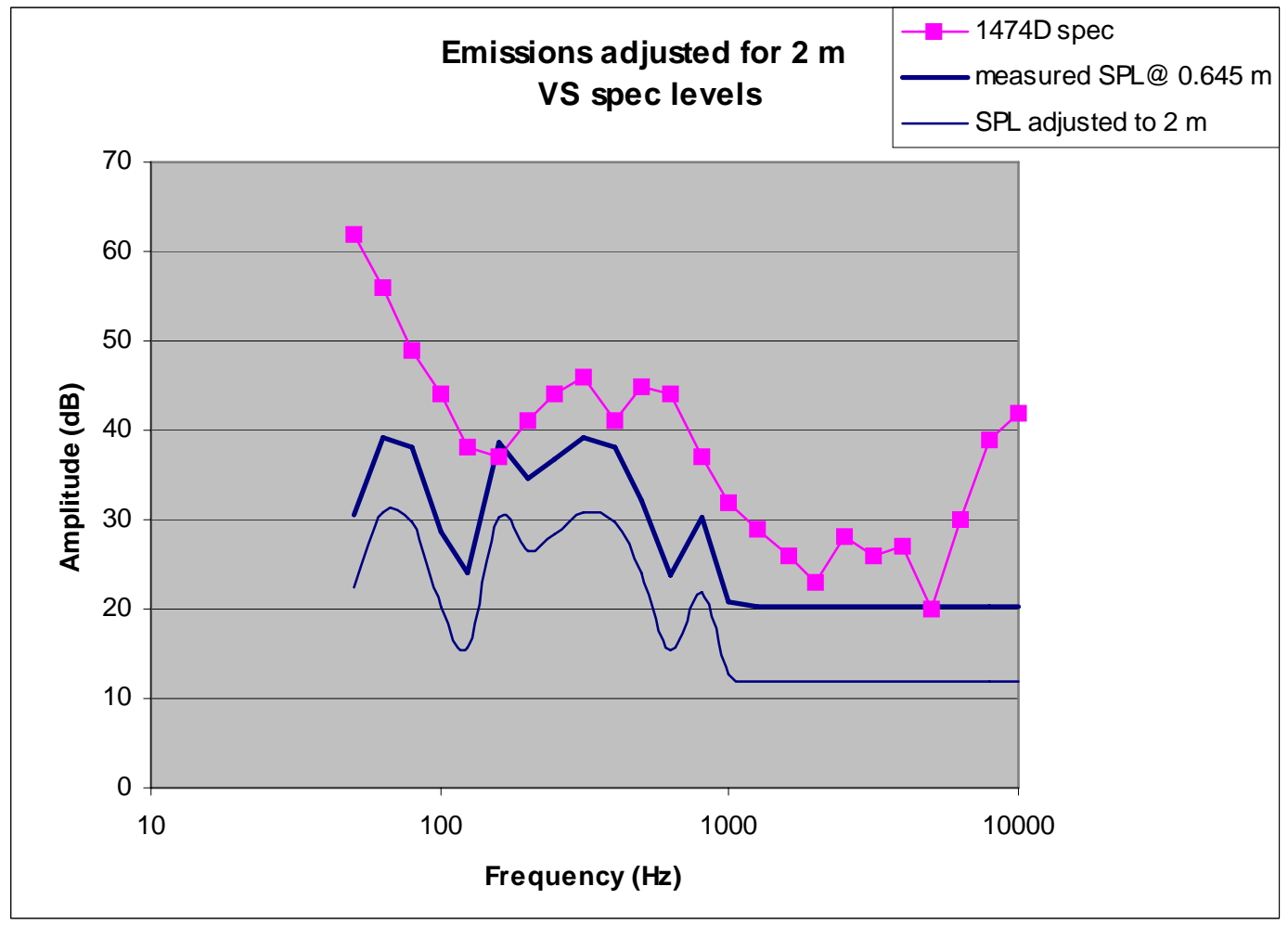

Figure 34 Worst Case Acoustic Emissions VS Specification (Fan powered by 13 VDC)

RSG fan at top of chamber (Light end up)

Description: 14 Sep- RSG in whisper chamber, RSG facing up, mic $0.645 \mathrm{~m}$ away from fan end (heavy end at bottom of chamber). Fan voltage for this case was limited to $11 \mathrm{~V}$.

Table 8 RSG Test Cases- Unit in Chamber- Light end up

\begin{tabular}{|l|l|}
\hline Run \# & Description \\
\hline $62-63$ & $11 \mathrm{~V}$ inlet power to fan, linear measurement \\
\hline $64-65$ & $10 \mathrm{~V}$ inlet power to fan, linear measurement \\
\hline $66-67$ & $9 \mathrm{~V}$ inlet power to fan, linear measurement \\
\hline $68-69$ & $8 \mathrm{~V}$ inlet power to fan, linear measurement \\
\hline $70-71$ & $8 \mathrm{~V}$ inlet power to fan, A-weighted measurement \\
\hline
\end{tabular}




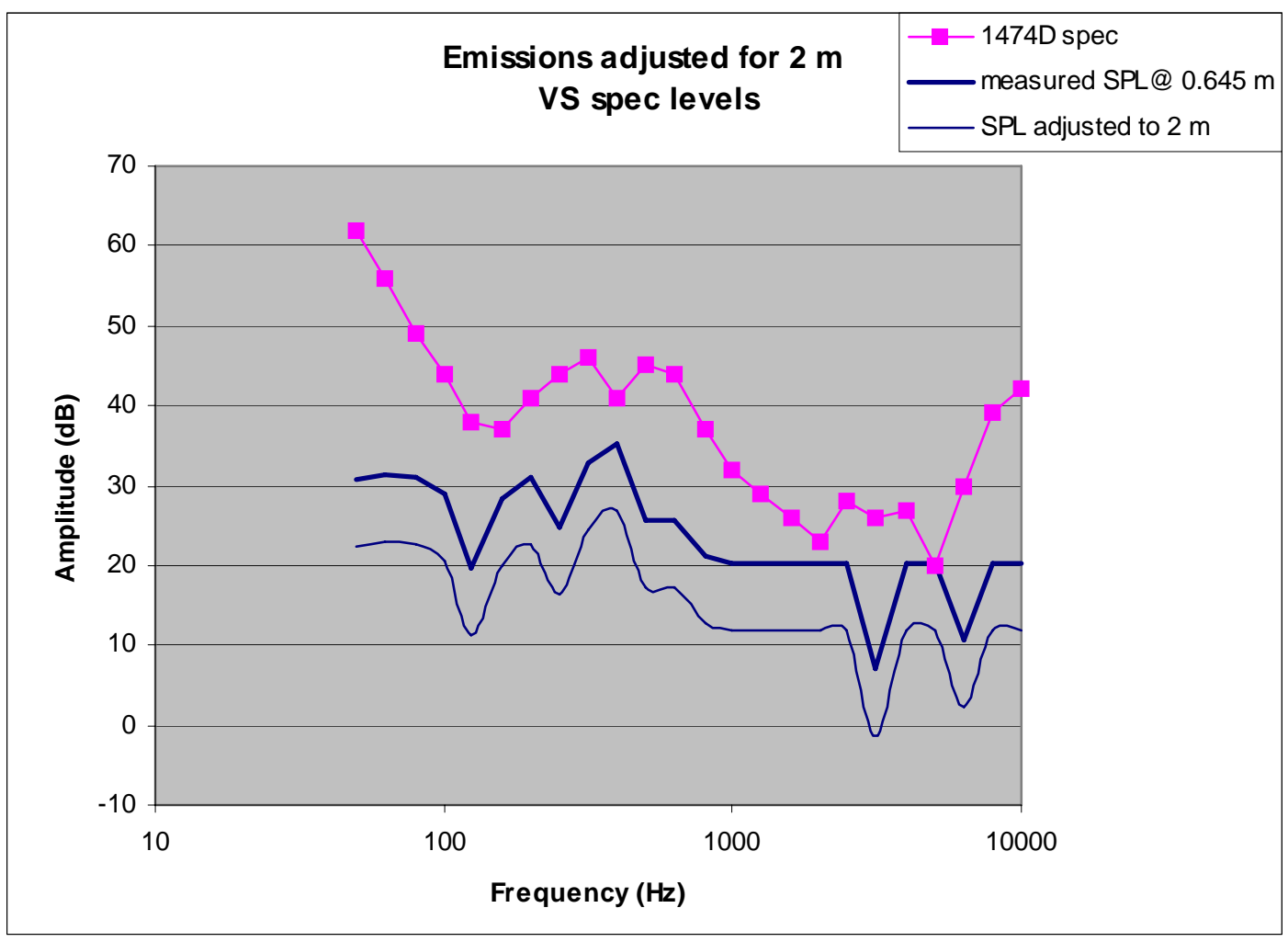

Figure 35 Worst Case Acoustic Emissions VS Specification (Fan powered by 13 VDC)

\section{Characterization Results}

A-weighted test measurements were taken on 13 September 2004 outdoors at PNNL. The fan noise on the deployment case was so low that the acoustic analyzer and DAT microphone had to be moved within 0.5 meter of the fan to be able to make measurements that were at least $6 \mathrm{~dB}$ above the equipment noise floor. Measurements were taken while the wind had died down. Ambient readings showed the A- weighted "quiet" noise level (no wind) to be under $20 \mathrm{dBA}$ everywhere across the $20-20,000 \mathrm{~Hz}$ band. Measurements were taken with the RSG packed within its backpack and (1) set in a prone position on 2 sawhorses (2) placed on a man's back with the fan facing down with the fan $0.5 \mathrm{~m}$ from the microphones and (3) placed on a man's back with the man between the RSG fan and the microphone. Measurements taken at 0.5 meters were extrapolated to a distance of 2 meters and compared with the $30 \mathrm{~m}$ acoustic nondetectable limit as measured from 2 meters. An extrapolation curve of $17 \mathrm{~dB} /$ decade was used to account for worst case additive ground bounce (vs $20 \mathrm{~dB} /$ decade in free space).

Nowhere did the A weighted acoustic noise measured exceed the MIL-STD-1474 specification when extrapolated to a distance of 30 meters when inlet voltage to the fan was set at $12 \mathrm{~V}$ or less. Two test case configurations (in prone position) that had 13 and 24 VDC inlet power to the fan showed that the emanations did not meet specifications a fraction of a $\mathrm{dB}$, but cognizant engineers noted the unit is not planned to be powered at these voltages. 
On September 14 the team decided to repeat measurements in the whisper sound chamber. Both A-weighted and linear measurements were taken. Since the specification did not explicitly state what type of measurements (Linear or A- weighted) were to be compared with the Table 2-II MIL-STD-1474D limit, linear measurements were used. Where only A-weighted measurements were taken in the field, a correction factor was added to the measurement to make it equivalent with a linear measurement. Linear measurements were in line with previous measurements PNNL recorded (and documented in RSG Case Design Review), although the NGIT-TASC equipment used for this test had a lower noise floor (more sensitive) and overall full band noise measurements were lower (although individual narrow band noise measurements at RSG noise peaks were comparable). Using linear measurements at a distance of 0.645 meters, RSG fan noise exceeded the MIL-STD-1474D limit in several places as was shown in the PNNL measurements, although when the space loss adjustment (from $0.645 \mathrm{~m}$ to $2 \mathrm{~m}$ ) was applied the noise met the requirement everywhere.

Audio recordings of each test case were taken along with emanation readings from the acoustic analyzer. Using parsed components of these digital recordings and the NGITTASC Acoustic Database Simulation tool, one may accurately simulate what these recorded emanations would sound like at various distances away from unit under test for each test case. In this way, an individual evaluator may determine at what distance the RSG actually becomes inaudible while comparing this level to the imposed specification. This tool is available for demonstrations immediately.

In conclusion, the $55 \mathrm{~W}$ RSG Deployment Case in its present configuration has been shown to meet its MIL-STD-1474D requirement in all realistic deployment configurations at a distance of 30 meters. 


\section{Magnetic Field Radiated Emissions}

MIL-STD-461E RE101, Radiated Emissions, $10 \mathrm{KHz}$ to $18 \mathrm{GHz}$

The RSG electronics control package was tested by CKG Laboratory to the MIL-STD461E RE101, magnetic field radiated emissions specification limit per figure RE101-2 for Navy applications. This test regimen is for radiated emissions from $10 \mathrm{kHz}$ to $18 \mathrm{GHz}$ using the $7 \mathrm{~cm}$ and $50 \mathrm{~cm}$ limits on all six faces of the electronics control package. The final outcome of the test program was that the system passed the test. The results can be found in Appendix F.

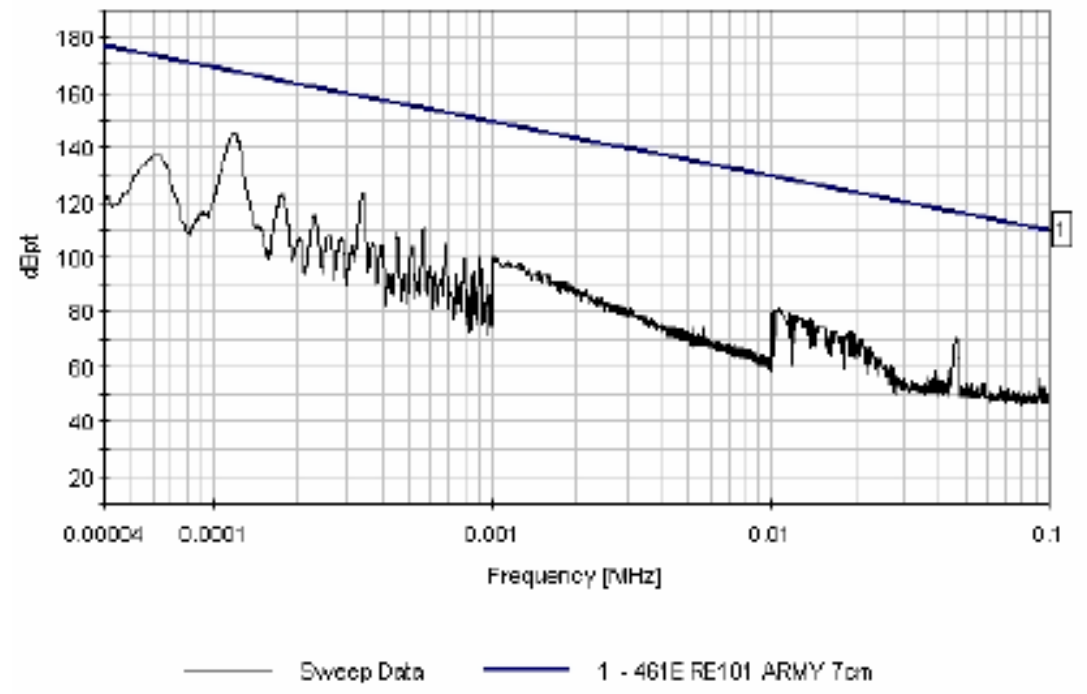




\section{Electric Field Radiated Emissions}

MIL-STD-461E RE102, Radiated Emissions, $10 \mathrm{KHz}$ to $18 \mathrm{GHz}$

The RSG electronics control package was tested by CKG Laboratory to the MIL-STD461E RE102, radiated emissions specification limit per figure RE102-3 for helicopter applications. This test regimen is for radiated emissions from $10 \mathrm{kHz}$ to $18 \mathrm{GHz}$. The final outcome of the test program was that the system failed the test. The UUT exhibited out of specification conditions for $30 \mathrm{MHz}$ to $200 \mathrm{MHz}$ in the Vertical and Horizontal antenna polarizations and from $200 \mathrm{MHz}$ to $1000 \mathrm{MHz}$ in Horizontal polarization. The results can be found in Appendix F. 


\section{Electric Field Radiated Susceptibility}

MIL-STD-461E RE103, Radiated Susceptibility, Electric Field, 10KHz to $18 \mathrm{GHz}$

\section{Electric Field Radiated Susceptibility}

The RSG electronics control package was tested by CKG Laboratory to the MIL-STD461E RE103, radiated susceptibility specification. This test regimen is for radiated susceptibility from $10 \mathrm{kHz}$ to $18 \mathrm{GHz}$. The final outcome of the test program was that the system failed the test. The UUT exhibited out of specification conditions for 675$690 \mathrm{MHz}$ in the Horizontal antenna polarization a slight reduction in fan rotation speed was detected. This was the only area where the system was found to be out of specification. The results can be found in Appendix F.

\section{System Reliability}

MIL-HDBK-217F, 0.999 per year

The reliability analysis procedure complies with the methodology detailed in Military Handbook 217 Revision F (MIL-HDBK-217F-2) dated 2-December-1991. This method calculates the system reliability by combining the reliability data for each component. A software program, RelCalc for Windows Version 5.0-217F2, was used to make all computations of the RSG Fan Controller reliability.

Central to this methodology is the temperature which the components will be exposed, or stressed. Failure rates are presumed to follow an Arrhenious relationship, which states that the failure rate is a function of operating temperature. Consequently, the operating temperature must be specified in order to determine the component failure rate. Because failure rates are the number of failures per unit time, such as per million hours, a time period must be specified to calculate the expected number of failures.

The part total failure rate is calculated from the basic part failure rate plus several stress modifiers, which include effects of temperature, environmental and electrical stresses. The failure rates of the components in an assembly are added to determine the assembly's failure rate in failures per million hours operation (fpmh). The Mean Time Between Failures (MTBF) is one million hours divided by the failure rate in fpmh:

$$
\text { Assembly MTBF }=1,000,000 \text { / [Assembly Failure Rate (fpmh)] }
$$

The assembly reliability is:

$$
\text { Assembly Reliability }=1-[\text { Mission Time (hr)] / [Assembly MTBF] }
$$

Perfect reliability is one, and a reliability of 0.99 has a $1 \%$ probability of failure.

A similar process is used to calculate the failure rate of a system comprising several assemblies. The failure probability is the failure rate times the period of time in service. The reliability of the system is inversely proportional to the failure rate of that system. A system with a zero failure rate has a reliability of one. Redundant assemblies have a combined reliability higher than their individual reliabilities. For instance, two redundant 
assemblies, each with a failure probability of $1 \%$, would have a combined failure probability of $0.01 \%$ :

$$
\begin{aligned}
\text { Reliability (A, B) } & =1-(1-\text { Reliability (A) }) *(1-\text { Reliability (B)) } \\
& =1-(1-0.99) *(1-0.99) \\
& =0.9999
\end{aligned}
$$

Failure Probability $=1 /$ Reliability $=0.01 \%$

Total mission reliability can be increased further by providing one, or more, spare controllers. The spare controllers are treated as redundant systems.

Separate reliability calculations must be made, and then combined, if the system will be exposed to multiple environmental conditions. This is because failure rates are an exponential function of temperature; small variations in temperature cause wide variations in failure rates. For instance, if the equipment is in service for one year, but is exposed to $50^{\circ} \mathrm{C}$ for one month, the reliabilities could be computed for the one hot month and the eleven cool months. The total reliability is the product of the two time periods. The reliability calculation of the RSG fan control requires computing the reliability of six assemblies:

1. Thermistor probes ("Sensors")

2. Processor A ("Sense")

3. Processor B ("Sense")

4. Processor C ("Sense")

5. EMI Filter ("Filter")

6. DC-DC Converter ("Switch")

Note: The sense board includes Processors A, B and C with A and B redundant.

The computed reliability of the fan controller is:

\begin{tabular}{|c|c|c|c|}
\hline Temperature (C) & One Week & One Month & One Year \\
\hline 25 & 0.9964 & 0.9842 & 0.8288 \\
\hline 50 & 0.9928 & 0.9687 & 0.6872 \\
\hline & & & \\
\hline
\end{tabular}

The reliability with one spare is:

\begin{tabular}{|c|c|c|c|}
\hline Temperature (C) & One Week & One Month & One Year \\
\hline 25 & 0.99999 & 0.99975 & 0.9707 \\
\hline 50 & 0.99995 & 0.999 & 0.9022 \\
\hline & & & \\
\hline
\end{tabular}




\section{Appendices}



Appendix A 

Material Properties

\section{Material Properties of Outer Shell}

Properties of Outer Shell

http://www.fibercote.com/ppro2.html

FiberCote E-765

The largest single regulatory obstacle to using advanced composite materials in certified aircraft applications has been the generation of design allowables which will satisfy Regulatory agency requirements. Previously, individual airframe manufacturers generated design allowable databases as a routine part of their certification effort. However, with expensive qualification costs and timelines that can be longer than 12 months, this approach has proved unfeasible for smaller manufacturers and has often led larger manufacturers with established databases to continue to use "old" material systems.

Since 1996, FiberCote has worked closely with the FAA, Wichita State University, and NASA's Advanced General Aviation Transport Experiments (AGATE) program to develop a method for composite materials suppliers to generate design allowable databases and share them with airframe manufacturers. As a result, FiberCote has created a set of design allowable databases that are approved by the FAA for a family of materials based on E-765 - a tough, shop-friendly, $180^{\circ} \mathrm{F}$ Wet service (Wet/Dry Tg = $334^{\circ} \mathrm{F} / 247^{\circ} \mathrm{F}$ - DMA Tan $\Delta$ ) epoxy system that cures at just $250^{\circ} \mathrm{F}$. Designed specifically for critical aircraft structures and based on the latest developments in resin technology, E-765 demonstrates good toughness, outstanding fiber property translation and is suitable for vacuum bag or autoclave processing.

\section{The E-76s Materials \& Databases Family

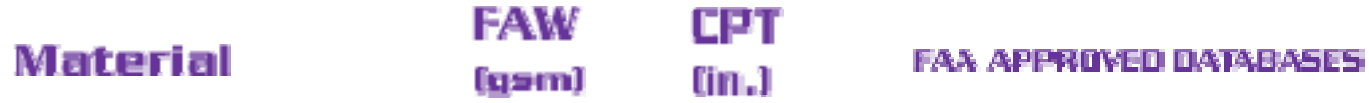 Lamina Laminate Prdpertias Properties

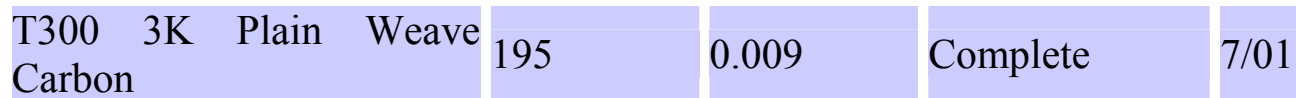

Properties of Inlet and Outlet Plenums

http://www.laserrepro.com/pdfs/Somos9120.pdf 

Appendix B 



\section{Technical Data Sheet for Case Foam}

\section{Technical Data Sheet}

illbruck Material Designation

Y200E

DESCRIPTION

APPLCATION

PHYSICAL PROPERTIES

Density (lbs/ ft 3 )

Tensile Strength, PSI

\% Elongation

Tear Strength, PU

Compression Strength, PSI, at $25 \%$ deflection

$50 \%$ deflection

Compression set, \% original

thic kness@ @ 50\%

Therma I Sta bility, \% at 158F/24

hrs

Thermal Conductivity

(BTU in/ft. ${ }^{2} \mathrm{hr}^{0} \mathrm{~F}$ )

Temperature
Y200E is c hemic a lly c ross linked, very soft polyethylene bun foam with very fine, closed cell struc ture.

Toys, specialty packaging, flotation devices, and sporting goods, vacuum forming, compression molding. Excellent cushioning, elastic, insulating, a esthetic appearance, extremely low in water absorption, very low water vapor transmission, highly resistant to most chemic als, conta ins no CFC or HCFC, non-toxic, can be slit, die cut.

\section{TYPICAL VALUES \\ 2.0}

56

367

10

5.0

13.0

4.4

$-0.6$

0.24

$-100^{\circ}$ to $+215^{\circ} \mathrm{F}$
TEST METHODS

ASTM D-3575

ASTM D-3575

ASTM D-3575

ASTM D-3575

ASTM D-3575

ASTM C -177
The data and information represents typic al values that a re generally accepted throughout the industry and appear in manufacturer's literature. Actual physical properties may vary by manufacturing lot. These values do not constitute a guarantee of performance, actual or implied. The suitability of this product may be application specific and should be determined prior to being specified. 

Appendix C 

Appendix D 

Appendix E 

Appendix F 

Appendix G 



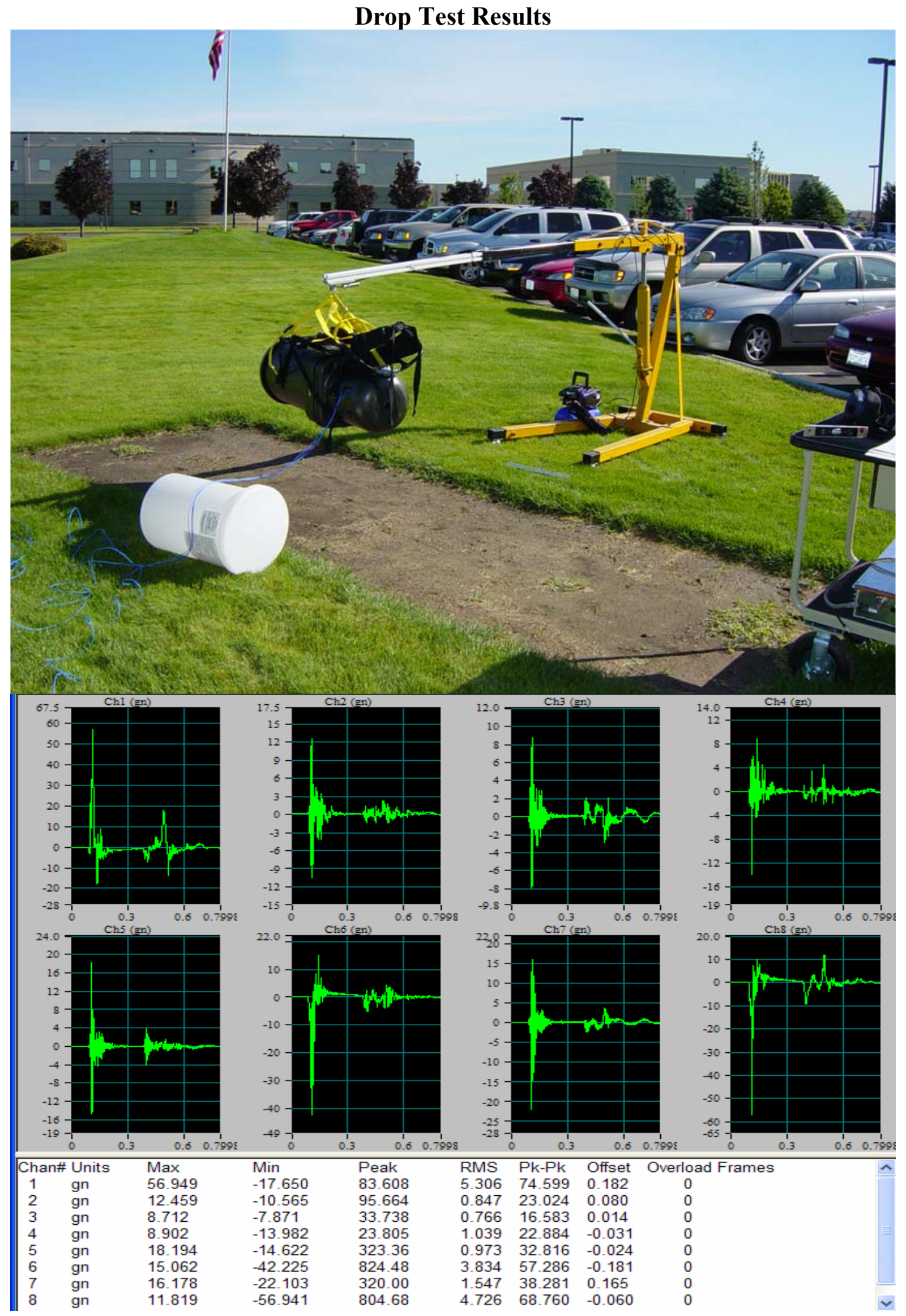

Drop 1 - Side Drop on Case (6/23/2005) 

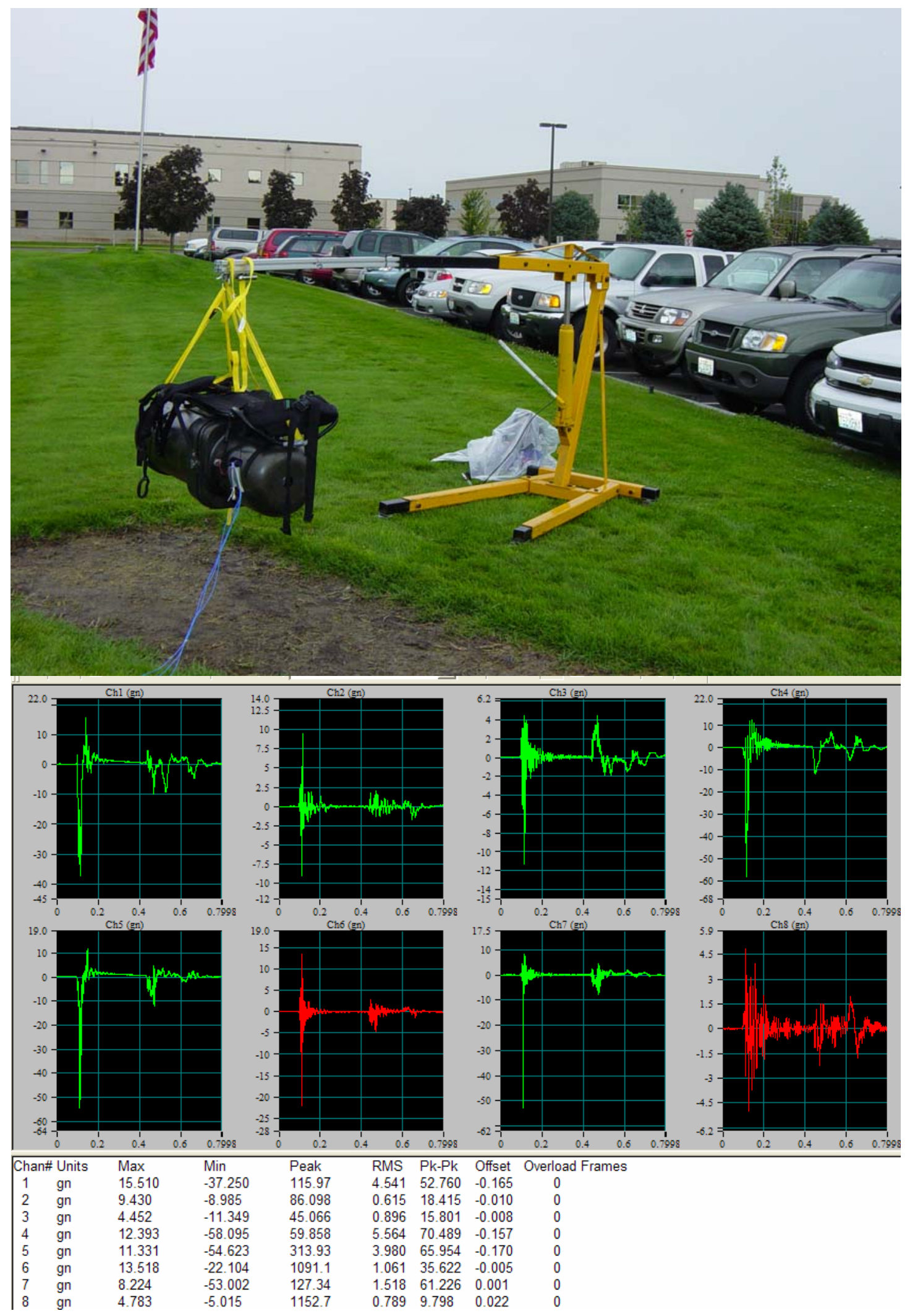

Drop 1 - Side Drop on Case (8/17/2005) 

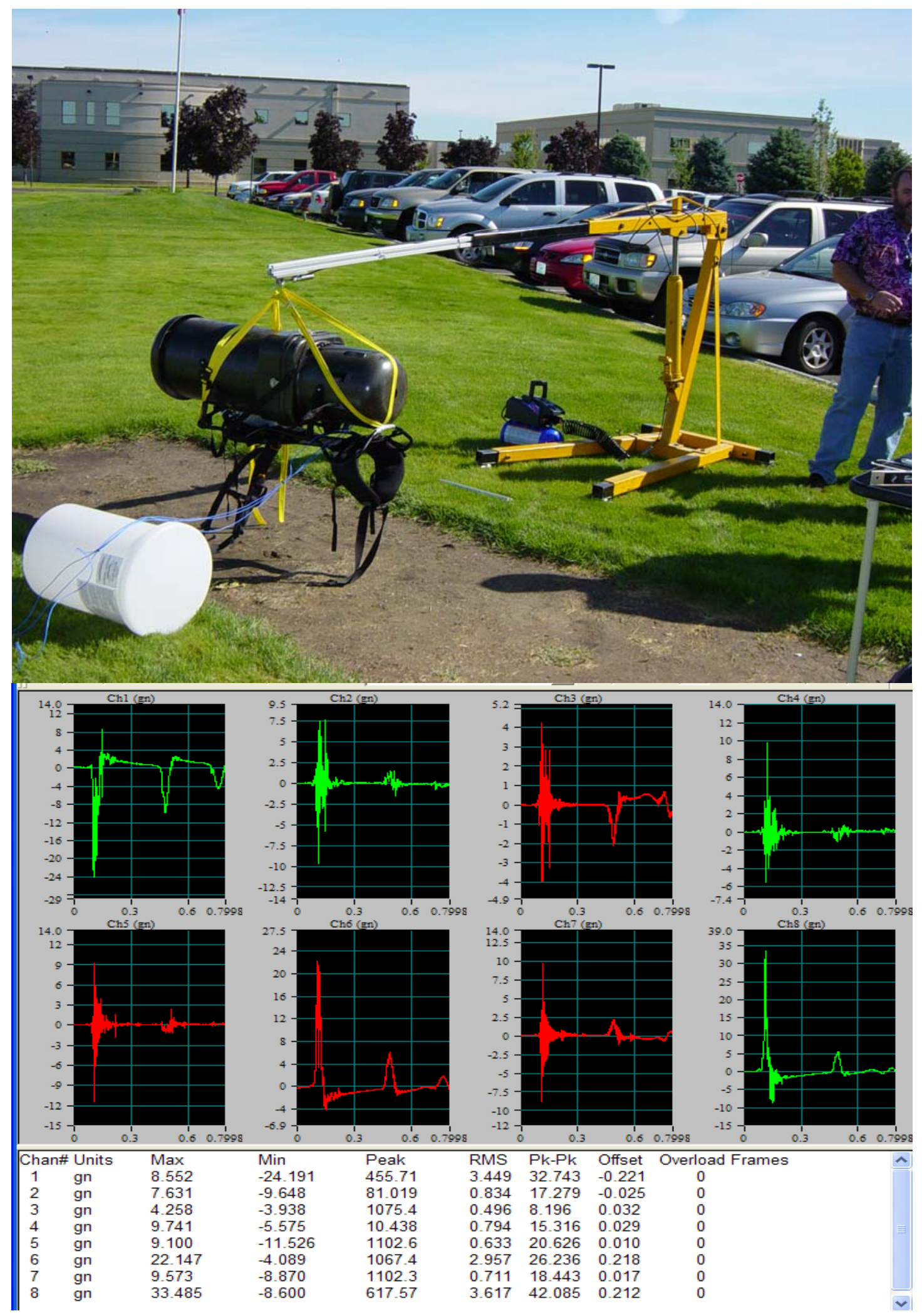

Drop 2 - Side Drop on Backpack (6/23/2005) 

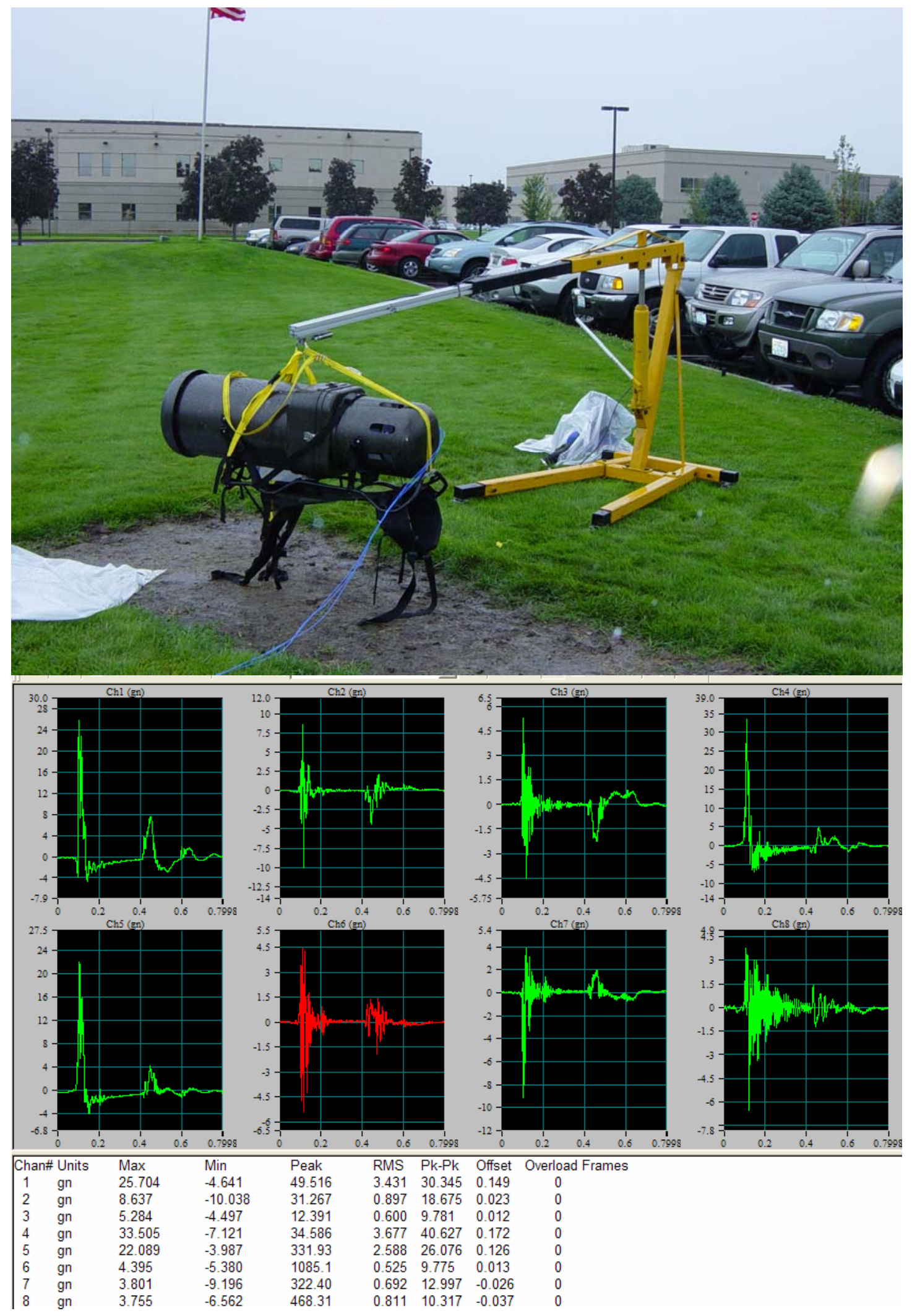

Drop 2 - Side Drop on Backpack (8/17/2005) 

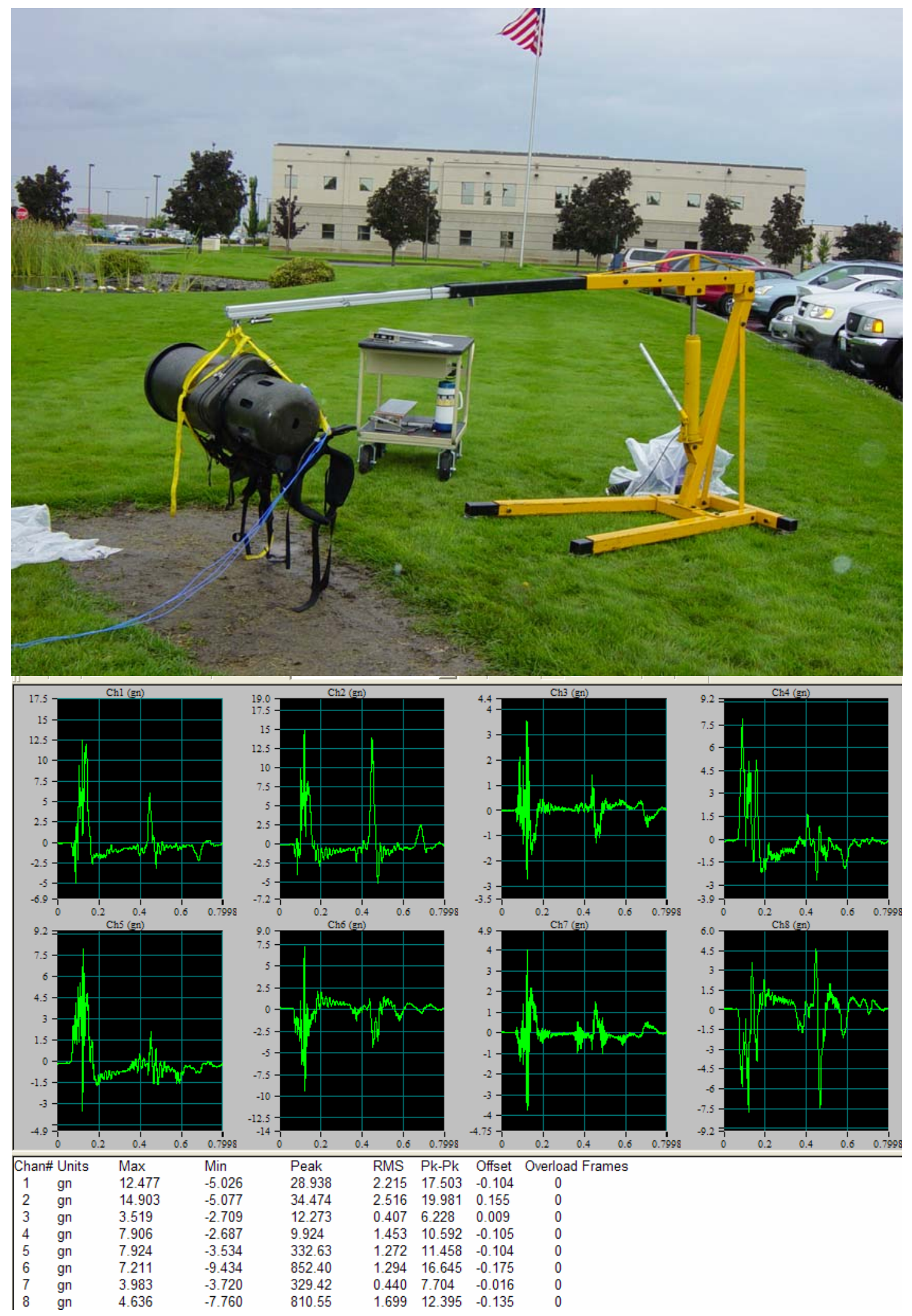

Drop 3 - Side Corner Drop on Backpack (8/17/2005) 

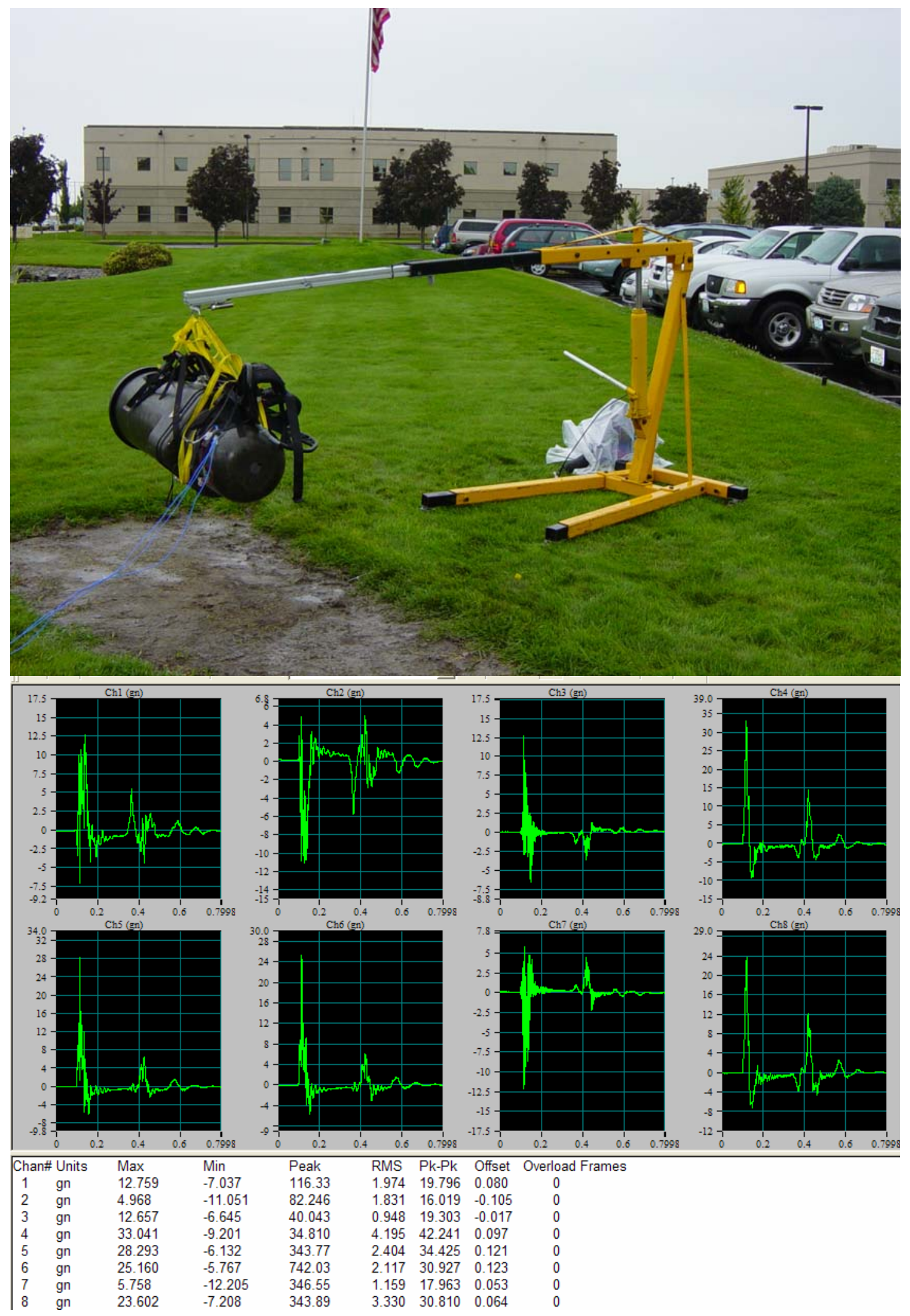

Drop 4 - Side Corner Drop on Case (8/17/2005) 

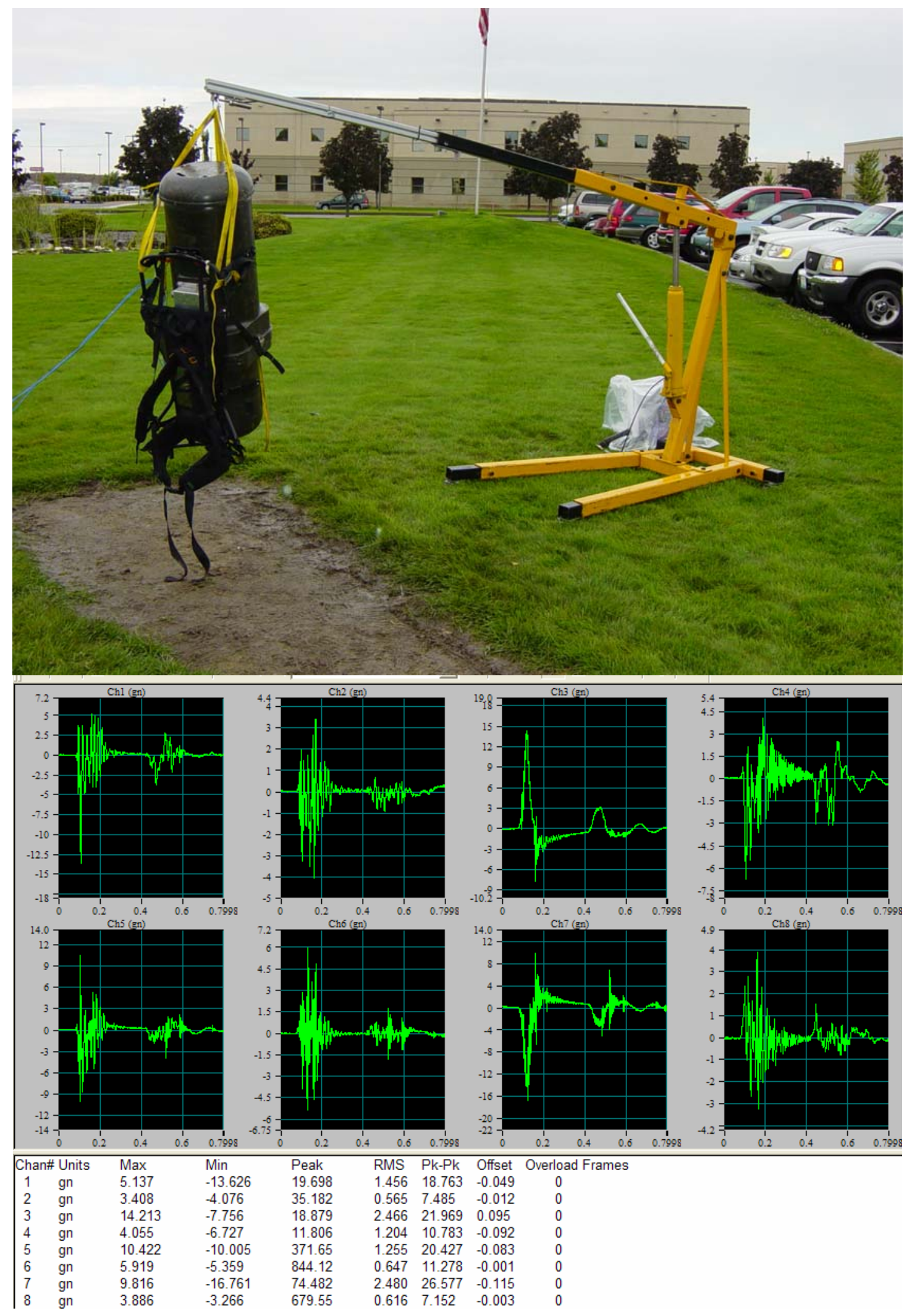

\section{Drop 5 - On End of Backpack (8/17/2005)}



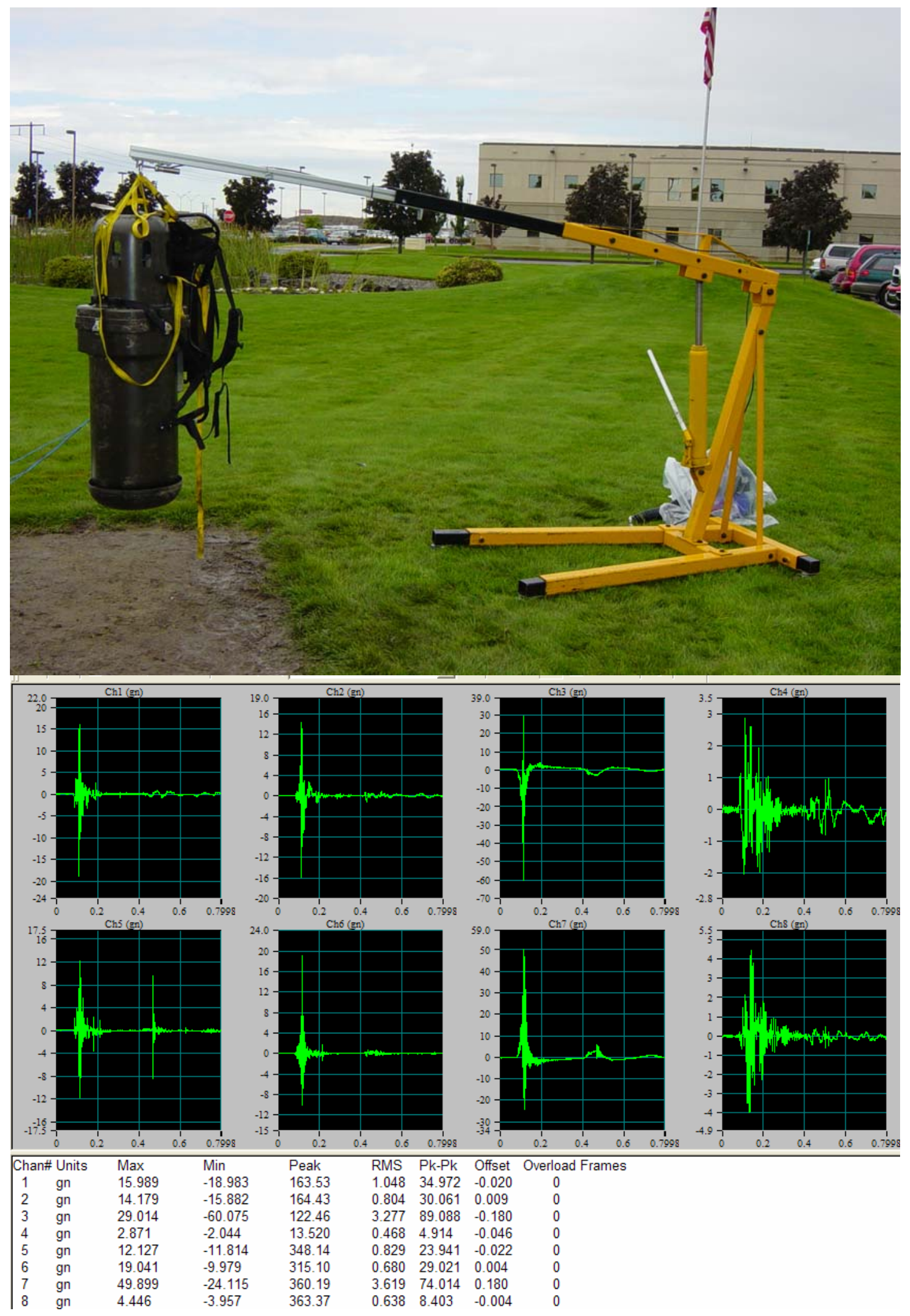

Drop 6 - On Rain Cap (8/17/2005) 

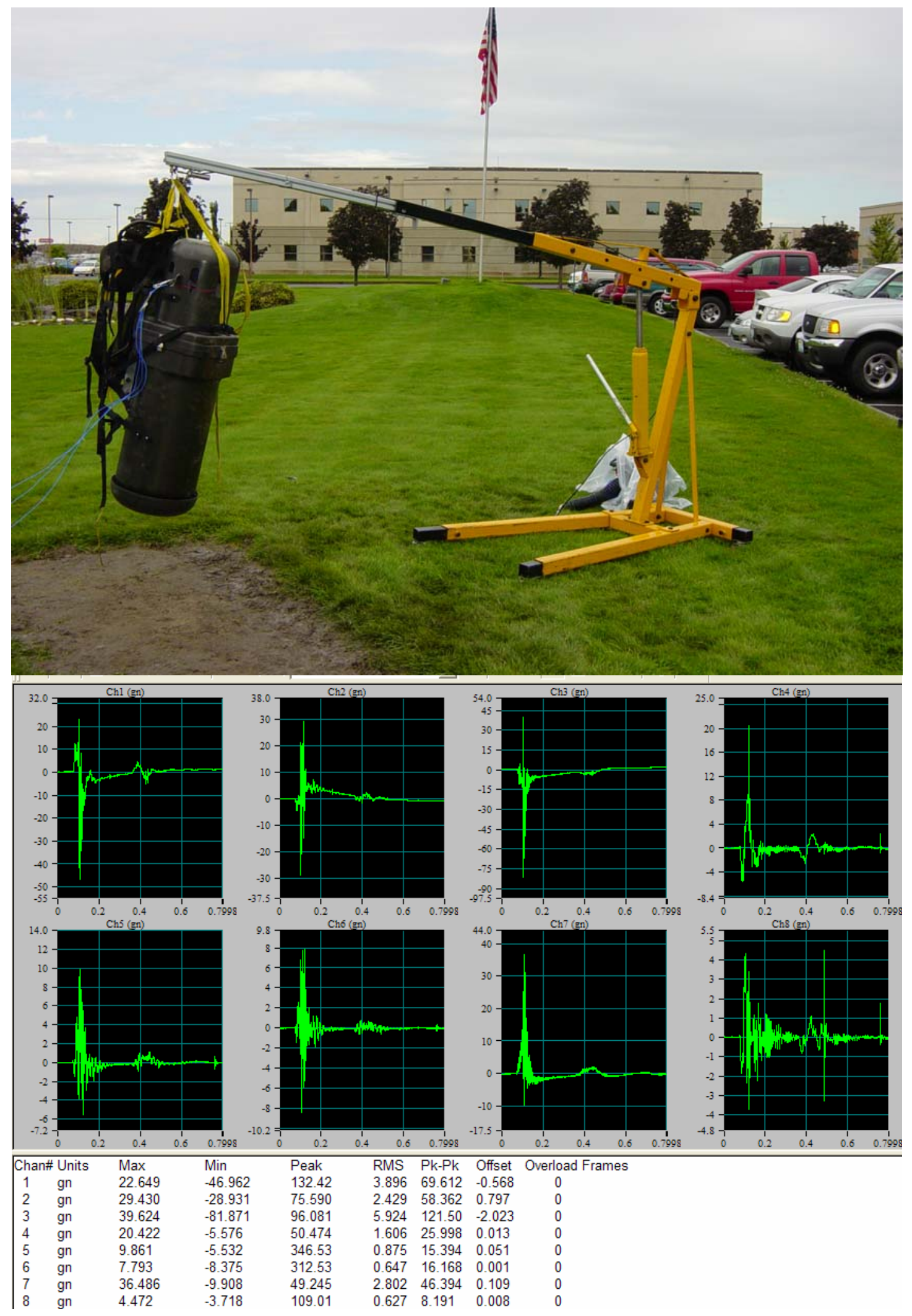

\section{Drop 7 - On Top Corner of Case (8/17/2005)}



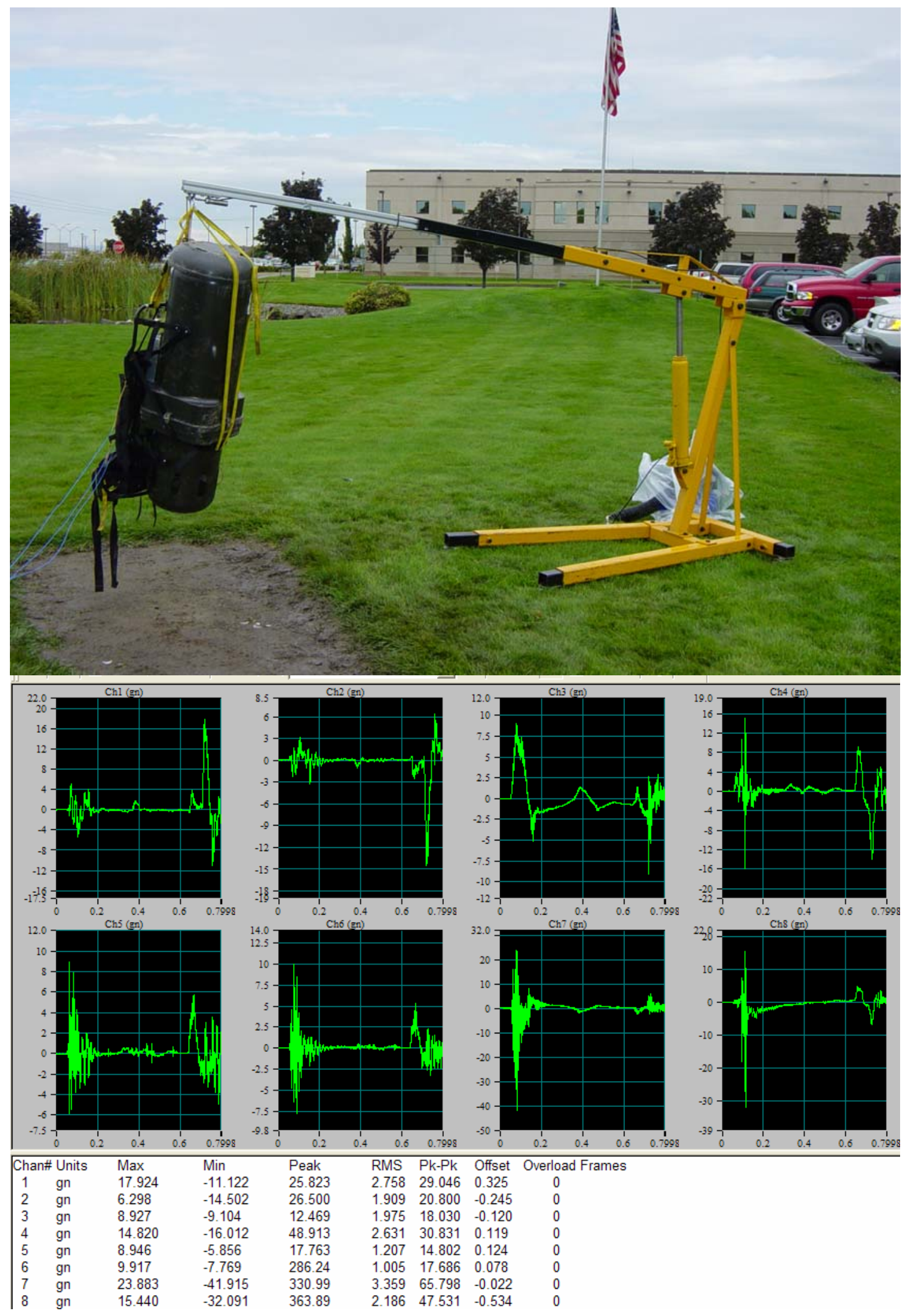

Drop 8 - On Bottom Corner of Case (8/17/2005 
